Aus der Klinik für Klinische Neurophysiologie

(Prof. Dr. med. W. Paulus)

der Medizinischen Fakultät der Universität Göttingen

\title{
Entwicklung eines Laufrad-basierten Maus-Modells zur Untersuchung der Effekte von Botulinum-Neurotoxinen
}

\author{
INAUGURAL-DISSERTATION \\ zur Erlangung des Doktorgrades \\ der Medizinischen Fakultät der \\ Georg-August-Universität zu Göttingen \\ vorgelegt von \\ Marie-Christine Reinert
}

aus Göttingen

Göttingen 2016 
Dekan:

Prof. Dr. rer. nat. H. K. Kroemer

Referent: $\quad$ Prof. Dr. med. D. Liebetanz

Ko-Referent: Prof. Dr. med. J. Schmidt

Tag der mündlichen Prüfung: 23.03.2017 
Hiermit erkläre ich, die Dissertation mit dem Titel "Entwicklung eines Laufrad-basierten Maus-Modells zur Untersuchung der Effekte von Botulinum-Neurotoxinen" eigenständig angefertigt und keine anderen als die von mir angegebenen Quellen und Hilfsmittel verwendet zu haben.

Göttingen, den 26.09.2016

(Unterschrift) 
Teile dieser Arbeit wurden bereits veröffentlich:

- Kutschenko A, Reinert MC, Klinker F, Paulus W, Hesse S, Liebetanz D (2011): Botulinum toxin-induced focal paresis in mice is unaffected by muscle activity. Muscle Nerve 44, 930-936

- Kutschenko A, Reinert MC, Klinker F, Paulus W, Hesse S, Liebetanz D (2011): Novel in vivo test shows low-dosage botulinum toxin-induced focal calf muscle paresis is independent of increased muscle activity in wild-type mice. Poster presented at Toxins 2011, $7^{\text {th }}$ International Conference on Basic and Therapeutic Aspects of Botulinum and Tetanus Toxins, 02.-05.10.2011, Santa Fe, New Mexico, USA 


\section{Inhaltsverzeichnis}

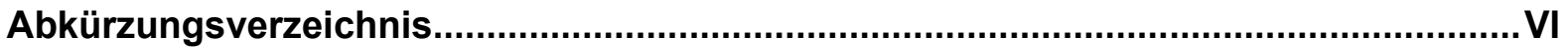

Abbildungsverzeichnis................................................................................................ VII

Tabellenverzeichnis........................................................................................ IX

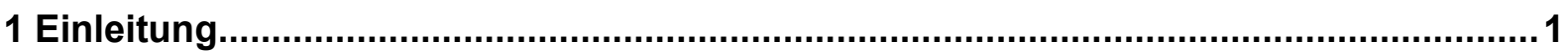

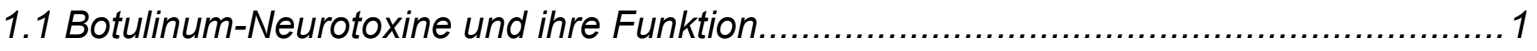

1.2 Therapeutische Nutzung von BoNT ............................................................. 2

1.3 Limitationen und Herausforderungen der therapeutischen Nutzung...........................

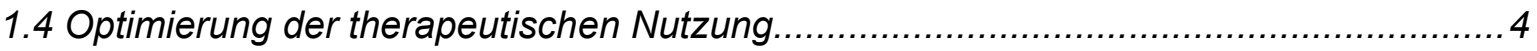

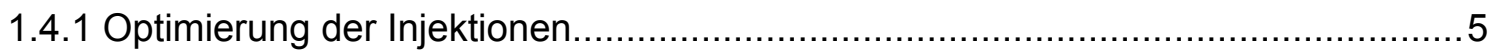

1.4.2 Optimierung der Wirksamkeit durch neuromuskuläre Aktivierung........................5

1.4.3 Entwicklung neuer BoNT-Konstrukte............................................................ 6

1.5 BoNT-Potenzbestimmung und qualitative Analysen der Toxin-Wirkung....................... 7

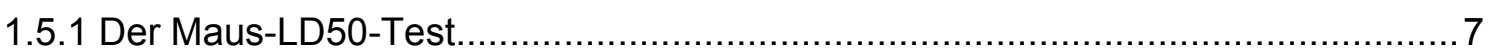

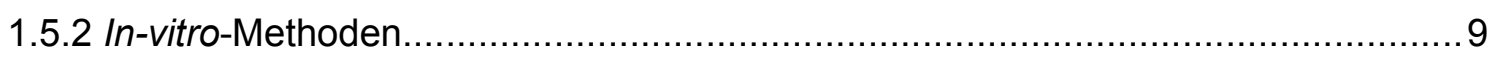

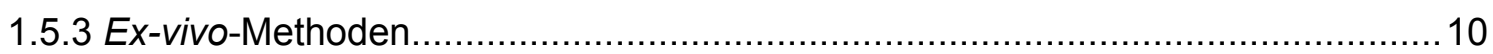

1.5.4 In-vivo-Methoden auf Basis lokaler Paralyse.............................................. 10

1.6 Maus-Laufradmodelle in der neurologischen Forschung..................................... 12

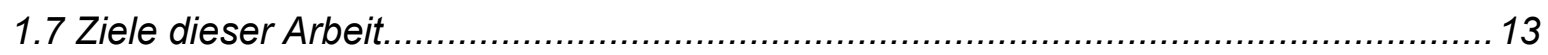

2 Material und Methoden....................................................................................... 14

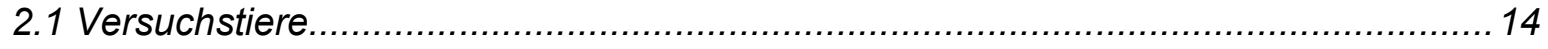

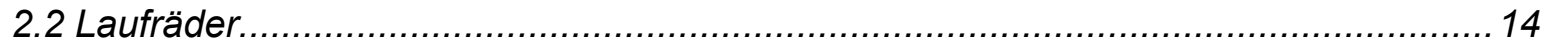

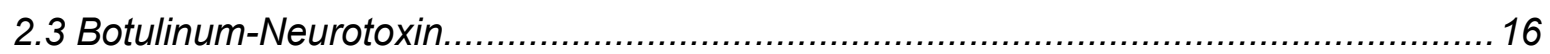

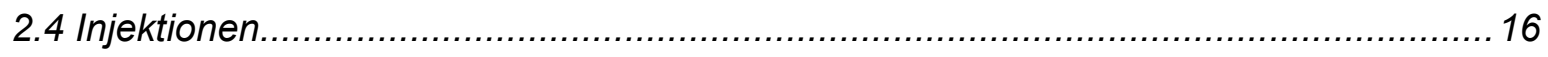

2.5 Aufzeichnungsgeräte und Laufdatenanalyse................................................. 17

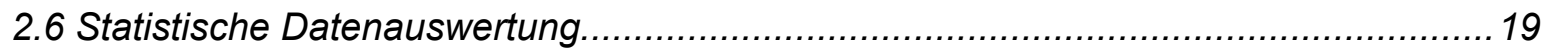

3 Ergebnisse

3.1 Die Laufleistung im Langzeit-Verlauf.......................................................... 20

3.2 Der Effekt intramuskulärer Injektionen von BoNT in den M. gastrocnemius im Vergleich zu Injektionen in den M. tibialis anterior.............................................. 21

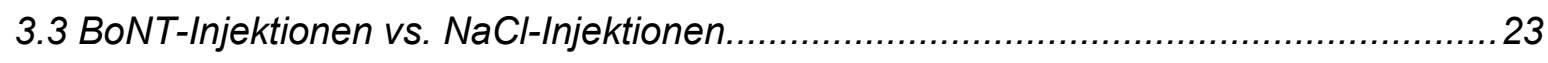


3.3.1 Laufleistung nach $\mathrm{NaCl}$-Injektionen.

3.4 Die Auswirkungen unterschiedlich hoher Toxin-Dosierungen auf die verschiedenen

Laufparameter. 28

3.5 Vergleich der Toxin-Wirkung bei Mäusen unterschiedlichen Alters und Gewichts.....32

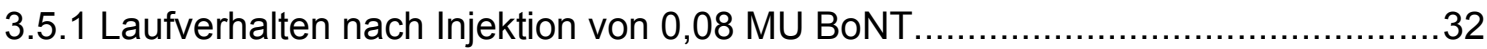

3.5.2 Laufverhalten nach Injektion von 0,24 MU BoNT.......................................... 34

3.5.3 Korrelationsanalyse von Laufleistung und Gewicht bei Mäusen einer Altersgruppe.

3.5.4 Korrelationsanalyse von Gewicht und maximalem Toxin-Effekt in einer Altersgruppe. 36

3.6 Die Auswirkung neuromuskulärer Aktivität auf die Wirkung der BoNT-Injektionen......37

4 Diskussion

4.1 Im Laufradmodell können durch niedrig dosierte BoNT-Injektionen in die

Mm. gastrocnemii induzierte latente Paresen unter Verwendung komplexer

Laufräder sicher detektiert werden.

4.1.1 Der M. gastrocnemius ist ein geeigneter Injektionsmuskel............................40

4.1.2 Die Nutzung eines einheitlichen Injektionsvolumens von $10 \mu \mathrm{l}$ pro Muskel eignet sich gut für Dosierungen, die eine subtotale Paralyse induzieren.

4.1.3 Niedrigdosierte BoNT-Injektionen haben einen massiven Einfluss auf das Laufverhalten im Laufrad.

4.1.4 Durch das Laufradmodell können Toxin-Effekte qualitativ untersucht werden, die in einem Niedrigdosisbereich vergleichbar mit therapeutischen Dosierungen liegen.

4.2 Die relative Maximalgeschwindigkeit ist der Laufparameter, der sich am besten zur Analyse der BoNT-Wirkung eignet. 44

4.2.1 Das Laufradmodell ermöglicht Aussagen zur Wirkstärke des Toxins. 47

4.2.2 Das Laufradmodell ermöglicht Aussagen zur Wirkdauer des Toxins. .48

4.2.3 Die Regeneration zeigt einen mehrphasigen Verlauf mit inkompletter Erholung..50

4.3 Der BoNT-Effekt auf das Laufverhalten ist unabhängig von Gewicht und Alter der Mäuse.

4.4 Motorische Aktivität nach den Injektionen zeigt keine Auswirkungen auf die durch BoNT-Injektionen induzierten Paresen.

4.5 Schlussfolgerung und Ausblick

5 Zusammenfassung 


\section{Abkürzungsverzeichnis}

\begin{tabular}{|c|c|}
\hline Abb. & Abbildung \\
\hline ANOVA & analysis of variance \\
\hline BoNT & Botulinum-Neurotoxin \\
\hline BoNT/A & Botulinum-Neurotoxin A \\
\hline BoNT/B & Botulinum-Neurotoxin B \\
\hline BoNT/C & Botulinum-Neurotoxin C \\
\hline BoNT/D & Botulinum-Neurotoxin D \\
\hline BoNT/E & Botulinum-Neurotoxin E \\
\hline BoNT/F & Botulinum-Neurotoxin F \\
\hline BoNT/G & Botulinum-Neurotoxin G \\
\hline BoNT/H & Botulinum-Neurotoxin $\mathrm{H}$ \\
\hline DAS & digit abduction scoring \\
\hline Distmean & durchschnittliche Distanz \\
\hline ELISA & enzyme-linked immunosorbent assay \\
\hline EMG & Elektromyographie \\
\hline FDA & US Food and Drug Administration \\
\hline $\mathrm{H}_{\mathrm{C}}$ & C-terminaler Anteil der schweren Kette von Botulinum-Neurotoxin \\
\hline $\mathrm{H}_{\mathrm{CC}}$ & C-terminaler Anteil der $\mathrm{H}_{\mathrm{C}}$-Domäne von Botulinum-Neurotoxin \\
\hline $\mathrm{H}_{\mathrm{CN}}$ & $\mathrm{N}$-terminaler Anteil der $\mathrm{H}_{\mathrm{C}}$-Domäne von Botulinum-Neurotoxin \\
\hline$H_{N}$ & N-terminaler Anteil der schweren Kette von Botulinum-Neurotoxin \\
\hline IGF-1 & insulin-like growth factor 1 \\
\hline $\mathrm{kDa}$ & Kilodalton \\
\hline $\mathrm{LD}_{50}$ & mittlere letale Dosis \\
\hline M. & Musculus \\
\hline Mm. & Musculi \\
\hline MPU & median paralysis unit \\
\hline MU & mouse unit \\
\hline N. & Nervus \\
\hline $\mathrm{NaCl}$ & Natriumchlorid \\
\hline Nlauf & Anzahl der Läufe \\
\hline NMJ & neuromuscular junction \\
\hline RMF & rat muscle force \\
\hline
\end{tabular}


SNAP-25 synaptosomal-associated protein of $25 \mathrm{kDa}$

SNARE soluble $\mathrm{N}$-ethylmaleimide-sensitive factor-attachment protein-receptor

Tab. Tabelle

TeNT Tetanus-Neurotoxin

Tges Gesamtzeit

Tmean durchschnittliche Zeit

VAMP vesicle-associated membrane protein

Vmax Maximalgeschwindigkeit

Vmean Durchschnittsgeschwindigkeit 


\section{Abbildungsverzeichnis}

\begin{tabular}{|c|c|c|}
\hline Abbildung Nr. & Titel & Seite \\
\hline 1 & Laufradtypen & 16 \\
\hline 2 & Laufleistung der Mäuse im Langzeitverlauf & 20 \\
\hline 3 & $\begin{array}{l}\text { Injektion von } 0,2 \mathrm{MU} \text { BoNT in unterschiedliche Muskeln der } \\
\text { Hinterläufe }\end{array}$ & 22 \\
\hline 4 & $\begin{array}{l}\text { Relative Vmax nach Injektion von } 0,2 \text { MU BoNT in den } \\
\text { M. tibialis anterior und in den M. gastrocnemius }\end{array}$ & 23 \\
\hline 5 & $\begin{array}{l}\text { Laufparameter nach Injektion von 0,1 MU BoNT im Vergleich zu } \\
\text { einer } \mathrm{NaCl} \text {-Kontrollgruppe (1) }\end{array}$ & 24 \\
\hline 6 & $\begin{array}{l}\text { Laufparameter nach Injektion von 0,1 MU BoNT im Vergleich zu } \\
\text { einer } \mathrm{NaCl} \text {-Kontrollgruppe (2) }\end{array}$ & 25 \\
\hline 7 & Laufleistung nach Injektion von $\mathrm{NaCl}$ & 27 \\
\hline 8 & Laufparameter nach Injektion von 0,1 MU und 0,2 MU BoNT (1) & 30 \\
\hline 9 & Laufparameter nach Injektion von 0,1 MU und 0,2 MU BoNT (2) & 31 \\
\hline 10 & $\begin{array}{l}\text { Injektion von } 0,08 \mathrm{MU} \text { BoNT bei Mäusen unterschiedlichen } \\
\text { Alters }\end{array}$ & 33 \\
\hline 11 & Vmax nach Injektion von 0,24 MU BoNT & 34 \\
\hline 12 & Korrelation von Gewicht und Laufleistung & 35 \\
\hline 13 & $\begin{array}{l}\text { Korrelation von Gewicht und Abfall der Laufleistung nach BoNT- } \\
\text { Injektion }\end{array}$ & 36 \\
\hline 14 & $\begin{array}{l}\text { Profile der Tges für die beiden Nächte vor sowie die Nacht nach } \\
\text { den Injektionen }\end{array}$ & 37 \\
\hline 15 & $\begin{array}{l}\text { Verlauf der Distanz (A) und der relativen } \operatorname{Vmax}(B) \text { nach } \\
\text { morgendlichen und abendlichen Injektionen von } 0,1 \text { und } 0,2 \mathrm{MU} \\
\text { BoNT }\end{array}$ & 38 \\
\hline
\end{tabular}




\section{Tabellenverzeichnis}

\begin{tabular}{|c|c|c|}
\hline Tabelle Nr. & Titel & Seite \\
\hline 1 & Laufparameter & 18 \\
\hline 2 & $\begin{array}{l}\text { Lineare Regressionsanalysen für Distanz und Vmax im } \\
\text { Langzeitverlauf }\end{array}$ & 21 \\
\hline 3 & $\begin{array}{l}\text { Ergebnisse der statistischen Auswertungen mittels ANOVA nach } \\
\text { Injektion von 0,2 MU BoNT }\end{array}$ & 22 \\
\hline 4 & $\begin{array}{l}\text { Ergebnisse der statistischen Auswertungen mittels ANOVA nach } \\
\text { Injektion von } \mathrm{NaCl} \text { vs. } 0,1 \mathrm{MU} \text { BoNT }\end{array}$ & 26 \\
\hline 5 & $\begin{array}{l}\text { Lineare Regresisonsanalysen für relative Distanz und Vmax } \\
\text { nach } \mathrm{NaCl} \text {-Injektion }\end{array}$ & 27 \\
\hline 6 & $\begin{array}{l}\text { Ergebnisse der statistischen Auswertungen mittels ANOVA nach } \\
\text { Injektion von } 0,1 \text { und } 0,2 \mathrm{MU} \text { BoNT }\end{array}$ & 29 \\
\hline 7 & $\begin{array}{l}\text { Gruppenübersicht der Mäuse unterschiedlichen Alters und } \\
\text { Gewichts }\end{array}$ & 32 \\
\hline 8 & $\begin{array}{l}\text { Ergebnisse der statistischen Auswertungen mittels ANOVA nach } \\
\text { Injektion von } 0,08 \mathrm{MU} \text { BoNT }\end{array}$ & 33 \\
\hline 9 & $\begin{array}{l}\text { Ergebnisse der statistischen Auswertungen mittels ANOVA nach } \\
\text { Injektion von } 0,24 \mathrm{MU} \text { BoNT }\end{array}$ & 35 \\
\hline 10 & Korrelation von Gewicht und Laufleistung & 35 \\
\hline 11 & $\begin{array}{l}\text { Korrelation von Gewicht und Abfall der Laufleistung nach BoNT- } \\
\text { Injektionen }\end{array}$ & 36 \\
\hline 12 & $\begin{array}{l}\text { Ergebnisse der statistischen Auswertungen mittels ANOVA nach } \\
\text { morgendlichen und abendlichen Injektionen von } 0,1 \text { und } 0,2 \mathrm{MU} \\
\text { BoNT }\end{array}$ & 39 \\
\hline 13 & $\begin{array}{l}\text { In-vivo-Modelle zur Untersuchung der BoNT-Wirkung im } \\
\text { Überblick }\end{array}$ & 57 \\
\hline
\end{tabular}




\section{$1 \quad$ Einleitung}

\subsection{Botulinum-Neurotoxine und ihre Funktion}

Botulinum-Neurotoxine (BoNT) zählen zur Gruppe der clostridialen Neurotoxine und sind die potentesten aller bakteriellen Toxine mit einer letalen Dosis unter $1 \mathrm{ng}$ pro kg Körpergewicht (Gill 1982). Die von den anaeroben, grampositiven Bakterien der Gattung Clostridium produzierten Toxine können beim Menschen das Krankheitsbild Botulismus hervorrufen, indem sie an der motorischen Endplatte cholinerger Neurone die Signalübertragung blockieren. Botulismus ist gekennzeichnet durch eine Schwäche der Skelettmuskulatur sowie vegetative Symptome wie Bradykardie, Hypotonie, Obstipation und Harnretention (Midura 1996, Sobel 2005).

Es sind sieben unterschiedliche BoNT-Serotypen (BoNT/A-G) bekannt, die sich anhand ihrer Aminosäuresequenz in weitere Subtypen unterteilen lassen, so dass insgesamt mehr als 40 unterschiedliche Toxine existieren (Rossetto et al. 2014). Die Existenz eines weiteren Serotyps (BoNT/H) wurde kürzlich postuliert (Dover et al. 2014).

Das Toxin mit einer Größe von ca. 150 Kilodalton (kDa) besteht aus einer schweren Kette (ca. $100 \mathrm{kDa}$ ) und einer leichten Kette (ca. 50 kDa) (Sugiyama 1980). Diese sind über eine Disulfidbrücke, nicht-kovalente Bindungen sowie eine Peptidschleife verbunden (Rossetto et al. 2014, Turton et al. 2002).

Ein BoNT-Protein besteht aus drei funktionellen Domänen. Der C-terminale Anteil der schweren Kette $\left(\mathrm{H}_{\mathrm{C}}\right)$ dient der Bindung an die Membran der Zielzelle mit anschließender Endozy-tose (Muraro et al. 2009). Die $\mathrm{H}_{\mathrm{C}}$-Domäne kann noch in einen C-terminalen $\left(\mathrm{H}_{\mathrm{CC}}\right)$ und einen $\mathrm{N}$-terminalen Anteil $\left(\mathrm{H}_{\mathrm{CN}}\right)$ unterschieden werden, wobei die Funktion des letzteren noch nicht abschließend geklärt ist (Rummel et al. 2011). Der N-terminale Anteil der schweren Kette $\left(\mathrm{H}_{\mathrm{N}}\right)$ ist verantwortlich für die Translokation der leichten Kette über die Vesikelmembran (Blaustein et al. 1987). Die toxische Wirkung wird schließlich durch die Metalloprotease-funktion der leichten Kette verursacht (de Paiva et al. 1993).

Der BoNT-Intoxikationsprozess lässt sich in vier Schritte unterteilen. Der erste Schritt, die Bindung des Toxins an die Zielmembran, funktioniert über eine Doppelrezeptor-Strategie (Rummel 2013). Zuerst bindet das Toxin über das C-terminale Ende der schweren Kette an einen Polysialogangliosidrezeptor der präsynaptischen Membran cholinerger Neurone (Montecucco 1986, Simpson und Rapport 1971), dann an einen Proteinrezeptor. BoNT/A, BoNT/D, BoNT/E und BoNT/F binden an synaptic vesical protein 2 (Dong et al. 2006, Dong et al. 2008, Fu et al. 2009, Peng et al. 2011), BoNT/B und BoNT/G an Synaptotagmin 
(Nishiki et al. 1994, Rummel et al. 2007). Für BoNT/C ist der Mechanismus noch nicht vollständig geklärt (Karalewitz et al. 2012, Kroken et al. 2011, Peng et al. 2012). Da die Bindungsstellen beider Rezeptorproteine in das Lumen der synaptischen Vesikel hineinragen, können BoNT-Moleküle nur binden, wenn Vesikel mit der präsynaptischen Membran fusionieren (Rossetto et al. 2014), also eine Aktivität an der motorischen Endplatte besteht. Darüber hinaus erfolgt die Bindung ausschließlich spezifisch an peripheren Nervenendigungen (Dolly et al. 1984). Als zweites erfolgt die Aufnahme des Toxins durch Ausnutzung der Endozytose synaptischer Vesikel (Black und Dolly 1986, Rossetto et al. 2014). Der dritte Schritt, die Translokation in das Zytosol, ist noch nicht im Detail verstanden. Es wird jedoch angenommen, dass es sich um eine $\mathrm{pH}$-Wert-abhängige Translokation der leichten Kette in das Zytosol mit Hilfe eines von der Translokationsdomäne der schweren Kette gebildeten Kanals handelt (Donovan und Middelbrook 1986, Galloux et al. 2008, Hoch et al. 1985, Koriazova und Montal 2003, Montal 2009). Der vierte und letzte Schritt ist dann die selektive Spaltung synaptischer SNARE (soluble N-ethylmaleimide-sensitive factorattachment protein-receptor)-Proteine durch die Metalloproteasefunktion der leichten Kette. Welches Protein des SNARE-Komplexes gespalten wird, hängt vom Toxin-Serotyp ab. BoNT/A und BoNT/E spalten SNAP-25 (synaptosomal-associated protein of $25 \mathrm{kDa}$ ) während BoNT/B, BoNT/D, BoNT/F und BoNT/G Synaptobrevin (auch VAMP = vesicle-associated membrane protein genannt) spalten (Blasi et al. 1993, Schiavo et al. 1992, Schiavo et al. 1993a, Schiavo et al. 1993b, Yamasaki et al. 1994). BoNT/C spaltet sowohl Syntaxin also auch SNAP-25 (Schiavo et al. 1995, Williamson et al. 1996). Da die SNARE-Proteine für die Fusion der synaptischen Vesikel mit der präsynaptischen Membran der Nervenendigungen notwendig sind (Bajjalieh und Scheller 1995, Bennett et al. 1992, Ramakrishnan et al. 2012), wird so die neuromuskuläre Übertragung blockiert und es kommt zu einer schlaffen Lähmung des entsprechenden Muskels.

\subsection{Therapeutische Nutzung von BoNT}

BoNT wird seit mehr als 30 Jahren therapeutisch genutzt, in erster Linie bei Erkrankungen, die mit einer muskulären Hyperaktivität einhergehen. Zur therapeutischen Nutzung sind zur Zeit drei verschiedene BoNT/A-Präparate zugelassen: BOTOX ${ }^{\circledR}$ (onabotulinumtoxinA; Allergan, Inc., Irland), Dysport ${ }^{\circledR}$ (abobotulinumtoxinA; Ipsen Ltd, UK) und Xeomin ${ }^{\circledR}$ (incobotulinumtoxinA; Merz Pharmaceuticals $\mathrm{GmbH}$, Deutschland). Darüber hinaus existiert ein zugelassenes BoNT/B-Produkt, welches als MYOBLOC ${ }^{\circledR}$ (rimabotulinumtoxinB; Solstice Neurosciences, LLC, USA) oder NeuroBloc ${ }^{\circledR}$ (rimabotulinumtoxinB; Eisai Ltd, UK) erhältlich ist. 
Die erste (publizierte) therapeutische Nutzung von BoNT erfolgte 1980 durch Alan Scott. Nachdem er zunächst gezeigt hatte, dass BoNT nach intramuskulärer Injektion zu einer Schwächung der äußeren Augenmuskeln führt (Scott et al. 1973), konnten die ersten erfolgreichen Behandlungen von Strabismus durchgeführt werden (Scott 1980). Auch die Krankheitsbilder Blepharospasmus und Spasmus hemifacialis rückten für eine klinische Nutzung früh in den Interessensfokus (Frueh et al. 1984, Savino et al. 1985), woraufhin die erste offizielle Zulassung der U.S. Food and Drug Administration (FDA) für BOTOX ${ }^{\circledR} 1989$ für diese drei Indikationen erfolgte (Chen S 2012).

Viele weitere Krankheitsbilder aus dem Bereich der Dystonien werden mittlerweile ebenfalls mit BoNT-Injektionen behandelt. Dazu gehören u.a. die zervikalen Dystonien (Jankovic und Orman 1987, Tsui et al. 1986), der Schreibkrampf (Tsui et al. 1993) und die spasmodische Dysphonie (Watts et al. 2006). Zu den weiteren offiziell zugelassenen Einsatzbereichen zählen u.a. die axilläre und palmare Hyperhidrose (Bushara et al. 1996, Schnider et al. 1997), chronische Migräne (Aurora et al. 2010, Diener et al. 2010) und eine DetrusorHyperaktivität im Rahmen neurologischer Grunderkrankungen (Reitz et al. 2004). Auch für Muskelspastiken nach Schlaganfall (Kaji et al. 2010, Shaw et al. 2010) und für die infantile Zerebralparese (Bjornson et al. 2007, Koman et al. 1993, Lukban et al. 2009) sind BoNTInjektionen als Therapieoption zugelassen. Für andere Krankheitsbilder mit bisher fehlender Zulassung ist eine off label Nutzung weit verbreitet. Dazu gehören beispielsweise verschiedene Komplikationen der multiplen Sklerose, wie u.a. Spastiken oder Tremor (Cameron et al. 2014, Snow et al. 1990, van der Walt et al. 2012), sowie die Sialorrhoe, z.B. im Rahmen von M. Parkinson, amyotropher Lateralsklerose oder infantiler Zerebralparese (Giess et al. 2000, Pal et al. 2000, Porte et al. 2014). Weitere Einsatzfelder finden sich u.a. in der Gastroenterologie, der Urologie, der Orthopädie, der Dermatologie sowie der Schmerztherapie (Chen S 2012).

\subsection{Limitationen und Herausforderungen der therapeutischen Nutzung}

Da die Wirkung von BoNT zeitlich begrenzt ist (Eleopra et al. 1998), sind wiederholte Injektionen (je nach Krankheitsbild in unterschiedlichen Intervallen, meistens ca. alle drei Monate) notwendig. Das hat verschiedene Nachteile. Neben finanziellen Aspekten spielen der Aufwand für das medizinische Personal sowie die Belastung für die Patientinnen und Patienten eine Rolle. Hinzu kommt die Gefahr eines sekundären Therapieversagens, welches in knapp der Hälfte der Fälle auf neutralisierende Antikörper zurückgeführt werden kann (Dressler 2004, Kessler et al. 1999, Lange et al. 2009). Solch ein antikörper-bedingtes Therapie-versagen tritt in der Regel erst nach mehrmonatiger bis mehrjähriger Behandlung 
auf (Dressler und Hallett 2006, Hefter et al. 2014). Kürzere Injektionsintervalle (Atassi 2004, Dressler 2002, Greene et al. 1994, Herrmann et al. 2004) und höhere Dosierungen (Atassi 2004, Greene et al. 1994, Herrmann et al. 2004, Jankovic und Schwartz 1995) scheinen das Risiko der Antikörperbildung zu erhöhen. Bei der Dosis spielt dabei nicht nur die Anzahl der injizierten mouse units (MU, vgl. Kap. 1.5.1) eine Rolle, sondern auch die Proteinmenge, da auch inaktives Toxin, welches nicht zur Wirkung beiträgt, als Antigen wirksam werden kann (Dressler und Hallett 2006). Auch Komplexproteinen, welche normalerweise mit dem Toxin assoziiert sind, wird ein Einfluss auf das Risiko der Antikörperbildung zugeschrieben (Kukreja et al. 2009), wobei eine vergleichende Studie der unterschiedlichen BoNTPräparate mit und ohne Komplexproteine bisher nicht existiert (Benecke 2012).

Die Zahlen, wie viele behandelte Patientinnen und Patienten nach BoNT-Injektionen neutralisierende Antikörper entwickeln, variieren je nach Studie und behandeltem Krankheitsbild. Auch wenn eine große Metaanalyse von Naumann et al. 2010 nur bei 0,13 \% der Patientinnen und Patienten ein Therapieversagen durch Antikörperbildung feststellen konnte, liefern andere Studien Zahlen im niedrigen einstelligen Prozentbereich bis zu 6 \% (Brin et al. 2008, Mohammadi et al. 2009, Müller et al. 2009, Truong et al. 2010). Höher liegen die Zahlen jedoch bei urologischen Krankheitsbildern (Schulte-Baukloh et al. 2008, Schulte-Baukloh et al. 2011) sowie bei Anwendung im pädiatrischen Bereich (Herrmann et al. 2004) und damit einhergehend auch generell bei Therapiebeginn in jüngerem Alter (Jankovic und Schwartz 1995).

Generell ist BoNT/A aufgrund seiner langen Wirkdauer in der Regel Mittel der Wahl in der Therapie. Wenn es bereits zu einem Therapieversagen durch Antikörper gekommen ist, ist eine mögliche Strategie die Nutzung eines anderen BoNT-Serotyps, beispielsweise nach initialer Therapie mit BoNT/A die Nutzung von BoNT/B (Brin et al. 1999). Meistens ist dies jedoch nur für eine begrenzte Zeit erfolgreich, bis auch gegen BoNT/B Antikörper gebildet werden (Dressler et al. 2003).

\section{$1.4 \quad$ Optimierung der therapeutischen Nutzung}

Um den unter 1.3 genannten Herausforderungen zu begegnen, ergeben sich unterschiedliche Ansätze, die von einer Optimierung der Injektionstechnik bzw. des Injektionsvorganges über Maßnahmen zur Verbesserung der Effektivität von Injektionen bis zur Entwicklung neuer BoNT-Konstrukte reichen. Alle haben das Ziel, durch größere Injektionsintervalle und/oder geringere Dosierungen die Belastung der Patientinnen und Patienten zu reduzieren sowie das Risiko einer Antikörperbildung zu verringern. 


\subsubsection{Optimierung der Injektionen}

Um alleine durch optimierte Injektionen einen größtmöglichen Toxin-Effekt bei geringstmöglicher Dosis zu erzielen, wurden in der Vergangenheit verschiedene Möglichkeiten eruiert. Shaari und Sanders untersuchten 1993 unter anderem die Rolle des Injektionsortes. Sie stellten fest, dass bei Injektionen in den M. gastrocnemius der Ratte eine um 0,5 cm veränderte Injektionslokalisation eine Veränderung des Toxin-Effektes um 50 Prozent verursachen kann, da die motorischen Endplatten in einem eng umschrieben Bereich des Muskels liegen.

Auch die Auswirkungen des Injektionsvolumens auf den Toxin-Effekt wurden untersucht. In tierexperimentellen Arbeiten konnte teilweise eine Korrelation von Volumen und Toxin-Effekt festgestellt werden (Kim HS et al. 2003, Kutschenko et al. 2016, Shaari und Sanders 1993), andere Arbeiten sahen keinen Einfluss des Injektionsvolumens auf die Toxin-Wirkung (Hulst et al. 2014).

\subsubsection{Optimierung der Wirksamkeit durch neuromuskuläre Aktivierung}

Bereits im Jahr 1924 wurde erstmals die Vermutung geäußert, dass (Muskel-)Inaktivität den Wirkungseintritt des Toxins verzögert (Bronfenbrenner und Weiss 1924). Später konnte im Ex-vivo-Hemidiaphragma-Test gezeigt werden, dass eine erhöhte Rate an elektrischer Nervenstimulation zu einem schnelleren Eintritt der Paralyse (Hughes und Whaler 1962) sowie einer schnelleren Aufnahme des Toxins in die Nervenendigungen führt (Black und Dolly 1986). Es wird daher mittlerweile angenommen, dass hyperaktive Synapsen BoNT bevorzugt aufnehmen (Glocker et al. 1995). Diese Annahme wird durch die Erkenntnis unterstützt, dass die Rezeptoren der BoNT-Moleküle für diese nur erreichbar sind, wenn Vesikel mit der präsynaptischen Membran fusioniert sind (Rossetto et al. 2014).

Mehrere klinische Studien demonstrierten einen größeren klinischen Effekt von BoNTInjektionen bei Patientinnen und Patienten mit spastischer Parese, wenn anschließend eine elektrische Stimulation erfolgt (Bayram et al. 2006, Frasson et al. 2005, Hesse et al 1995, Hesse et al. 1998). Bei gesunden Probandinnen und Probanden konnte durch elektrische Stimulation nach den Injektionen ein größerer Effekt auf das Summenaktionspotenzial gezeigt werden (Eleopra et al. 1997). Physiotherapie frühzeitig nach BoNT-Injektionen zeigt bei Patientinnen und Patienten mit spastischer Parese im Rahmen einer Multiplen Sklerose ebenfalls einen besseren Effekt als BoNT-Injektionen alleine (Giovannelli et al. 2007), jedoch kann es sich hierbei auch um einen additiven Effekt handeln. Chen und Kollegen untersuchten den Effekt freiwilliger Muskelaktivität nach BoNT-Injektionen bei Patienten mit Schreibkrampf, konnten hier jedoch keinen signifikanten Effekt feststellen (Chen $\mathrm{R}$ et al. 
1999). Elwischger et al. sahen in ihrer Arbeit aus dem Jahr 2014 ebenfalls keinen Einfluss von zusätzlicher Muskelaktivität auf die Diffusion oder die Verteilung des Toxins. Und selbst unter den genannten Studien, die einen positiven Einfluss von elektrischer Stimulation oder Muskelaktivität auf den Toxin-Effekt zeigen, sind die Ergebnisse nicht immer eindeutig, und eine Verbesserung des Outcomes zeigt sich teilweise auch nur in einem sehr umschriebenen Bereich (Hesse et al. 1998).

Im Tierversuch konnte gezeigt werden, dass die Kombination aus passiver Flexion und Extension sowie elektrischer Stimulation nach BoNT-Injektion einen stärkeren Effekt aufweist als BoNT-Injektionen allein (Kim HS et al. 2003). Darüber hinaus führten auch BoNTInjektionen mit nachfolgend nur einer der beiden Varianten - entweder neuromuskuläre Aktivität (isometrische Kontraktionen) oder Muskelaktivität (passive Bewegung) - jeweils zu einem stärkeren Effekt als BoNT alleine, wobei zwischen den beiden Aktivitäts-Varianten kein Unterschied gezeigt werden konnte (Minamoto et al. 2007). Ein Einfluss von vermehrter Muskelaktivität auf BoNT/A-induzierte histologische Veränderungen des Muskels im Sinne einer veränderten Muskelproteinzusammensetzung ließ sich in einer Arbeit von Legerlotz et al. 2009 nicht darstellen.

\subsubsection{Entwicklung neuer BoNT-Konstrukte}

Die Arbeiten an veränderten BoNT mit unterschiedlichen Ansätzen und Zielen haben in den vergangenen Jahren zu verschiedenen neuen BoNT-Konstrukten geführt (Masuyer et al. 2014). In den meisten Fällen wird dabei bisher das Ziel einer Potenzsteigerung bei maximaler Wirkdauer verfolgt. Die Basis dafür ist das Verständnis der Mechanismen, die die Dauer der Aktivität von BoNT determinieren (Fernández-Salas et al. 2004, Tsai et al. 2010). Von besonderem Interesse ist dabei die unterschiedliche Wirkdauer der BoNT-Serotypen und die protrahierte Wirkung von BoNT/A (Adler M et al. 2001, Foran et al. 2003, Keller et al. 1999, Whitemarsh et al. 2014). So haben BoNT/A und BoNT/E zwar dieselbe Zielstruktur (SNAP25), unterschieden sich jedoch massiv in ihrer Wirkdauer, die für BoNT/A mehrere Monate, für BoNT/E jedoch nur ca. einen Monat beträgt (Eleopra et al. 1998). Im Gegensatz dazu verfügt BoNT/E über eine höhere Potenz und einen schnelleren Wirkeintritt (Lawrence et al. 2007, Simpson 1980, Simpson und Dasgupta 1983). Wang et al. machten sich dies in ihrer im Jahr 2011 veröffentlichten Arbeit zunutze und konstruierten ein Fusionsprotein aus der leichten Kette von BoNT/E und einer enzymatisch inaktiven BoNT/A-Mutante, um die lange Wirkdauer von BoNT/A mit der Potenz von BoNT/E zu kombinieren. Auch die Kombination der stärkeren Wirkung von BoNT/B auf autonome cholinerge Neurone (Dressler und Benecke 2004, Jenzer et al. 1975, Lew et al. 1997) mit der längeren Wirkdauer von BoNT/A 


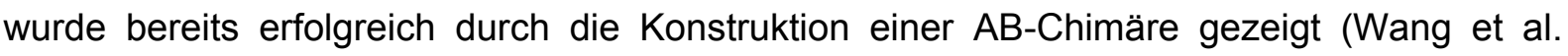
2012). Ein Konstrukt, bei dem die $\mathrm{H}_{\mathrm{cc}}$-Domäne von BoNT/A durch die von BoNT/B ersetzt wurde, zeigt in der biochemischen Analyse eine vierfach höhere Potenz als Wildtyp-BoNT/A (Rummel et al. 2011). Auch die Kombination von BoNT- und Tetanus-Neurotoxin (TeNT)Strukturen stellt eine Möglichkeit der Wirkungsoptimierung dar (Guo et al. 2013).

Eine andere Alternative ist der Versuch, Toxine mit geringerer Immunogenität zu entwickeln (Dressler 2004). So wurde mit incobotulinumtoxinA (Xeomin $\left.{ }^{\circledR}\right)$ erstmals ein Toxin entwickelt, welches frei von Komplexproteinen ist (Dressler 2012). Diese Komplexproteine, welche eine erhöhte Immunogenität aufweisen, sind normalerweise mit dem Toxin assoziiert, haben jedoch keine Funktion im Rahmen des Intoxikationsprozesses (Singh et al. 1996). So kann mit Xeomin ${ }^{\circledR}$ zwar das Risiko der Antikörperbildung verringert, jedoch nicht beseitigt werden (Frevert 2015).

Auch eine Verlängerung der Wirkdauer über die von BoNT/A hinaus wäre ein mögliches Ziel neuer Toxin-Konstrukte, dieses konnte bisher jedoch noch nicht erreicht werden.

\subsection{BoNT-Potenzbestimmung und qualitative Analysen der Toxin-Wirkung}

Die Untersuchung der Wirkung von BoNT-Präparaten sowie BoNT-Konstrukten hat in der Regel einen von zwei möglichen Hintergründen: Entweder es geht um die Potenzbestimmung von Präparaten für den klinischen Gebrauch oder um die Untersuchung von Toxinen vor dem Hintergrund einer wissenschaftlichen Fragestellung. Für den klinischen Gebrauch geht es primär um eine exakte Potenzbestimmung. Bei vielen Forschungsfragen geht es prinzipiell ebenfalls oft um Fragen der Potenz bzw. der klinischen Wirksamkeit. Allerdings steht dann oft der direkte Vergleich unterschiedlicher Toxine oder Injektionstechniken im Vordergrund. Da es meist um eine Optimierung der therapeutischen Nutzung geht, wird im Gegensatz zur reinen Potenzmessung außerdem ein mit der klinischen Anwendung vergleichbares Setting benötigen. Darüber hinaus stellen sich in diesem Kontext oft Fragen, die über die reine Potenz hinausgehen, wie beispielsweise Untersuchungen der Wirkdauer oder des Wirkungsverlaufs. Für die Untersuchung der BoNT-Potenz und der Toxin-Effekte stehen zur Zeit verschiedene Methoden zur Verfügung.

\subsubsection{Der Maus-LD ${ }_{50}$-Test}

Aufgrund der hohen Toxizität von BoNT ist eine exakte Dosierung von enormer Wichtigkeit. Da BoNT eine biologische Substanz ist, deren biologische Aktivität nicht mit der quantitativen Menge gleichgesetzt werden kann (Schantz und Johnson 1990), muss die Potenz jeder einzelnen Charge des Toxins mittels Potenztests bestimmt werden. Geregelt ist dies in der 
European Pharmacopoeia (Council of Europe 2014). Das dafür aktuell in der Regel genutzte Verfahren ist der so genannte Maus-LD ${ }_{50}$-Test, der ursprünglich für die Toxin-Detektion im Rahmen der Botulismusdiagnostik entwickelt wurde und auch dort immer noch den Goldstandard darstellt (Adler S et al. 2010). Durch intraperitoneale Injektionen unterschiedlicher Toxin-Verdünnungen in der Maus wird mit diesem Verfahren die Dosis gesucht, die innerhalb von vier Tagen bei der Hälfte der Tiere zum Tod führt. Diese wird als mittlere letale Dosis $\left(L D_{50}\right)$ bezeichnet (Schantz und Kautter 1978). Die Mengenangabe des Toxins erfolgt dementsprechend grundsätzlich in Aktivitäts-Einheiten (Miles 1951), auch mouse units (MU) genannt, wobei eine $M U$ der $L D_{50}$ entspricht.

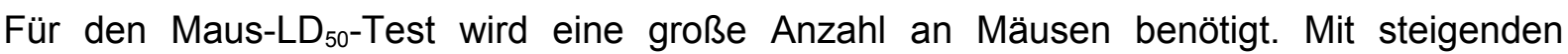
Tierzahlen, die für die zahlreichen pharmakologischen Tests sowie die vermehrte Forschung auf dem Gebiet der Botulinum-Neurotoxine genutzt werden, mehrte sich in der Vergangenheit Kritik aus ethischer Sicht (Balls und Straugham 1996, Liebsch et al. 2011). Neben der Tierzahl spielt hier insbesondere eine Rolle, dass die Tiere durch den letalen Endpunkt großem Stress ausgesetzt sind und in der Regel durch Ersticken aufgrund einer Lähmung der Atemmuskulatur sterben (Adler S et al. 2010, Liebsch et al. 2011). Mangels Alternativen ist der Maus- $\mathrm{LD}_{50}$-Test zur Zeit nichtsdestoweniger immer noch der Goldstandard, wenn auch seit 2011 ein erster In-vitro-Assay als bisher einzige alternative Methode eine Zulassung für die Potenzmessung erhielt (vgl. Kapitel 1.5.2).

In den letzten Jahren wurden immer wieder neue Methoden entwickelt mit dem Ansatz, den $L D_{50}$-Test abzulösen. Der Versuch, den Maus-LD ${ }_{50}$-Test selber zu verbessern, indem frühere („humane“) Endpunkte genutzt werden, zeigte keine verheißungsvollen Ergebnisse (Adler S et al. 2010). Grundlage für die Entwicklung neuer Methoden ist die so genannte 3-R-Strategie mit den Komponenten reduction (Reduktion der benötigten Tierzahl), refinement (Verbesserung durch weniger Leid der Tiere) und replacement (Ersatz von In-vivo-Tests durch In-vitro-Methoden), analog zu den von Russel und Burch im Jahr 1959 formulierten Principles of Humane Experimental Technique. Neben den erwähnten ethischen Aspekten stellte sich jedoch auch schon früh in der Geschichte der therapeutischen BoNT-Nutzung die Frage, ob der $L D_{50}$-Test aufgrund seiner geringen Nähe zur klinischen Anwendung tatsächlich der optimale Test ist oder eine Methode auf Basis einer regionalen Denervierung den Effekt der klinischen Wirksamkeit des Toxins nicht besser widerspiegelt (Pearce et al. 1995b).

Neben der Suche nach Alternativen zum Maus-LD ${ }_{50}$-Test stieg und steigt außerdem der Bedarf nach Methoden, mit deren Hilfe möglichst viele Aussagen zur Toxin-Wirkung in einem mit dem klinischen Gebrauch vergleichbaren Setting getroffen werden können. Die klinische 
Anwendung hat wenig Ähnlichkeit mit dem LD $_{50}$-Test, unter anderem da therapeutische Injektionen intramuskulär oder intraglandulär erfolgen und die Dosierungen subletal und somit deutlich geringer sind als beim LD $_{50}$-Test. Darüber hinaus ermöglicht der LD $_{50}$-Test keine längeren Beobachtungen und dadurch keine Beurteilung der Wirkdauer oder der Erholungsphase. Dies führte in den vergangenen Jahren und Jahrzehnten zur Entwicklung weiterer Assays, die über die funktionalen Ansprüche des Maus-LD ${ }_{50}$-Tests hinausgehen.

\subsubsection{In-vitro-Methoden}

Aus ethischer Sicht stellen In-vitro-Assays im Sinne eines replacements die Methode der Wahl für die BoNT-Potenzmessung dar - vorausgesetzt sie können eine Sicherheit vergleichbar mit der eines In-vivo-Assays gewährleisten.

Der schon lange angewandte immunologische Toxin-Nachweise mittels enzyme linked immunosorbent assay (ELISA) (Notermans et al. 1979, Shone et al. 1985) konnte im Laufe der Zeit so verbessert werden, dass inzwischen eine Sensitivität vergleichbar mit dem $L_{50^{-}}$ Test erreicht wird (Doellgast et al. 1993). Eine solche reine Mengenmessung kann jedoch aufgrund fehlender Aussagekraft bzgl. der Toxin-Aktivität (und somit unzureichender Sicherheit) eine Aktivitätsmessung nicht ersetzen (Pellett 2013).

Eine weitere Methode sind Endopeptidase-Assays, die auf dem Nachweis spezifischer Spaltprodukte der Endopeptidase des jeweiligen BoNT-Sertotyps basieren (Ekong et al. 1997, Hallis et al. 1996, Wictome et al. 1999). Ihre Vorteile sind die Serotypen-Spezifität (Sesardic 2006a) sowie eine dem $L D_{50}$-Test überlegene Sensitivität (Ekong et al. 1997, Wictome et al. 1999). Nachteil ist, dass nicht alle funktionellen Bereiche des Toxins erfasst werden (Adler $S$ et al. 2010). Nichtsdestoweniger sind Einsatzmöglichkeiten denkbar, so dass Weiterentwicklungen von Assays zur Messung der proteolytischen Aktivität Gegenstand aktueller Forschung sind (u.a. Bagramyan et al. 2013, Dunning et al. 2012, Gregory et al. 2014, Lévêque et al. 2013, Liu et al. 2012, Ouimet et al. 2013, Ruge et al. 2011).

Die vielversprechendste In-vitro-Methode stellen aktuell die Zell-basierten Assays dar, da sie als einzige alle Mechanismen des Intoxikationsprozesses erfassen (Adler S et al. 2010, Pellett 2013). Viele von innen erreichen mittlerweile eine Sensitivität, die mit der des $L_{50^{-}}$ Tests vergleichbar ist (Fernández-Salas et al. 2014, Pellett et al. 2010, Pellet et al. 2011). Im Jahr 2011 wurde von der amerikanischen FDA ein Zell-basierter In-vitro-Assay (FernándezSalas et al. 2014) von Allergan, Inc., USA für die Stabilitäts- und Potenzmessung zugelassen, jedoch bisher nur für die Allergan-Produkte BOTOX® und BOTOX® Cosmetic (Pellett 2013). Für viele Fragestellungen bzgl. klinischer Aspekte eignen sich In-vitro- 
Methoden jedoch nicht, da sie die Wirkung im Organismus nicht ausreichend widerspiegeln können.

\subsubsection{Ex-vivo-Methoden}

Unter Ex-vivo-Methoden werden Verfahren verstanden, bei denen Muskel- oder MuskelNerven-Präparate aus Tieren verwendet werden. Es werden verschiedene Muskelpräparate beschrieben, die sich prinzipiell zur Ex-vivo-Arbeit mit BoNT eignen, beispielsweise der Plantarmuskel der Maus (Clark et al. 1987), der M. levator auris longus der Maus (AngautPetit et al. 1987) oder Muskelstreifen aus der Harnblase der Ratte (Smith et al. 2003, van Uhm et al. 2014).

Ein etabliertes Verfahren ist der Hemidiaphragma-Test (Göschel et al. 1997, Wohlfarth et al. 1997). Nach Entnahme eines Muskel-Nerven-Präparates, bestehend aus N. phrenicus und dem von diesem innervierten Hemidiaphragma, wird bei diesem Verfahren über den N. phrenicus der Muskel stimuliert und die isometrische Kontraktion registriert. Anschließend wird das umgebende Medium gegen eine BoNT-Lösung ausgetauscht und die Zeit gemessen, die benötigt wird, um eine prozentige Reduktion der Kontraktionen zu erreichen. Dann kann eine Dosis-Wirkungs-Kurve erstellt werden. (Wohlfarth et al. 1997)

Als weiteres Verfahren wurde 2008 der so genannte intercostal neuromuscular junction (NMJ) Assay entwickelt, der Intercostalmuskelpräparate aus der Ratte nutzt (Huber et al. 2008).

Vorteile von Ex-vivo-Methoden sind eine Reduktion der benötigten Tierzahlen um ca. 50 Pro-

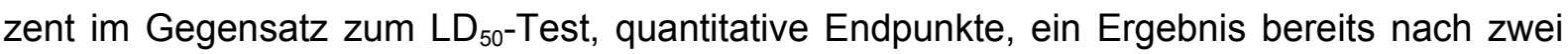
Stunden und Versuchsbedingungen, die leicht variierbar sind; dem steht jedoch gegenüber, dass eine komplexe Ausstattung sowie eine technisch sehr anspruchsvolle Versuchsdurchführung notwendig sind (Rummel 2006). Auch sind In-vivo-Bedingungen mit dem Versuchsrahmen nicht direkt vergleichbar, da beispielsweise pharmakokinetische Aspekte im Hemidiaphragma-Test umgangen werden (Wohlfarth et al. 1997). Das zeigt sich auch in einer unzureichenden Korrelation der Ergebnisse mit dem LD LD -Test sowie mit In-vivo-ParalyseModellen (Sesardic und Gaines Das 2008). Darüber hinaus werden im Rahmen der Ex-vivoMethoden verhältnismäßig hohe BoNT-Dosierungen genutzt, die nicht mit den klinisch genutzten Dosierungen vergleichbar sind.

\subsubsection{In-vivo-Methoden auf Basis lokaler Paralyse}

Sowohl für In-vitro- als auch Ex-vivo-Methoden bestehen bezüglich klinischer Fragestellungen (z.B. in Bezug auf die Wirkungsdauer oder eine Optimierung der Injektionen) Grenzen. 
Für diesen Einsatzbereich scheinen daher In-vivo-Modelle notwendig, von denen aufgrund der Entwicklung der vergangenen Jahre mit steigendem Interesse an der BoNT-Forschung mittlerweile mehrere existieren. Die bekanntesten und erfolgversprechendsten werden im Folgenden beschrieben.

Die einzige bekanntere Methode, bei der das Toxin nicht intramuskulär injiziert wird, ist der mouse abdominal ptosis Assay (Sesardic 2006b). Er basiert auf subkutanen BoNT-Injektionen in die Inguinalregion von Mäusen und der späteren Beurteilung der Wölbung des Abdomens (Takahashi et al. 1990). Es können drei Stufen der Paralyse unterschieden werden, so dass zusammen mit dem Status des Fehlens der Paralyse eine vierstufige Skala existiert, die von zwei unabhängigen Beobachtern angewendet wird (Sesardic et al. 1996).

Die Mehrzahl der weiteren entwickelten Methoden beruht auf intramuskulären Injektionen. Diese Methoden versuchen so, der klinischen Anwendung möglichst nahe zu kommen. Die Messung der median paralysis unit (MPU) ist eine davon. Sie ist definiert als die BoNTDosis, bei der nach intramuskulärer Injektion in den M. gastrocnemius von Mäusen die Hälfte der Tiere eine komplette Paralyse des Hinterlaufs zeigt. Das Verfahren setzt also im Vergleich zum LD $_{50}$-Test eine lokale schlaffe Lähmung als Endpunkt, anstatt den Tod der Tiere. (Pearce et al. 1995a)

Auf Basis einer Arbeit von Sugiyama et al. 1975, in der nach Injektion von BoNT in den M. gastrocnemius der Maus eine Einteilung der lokalen Paralyse in drei Stufen erfolgte, entwickelte Aoki 1999 den mouse digit abduction scoring Assay (DAS-Assay, Aoki 1999). Die Einteilung der Lähmung erfolgt in diesem Assay auf Basis einer 5-Punkt-Skala durch zwei unabhängige, verblindete Beobachter (Aoki 2001). Mittlerweile wurde der DAS-Assay auch für andere Studien genutzt (Morbiato et al. 2007, Wang et al. 2011) sowie in ein RattenModell übertragen (Broide et al. 2013).

Die Methode der Messung der dorsiflexion torque, d.h. des Drehmoments der Dorsalflexion (Peters et al. 2003), wurde von Minamoto et al. 2007 zur Quantifizierung der Toxin-Wirkung nach Injektion in den M. tibialis anterior der Ratte genutzt.

Nach BoNT-Injektionen in den M. extensor digitorum longus kann der Toxin-Effekt mit Hilfe des Zehenspreiz-Reflexes quantifiziert werden (Wilder-Kofie et al. 2011). Nachdem bereits in früheren Arbeiten der M. extensor digitorum longus der Ratte als Injektionsmuskel genutzt worden war (Adler M et al. 1996, Adler M et al. 2001, Cull-Candy et al. 1976), entwickelten Wilder-Kofie und Kollegen dieses Modell weiter. Sie nutzen im Vergleich zu früheren Arbeiten zum einen Mäuse anstatt Ratten, zum anderen versuchten sie, die subjektive Beurteilung der Paralyse (Adler $\mathrm{M}$ et al. 2001) zu objektivieren. Bei dem Verfahren werden an festen Zeitpunkten nach den Injektionen nach Auslösen des Zehenspreiz-Reflexes Fotos 
angefertigt. Mit deren Hilfe werden Länge und Breite der Hinterpfote nach definierten Kriterien gemessen und anschließend mit dem als Kontrolle dienenden anderen Hinterbein vergleichen. (Wilder-Kofie et al. 2011)

Auch die Muskelkraft (Pickett et al. 2008, Stone et al. 2007) und andere neurophysiologische Methoden wie beispielsweise die Messung des Summenaktionspotenzials mittels Elektromyographie (EMG) können zur Untersuchung der Toxin-Wirkung verwendet werden und liefern aussagekräftige Ergebnisse (Brillante et al. 2002, Cichon et al. 1995, Kim SH et al. 2012, Ma et al. 2004, Morbiato et al. 2007, Stone et al. 2011). Hervorzuheben ist hier der rat muscle force Assay (RMF-Assay) von Pickett und Kollegen, der nach BoNT-Injektion in den M. gastrocnemius der Ratte aussagekräftige Ergebnisse mittels Messung der Kraftentwicklung im M. triceps surae nach elektrischer Stimulation des N. ischiadicus erzielt (Pickett et al. 2008).

Eine weitere Methode zur Messung der Wirkung von BoNT ist die Analyse der Laufradaktivität von Mäusen nach Injektion in den M. gastrocnemius, die zuerst von Keller 2006 beschrieben wurde. Der von Keller und auch von Auguet et al. 2011 genutzte MessParameter ist dabei die Laufdistanz.

\subsection{Maus-Laufradmodelle in der neurologischen Forschung}

Maus- (und teilweise auch Ratten-) Laufradmodelle sind etablierte Versuchsmethoden im Bereich neurologischer Fragestellungen. Sie dienen der Messung physikalischer Aktivität sowie koordinativer Fähigkeiten (Dowling et al. 2011, Klinker et al. 2013, Schmitz et al. 2012). Außerdem kann der Einfluss motorischer Aktivität auf neuronale Prozesse, Strukturen sowie Erkrankungen untersucht werden (Liebetanz et al. 2004, Liebetanz et al. 2012, Zhao et al. 2005).

Besondere Vorteile zeigen Laufradmodelle bei der Erfassung latenter motorischer Defizite, die sich im alltäglichen Verhalten ansonsten nicht erkennen lassen (Liebetanz und Merkler 2006, Liebetanz et al. 2007). So lassen sich im Maus-Modell von Morbus Huntigton und Morbus Pompe im Laufradmodell bereits Reduktionen der Laufleistung feststellen, wenn andere Methoden noch keine Auffälligkeiten zeigen (Bijvoet et al. 1999, Hickey et al. 2005). Eine Muskelschwäche lässt sich auch im Maus-Modell der Muskeldystrophie Typ Duchenne (MDX-Maus, murine X-chromosomale Muskeldystrophie) gut detektieren (Hara et al. 2002, Weller et al. 2012), ebenso wie eine progressive Muskelschwäche und Muskelatrophie in einem Rattenmodell (Kitahara et al. 1997).

Insgesamt scheint ein Laufradmodell demnach geeignet, motorische Defizite, die durch eine BoNT-induzierte Muskelschwäche entstehen, zu messen. 


\subsection{Ziele dieser Arbeit}

Im Rahmen dieser Arbeit soll ein Laufrad-basiertes Maus-Modell entwickelt werden, das eine quantitative und qualitative Analyse der Wirkung niedrig dosierter intramuskulärer BoNTInjektionen ermöglicht. Insbesondere in Anbetracht der bereits bestehenden Methoden ist es das Ziel, eine möglichst sensitive Methode zu entwickeln, die bereits geringe injizierte Mengen BoNT zu detektieren vermag und geringe Dosisunterschiede erkennen kann. Neben diesen Aspekten, die sich auf die BoNT-Potenz beziehen, soll auch die Analyse der Wirkdauer und der Erholungsphase möglich sein, da dies für aktuelle Forschungsfragen von großer Relevanz und somit ein wichtiger Aspekt für die Verwendbarkeit der Methode ist.

BoNT soll in niedrigen, mit der klinischen Anwendung vergleichbaren, Dosierungen Mäusen intramuskulär injiziert und die Toxin-Wirkung mittels Analyse von Laufraddaten analysiert werden. Es soll dafür der am besten geeignete Injektionsmuskel gefunden werden (Kapitel 3.2). Auch soll eine Analyse unterschiedlicher Laufparameter (kumulative Distanz, Maximalgeschwindigkeit, Durchschnittsgeschwindigkeit, Anzahl der Läufe, Gesamtzeit im Laufrad, durchschnittliche Zeit im Laufrad, durchschnittliche Distanz pro Lauf) erfolgen, um den Parameter zu finden, der am sensitivsten die Toxin-Effekte detektieren kann und die stabilsten und am besten reproduzierbaren Ergebnisse liefert (Kapitel 3.3 und 3.4).

Bei Tierversuchen mit Mäusen werden in der Regel junge Tiere direkt nach der Lieferung verwendet. Aus ethischer und finanzieller Sicht stellt sich jedoch die Frage, ob auch ältere Tiere verwendet werden können und ob mehrfache Injektionen derselben Tiere zu denselben Ergebnissen führen. Daher soll auch untersucht werden, ob die Ergebnisse der Methode unabhängig von Alter und Gewicht der Mäuse reproduzierbar sind (Kapitel 3.5).

Ferner soll mit Hilfe des in dieser Arbeit etablierten Laufrad-basierten In-vivo-Tests in der Maus die Hypothese einer gesteigerten Wirksamkeit von BoNT durch neuromuskuläre Aktivierung getestet werden. Es soll der Einfluss forcierter Muskelaktivität direkt nach den BoNTInjektionen auf die Toxin-Wirkung hinsichtlich Wirkstärke und Wirkdauer untersucht werden (Kapitel 3.6). 


\section{Material und Methoden}

\section{$2.1 \quad$ Versuchstiere}

Für alle Versuche wurden männliche C57/BL6J-Mäuse verwendet. Für die in Kapitel 3.1, 3.2, 3.3, 3.4 und 3.6 beschrieben Versuche stammten diese von Charles River Laboratories, Sulzfeld (Deutschland). Für die Versuche, die in Kapitel 3.5 beschrieben werden, wurden Tiere von JANVIER SAS, St Berthevin Cedex (Frankreich) genutzt. Alle Versuche wurden mit Genehmigung der Bezirksregierung Braunschweig, Niedersachen, durchgeführt (AZ 10/0302 und 13/1090).

Die Mäuse wurden im Alter von vier Wochen geliefert und dann einzeln in Plastikkäfige $(24 \times$ $18 \times 16 \mathrm{~cm}$ ) mit Nahrung und Wasser gesetzt. Jeder Käfig war mit einem Laufrad ausgestattet, zu dem die Mäuse ständig Zugang hatten, so dass freiwilliges Laufen jederzeit möglich war. In dem Raum, in dem sich die Tiere befanden, herrschte ein zwölfstündiger Tag/Nacht-Zyklus mit Licht in der Zeit von 6:30 bis 18:30 Uhr (Sommerzeit) bzw. 5:30 bis 17:30 Uhr (Winterzeit). Die Temperatur lag bei durchschnittlich $21^{\circ} \mathrm{C}$ und die Luftfeuchtigkeit bei $50-55 \%$.

Einmal pro Woche wurden Käfige, Nahrung und Wasser erneuert. Außerdem wurde täglich nach den Tieren geschaut, um Verschlechterungen des Gesundheitszustandes umgehend zu bemerken und klinische Auswirkungen der Injektionen zeitnah feststellen zu können. Das Gewicht der Tiere wurde jeweils beim Einsetzen der Laufräder und im Rahmen jeder Injektion kontrolliert, um einen weiteren Parameter für den Gesundheitszustand der Mäuse zu erheben sowie im Rahmen der Versuche Auswirkungen des Gewichts auf die ToxinWirkung untersuchen zu können. Ergänzt wurden die Kontrollen durch die tägliche Analyse der Laufdaten. Durch die Kontrollen der Laufaktivität konnten Beeinträchtigungen der Mäuse teilweise bereits frühzeitiger als durch die reine Inspektion registriert werden. Zeigten Tiere nicht-versuchsbedingte gesundheitliche Beeinträchtigungen, wurden diese Mäuse aus dem Versuch genommen. Mäuse, die schon vor Versuchsbeginn eine verhältnismäßig geringe Laufleistung zeigten (Maximalgeschwindigkeit $<20$ Meter pro Minute oder Distanz konstant $<500$ Meter pro Tag), wurden ebenfalls nicht verwendet.

\subsection{Laufräder}

Die verwendeten Laufräder sind Anfertigungen der Werkstatt der Universitätsmedizin Göttingen, die speziell für entsprechende Versuche hergestellt wurden. Sie bestehen aus einer Metallachse und Metallstreben sowie einer Plexiglasscheibe an der Rückwand und einem 
Speichenkreuz aus Plexiglas an der Vorderseite. Die Laufräder sind in einer Metallhalterung aufgehängt, in der sie sich frei drehen können und die durch eine Sperrfunktion nur eine Drehrichtung zulässt. Durch diese wird verhindert, das beispielsweise Schaukelbewegungen möglich sind, die fälschlicherweise als Laufaktivität registriert werden könnten.

Der Zustand der Laufräder wurde regelmäßig mindestens einmal wöchentlich sowie stets im Rahmen der Injektionen kontrolliert, um Verschmutzungen, eine Einschränkung der freien Drehbarkeit oder Defekte feststellen zu können. Darüber hinaus wurde bei plötzlich veränderten auffälligen Laufwerten, beispielsweise einer verminderten Laufgeschwindigkeit oder einem deutlichen Abfall der gelaufenen Distanz, stets kontrolliert, ob diese auf ein technisches Problem, insbesondere des Laufrads, zurückzuführen waren. Verdreckte, klemmende oder schwergängige Laufräder wurden umgehend ausgetauscht und Veränderungen der Laufwerte, die durch entsprechende technische Ursachen entstanden waren, aus den Daten herausgenommen.

Es wurden zwei verschiedene Laufradvarianten genutzt: Konventionelle Laufräder, deren Streben einheitliche Abstände haben, und komplexe Laufräder, bei denen die Streben in irregulären Abständen angeordnet sind (vgl. Abb. 1). Die einzelnen Streben der komplexen Laufräder sind entsprechend schwerer als die der konventionellen, so dass die Laufräder trotz unterschiedlicher Anzahl an Streben dasselbe Gewicht haben und somit physikalische Ursachen für veränderte Laufdaten in diesen Laufrädern ausgeschlossen werden können.

Die Mäuse bekamen im Alter von vier Wochen zunächst je ein konventionelles Laufrad zur Verfügung gestellt. Nach etwa zwei Wochen hatten die Tiere das Laufen im Laufrad so gut trainiert, das sich für die einzelnen Mäuse individuell stabile Laufwerte in Sinne eines Plateaus zeigten. Daraufhin wurden die konventionellen durch komplexe Laufräder ersetzt. In diesen muss die Schrittlänge kontinuierlich angepasst werden. Es wird davon ausgegangen, dass so eine höhere Sensitivität für die Detektion einer motorischen Beeinträchtigung erreicht werden kann (Liebetanz et al. 2007). Waren hier nach ein bis zwei Wochen Training wieder konstante Werte erreicht, wurden die Injektionen durchgeführt. Bei den Versuchen, bei denen ältere Tiere verwendet wurden, hatten diese stets seit dem Alter von ca. 6 Wochen kontinuierlich Zugang zu einem komplexen Laufrad. Alle Versuche basieren somit auf Laufdaten, die in komplexen Laufrädern gemessen wurden. 

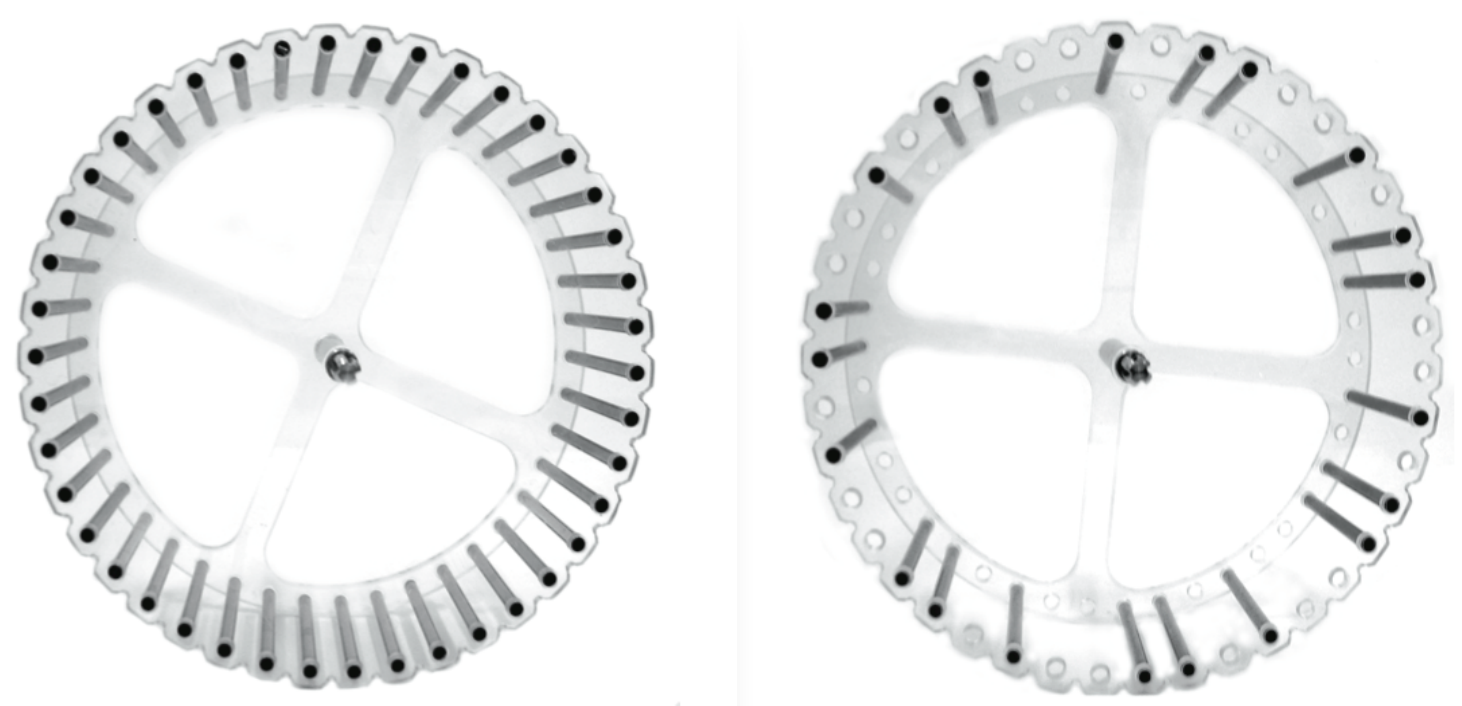

Abbildung 1: Laufradtypen. Konventionelles Laufrad (links) und komplexes Laufrad (rechts).

\subsection{Botulinum-Neurotoxin}

Es wurde für alle Injektionen Xeomin ${ }^{\circledast}$ Clostridium Botulinum-Neurotoxin Typ A (150 kD), frei von Komplexproteinen, von der Firma Merz Pharmaceuticals GmbH, Frankfurt/Main, Deutschland verwendet. Eine Flasche enthielt $100 L^{L} D_{50}$-Einheiten des Toxins in Form von Pulver. Für die Herstellung der Injektionslösung wurde dieses in $2 \mathrm{ml} \mathrm{0,9 \%} \mathrm{Natriumchlorid}$ $(\mathrm{NaCl})$ gelöst. Die notwendigen Verdünnungen für die Injektionen erfolgten ebenfalls in $\mathrm{NaCl}$ $0,9 \%$.

\section{$2.4 \quad$ Injektionen}

Die Injektionen wurden mit einer Mikroliterspritze und einer 33 G-Nadel der Firma Hamilton ${ }^{\circledR}$ unter einer Inhalationsnarkose mit Isofluran (Einleitung $3 \%$, Erhaltungsnarkose 1,5\%) durchgeführt, um möglichst wenig Stress, Schmerzen und lokale Traumata zu verursachen. Es wurden jeweils zwei identische Injektionen in äquivalente Muskeln des rechten und linken Hinterlaufs der Mäuse vorgenommen. Das Injektionsvolumen entsprach bei allen Versuchen mit Ausnahme der in Kapitel 3.3 beschriebenen Injektionen $10 \mu \mathrm{l}$ pro Muskel. In Kapitel 3.3 wurden $15 \mu \mathrm{l}$ Injektionsvolumen genutzt. Alle im Folgenden genannten Injektionsmengen beziehen sich auf die Toxin-Menge im gesamten Injektionsvolumen, also auf die Toxin-Dosis pro Maus.

Als Injektionsmuskeln wurden in einem ersten Injektions-Versuch (Kapitel 3.2) der M. gastrocnemius und der M. tibialis anterior, in allen weiteren Versuchen nur noch der 
M. gastrocnemius genutzt. Die Injektionen in den M. tibialis anterior erfolgten bei in Rückenlage gehaltenen Tieren und gestrecktem Hinterlauf durch Einführen der Nadel lateral der Tibia in einem Winkel von ca. $60-70^{\circ}$ zur Haut. Für die Injektionen in den M. gastrocnemius wurden die Mäuse in Bauchlage auf einer geraden Unterlage platziert. Dann konnte nach Dorsalextension der Pfote die Nadel parallel zur Achillessehne in den Muskelbauch vorgeschoben werden. Dabei wurde versucht, die Spitze der Nadel am Ort des größten Muskeldurchmessers zu platzieren. Es wurden dann stets die $10 \mu \mathrm{lbzw}$. $15 \mu \mathrm{l}$ Injektionslösung an einem Ort komplett injiziert.

Nach den Injektionen wurden die Mäuse umgehend zurück in ihren Käfig gesetzt und hatten dort sofort wieder Zugang zu ihrem Laufrad. Nach dem Erwachen aus der Narkose wurde durch Beobachten der Tiere im Käfig eine sichtbare Beeinträchtigung durch die stattgefundenen Injektionen ausgeschlossen. Darüber hinaus wurden tägliche Kontrollen des Gesundheitszustands vorgenommen (vgl. Kapitel 2.1).

\subsection{Aufzeichnungsgeräte und Laufdatenanalyse}

Über die Achse sind die Laufräder mit einem Rotationssensor (LEGO ${ }^{\circledR}$ Part 2977c01 Electric Rotation Sensor) verbunden, der wiederum an ein Aufzeichnungsgerät (Boenig \& Kallenbach oHG, Dortmund, Deutschland) angeschlossen ist. Über dessen Verbindung mit einem Computer und mittels Nutzung einer LabVIEW ${ }^{\mathrm{TM}}$-basierten (National Instruments Corp.) Software erfolgte über den kompletten Versuchszeitraum eine durchgehende Aufzeichnung der Laufraddaten. Diese wurden dann in einem MATLAB-Programm (The MathWorks, Inc., Natick, Massachusetts, USA) weiterverarbeitet.

Eine Laufradumdrehung entspricht einer Laufdistanz von 0,38 Metern. Der Rotationssensor misst Laufradaktivitäten mit einer Auflösung von 1/16 Umdrehung, so dass bereits Laufstrecken ab einer Länge von 2,375 cm registriert werden. Neben der jeweiligen Distanz wird in diesem System auch die zeitliche Komponente mit erfasst, so dass insgesamt sieben verschiedenen Parameter aufgezeichnet bzw. berechnet werden können: Die kumulierte Laufdistanz (Dist), die durchschnittliche Distanz pro Lauf (Distmean), die maximale Laufgeschwindigkeit (Vmax), die durchschnittliche Laufgeschwindigkeit (Vmean), die Anzahl der Laufradnutzungen (Nlauf), die kumulierte Laufzeit (Tges) und die Durchschnittsdauer eines Laufs (Tmean) (vgl. Tab. 1). Anhand dieser Parameter wurde im Rahmen der vorliegenden Arbeit das Laufverhalten der Mäuse beurteilt.

Die Zeitintervalle der Datenausgabe können frei gewählt werden. Bei kumulativen Werten (Distanz, Nlauf und Tges) werden alle Werte für den entsprechenden Zeitraum addiert. Bei Durchschnittswerten (Distmean, Vmean und Tmean) wird der Durchschnitt aller Werte in 
dem entsprechenden Zeitraum gebildet. Die Vmax stellt einen Maximalwert dar, der in dem betrachteten Zeitraum erreicht wurde. Im Rahmen von Vorversuchen sowie anderen Projekten, in denen mit demselben Laufradsystem gearbeitet wurde, hatte sich gezeigt, dass es bei der Maximalgeschwindigkeit regelmäßig zu eindeutig als Artefakt zu wertenden Ausreißern gekommen war. Diese waren dadurch zu erkennen, dass sie dem höchsten mit dem System registrierbaren Geschwindigkeitswert entsprachen oder diesem sehr nahe kamen und damit in der Regel deutlich über der sonstigen Laufgeschwindigkeit des jeweiligen Tieres lagen. Um solche Artefakte zu vermeiden wurde eine Anpassung der Software vorgenommen. Für die in dieser Arbeit verwendeten Daten wurde jeweils der höchste Geschwindigkeits-Wert des entsprechenden Zeitraums gestrichen und aus den drei nächsthöheren Werten der Mittelwert gebildet. Dieser Wert wurde als maximale Laufgeschwindigkeit für den betrachteten Zeitraum ausgegeben. Da die individuelle Maximalgeschwindigkeit eines Tieres in der Regel nicht nur zu einem einzigen Zeitpunkt eines Beobachtungszeitraums von 24 Stunden erreicht wird, wird davon ausgegangen, dass durch dieses Verfahren die Maximalgeschwindigkeit adäquat dargestellt werden kann.

\begin{tabular}{|l|l|l|l|}
\hline Parameter & Kurzform & Definition & Einheit \\
\hline Distanz & Distanz & Kumulierte Laufdistanz & $\mathrm{m}$ \\
\hline Durchschnittliche Distanz & Distmean & Durchschnittliche Distanz pro Lauf & $\mathrm{m}$ \\
\hline Maximalgeschwindigkeit & Vmax & Maximale Laufgeschwindigkeit & $\mathrm{m} / \mathrm{min}$ \\
\hline Durchschnittsgeschwindigkeit & Vmean & Durchschnittliche Laufgeschwindigkeit & $\mathrm{m} / \mathrm{min}$ \\
\hline Anzahl der Läufe & Nlauf & Anzahl der Laufradnutzungen & \\
\hline Gesamtzeit & Tges & Kumulierte Laufzeit & $\mathrm{min}$ \\
\hline Durchschnittliche Zeit & Tmean & Durchschnittsdauer eines Laufs & sek \\
\hline
\end{tabular}

Tabelle 1: Laufparameter

Die unterschiedlichen Laufparameter können je nach Fragestellung als stündliche oder tägliche Werte verwendet und analysiert werden, wobei in dieser Arbeit für die Auswertung fast ausschließlich 24-Stunden-Daten verwendet wurden. Ein Datentag beginnt dabei jeweils um 9 Uhr morgens. Die Datenangaben beziehen sich grundsätzlich jeweils auf den Zeitraum, der mit dem angegebenen Zeitpunkt endet. Der Wert des Injektionstages, der stets als „Tag 0“ angegeben wird, beinhaltet demnach den 24-Stunden-Zeitraum, der um 9 Uhr am Injektionstag endet. Daher wird der Datensatz des Injektionstages stets noch als Teil des Zeitraums vor der Injektion gewertet. Für spezifische Fragestellungen (vgl. Kapitel 3.6) wurden jedoch 
auch die aufgeschlüsselten Stundenwerte ausgewertet und in Abbildung 14 als Tagesprofil dargestellt.

Nach den Injektionen wurde das Laufverhalten, je nach Verlauf der Erholungsphase, für einen Zeitraum von 14-35 Tagen beobachtet. Die Beobachtung wurde jeweils dann beendet, wenn für die jeweilige Fragestellung kein weiterer Erkenntnisgewinn von einer längeren Beobachtung erwartet wurde bzw. spätestens dann, wenn die Erholungsphase abgeschlossen war und wieder dauerhaft stabile Laufwerte erreicht wurden.

\subsection{Statistische Datenauswertung}

Die Berechnung der Tages- bzw. Stundenwerte der einzelnen Parameter erfolgte durch die in Kapitel 2.5 erwähnte MATLAB-Software. Die statistische Auswertung wurde dann mit SPSS Version 18 (SPSS, Inc., Chicago, Illinois) durchgeführt. Die zeitlichen Verläufe wurden in einer Zwei-Faktoren-Analyse der Varianz für wiederholte Messungen, im Folgenden ANOVA (nach der englischen Bezeichnung analysis of variance) genannt, getestet. Bei signifikanten Ergebnissen wurde post hoc ein ungepaarter T-Test für den entsprechenden Zeitpunkt durchgeführt. Das Signifikanzniveau wurde durchgehend bei $p<0,05$ festgelegt. In den Grafiken sind alle Daten als Mittelwert +/- Standardfehler angegeben. Lineare Regressionsanalysen sowie die Berechnung von Korrelationskoeffizienten nach Pearson wurden mit der Macintosh-Version von GraphPad Prism 5.0a (GraphPad Software, Inc., USA) durchgeführt. Auch die Erstellung sämtlicher Grafiken erfolgte mit diesem Programm.

Die Daten werden in dieser Arbeit immer entweder als „tatsächliche Werte“ oder als „relative Werte" angegeben. Die tatsächlichen Werte entsprechen den aufgezeichneten und berechneten Werten der Parameter in den entsprechenden Einheiten. Die „relativen Werte" sind prozentuale Werte, denen eine Festlegung des Plateaus (Ausgangslevel), welches jedes Tier nach ausreichendem Training bzgl. der einzelnen Parameter erreicht hatte, zugrunde liegt. Für die Bestimmung dieses Ausgangslevels wurden für jedes einzelne Tier für den zu betrachtenden Parameter die Daten der vier Tage vor den Injektionen (entspricht den Werten der Tage „-3“ bis „0“) gemittelt und als Ausgangslevel von $100 \%$ festgelegt. Da die Tiere zum Zeitpunkt der Injektionen immer bereits ein stabiles Laufniveau zeigten, kann dieser Wert als repräsentativ für die Plateauphase gesehen werden. Alle angegebenen Werte wurden dann ins Verhältnis zu diesem Wert gesetzt. Mit Hilfe der relativen Werte kann somit der pro-zentuale Abfall oder Anstieg einzelner Parameter bestimmt werden. 


\section{$3 \quad$ Ergebnisse}

\subsection{Die Laufleistung im Langzeit-Verlauf}

70 Mäuse wurden ab einem Alter von 90 Tagen über einen Zeitraum von 74 Tagen beim Laufen in komplexen Laufrädern beobachtet. In diesem Zeitraum fanden keine Injektionen oder sonstigen Manipulationen an den Tieren statt, abgesehen vom wöchentlichen Umsetzen und einem gelegentlichen Austausch der Laufräder.

Die Parameter Distanz und Vmax sind in Abbildung 2 dargestellt, die statistischen Ergebnisse in Tabelle 2. Für beide Parameter zeigt sich im beobachteten Zeitverlauf eine Reduktion der Werte. Diese kann bei zufriedenstellender Anpassungsgüte und signifikanter Abweichung der Steigung der Regressionsgeraden von Null als signifikant angesehen werden. Dies bedeutet, dass die Mäuse mit höherem Alter langsamer Laufen und auch kürzere Strecken zurücklegen.

Betrachtet man lediglich den Zeitraum von Tag 90 bis Tag 120, zeigt sich hier zwar bereits eine signifikante Reduktion der Distanz, jedoch nicht der Vmax. Die Laufgeschwindigkeit bleibt also zunächst stabil und sinkt erst ab einem gewissen Alter der Mäuse nach und nach $\mathrm{ab}$.
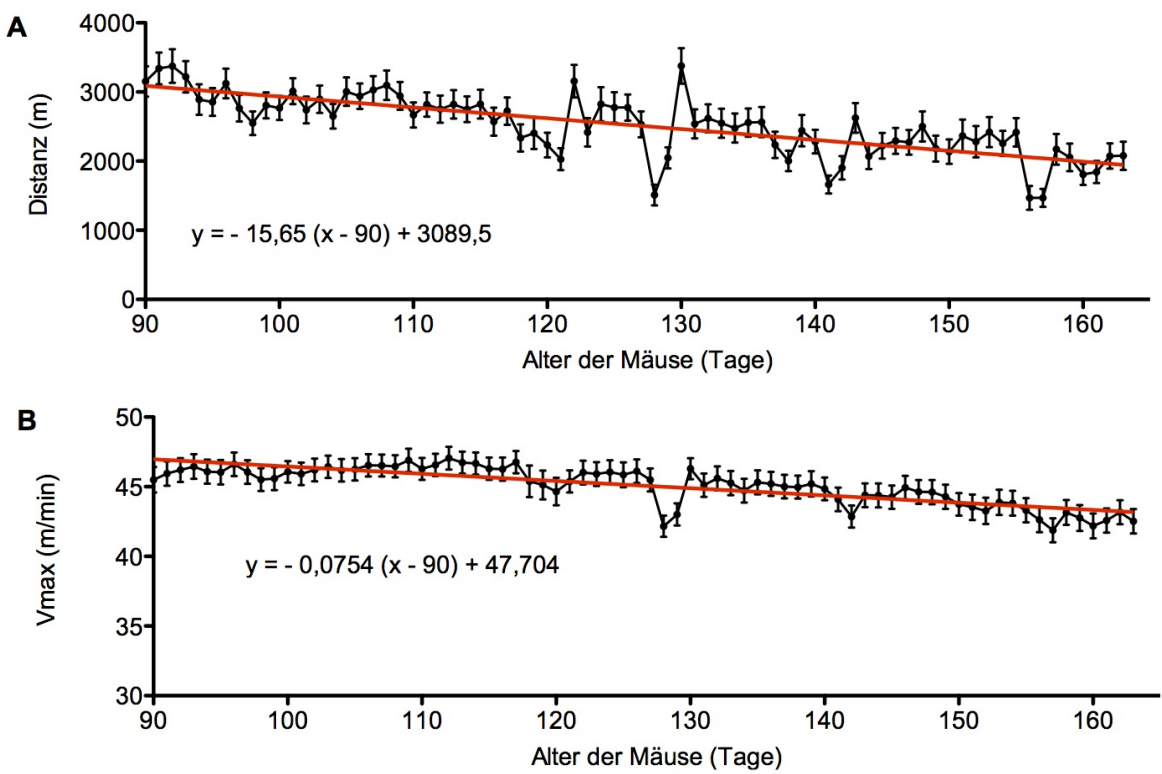

Abbildung 2: Laufleistung der Mäuse im Langzeitverlauf. Verlauf der Distanz (A) und der Vmax (B) beim Laufen in komplexen Laufrädern über einen Zeitraum von 74 Tagen ohne Injektionen. Die Gleichung der Regressionsgeraden ist jeweils mit angegeben. 


\begin{tabular}{|c|c|c|c|c|c|c|c|c|}
\hline \multirow[t]{2}{*}{ Zeitraum } & \multirow[t]{2}{*}{ Parameter } & \multicolumn{2}{|c|}{ Anpassungsgüte } & \multirow{2}{*}{$\begin{array}{l}\text { Steigung der } \\
\text { Regressions- } \\
\text { geraden }\end{array}$} & \multicolumn{4}{|c|}{$\begin{array}{l}\text { Abweichung der Steigung von } \\
\text { Null }\end{array}$} \\
\hline & & $r^{2}$ & Sy.x & & $F$ & DFn & DFd & $\mathbf{P}$ \\
\hline \multirow[t]{2}{*}{ Tag 90-163 } & Vmax & 0,6630 & 0,8011 & $\begin{array}{l}-0,05189 \\
(+/-0,004360)\end{array}$ & 141,6 & 1 & 72 & $<0,0001^{*}$ \\
\hline & Distanz & 0,5710 & 293,7 & $\begin{array}{l}-15,65 \\
(+/-1,599)\end{array}$ & 95,84 & 1 & 72 & $<0,0001^{*}$ \\
\hline \multirow[t]{2}{*}{ Tag 90-120 } & Vmax & 0,0002308 & 0,5410 & \begin{tabular}{|l|}
0,0008889 \\
$(+/-0,01086)$
\end{tabular} & 0,006696 & 1 & 29 & 0,9353 \\
\hline & Distanz & 0,4865 & 194,3 & $\begin{array}{l}-20,45 \\
(+/-3,901)\end{array}$ & 27,47 & 1 & 29 & $<0,0001^{*}$ \\
\hline \multirow[t]{2}{*}{ Tag 121-163 } & Vmax & 0,5824 & 0,8128 & $\begin{array}{l}-0,07552 \\
(+/-0,009988)\end{array}$ & 57,18 & 1 & 41 & $<0,0001^{*}$ \\
\hline & Distanz & 0,2579 & 350,8 & $\begin{array}{l}-16,28 \\
(+/-4,311)\end{array}$ & 14,25 & 1 & 41 & $0,0005^{*}$ \\
\hline
\end{tabular}

Tabelle 2: Lineare Regresisonsanalysen für Distanz und Vmax im Langzeitverlauf. Darstellung der Anpassungsgüte sowie der Steigung der jeweiligen Regressionsgeraden. Darüber hinaus Darstellung der Berechnungen der Wahrscheinlichkeit, dass die Steigung der Geraden von Null abweicht. Sterne $\left({ }^{*}\right)$ kennzeichnen eine signifikante Abweichung der Steigung der Regressionsgeraden von Null $(p<0,05)$.

\subsection{Der Effekt intramuskulärer Injektionen von BoNT in den M. gastro- cnemius im Vergleich zu Injektionen in den M. tibialis anterior}

Eine Gruppe von $\mathrm{n}=13$ Tieren im Alter von ca. 20 Wochen mit einem Gewicht zwischen 26,7 und 32,8 g bekam jeweils 0,2 MU BoNT injiziert. Bei einer Gruppe ( $\mathrm{n}=6$ Tiere, im Folgenden "Gastrocnemius-Gruppe") erfolgten die Injektionen beidseits in den $\mathrm{M}$. gastrocnemius. Bei der zweite Gruppe ( $n=7$ Tiere, im Folgenden „Tibialis-Gruppe“) wurde das Toxin in den M. tibialis anterior injiziert.

Für die Beurteilung der Toxin-Wirkung wurden die Vmax als Parameter für kurzfristig aufbringbare Muskelkraft sowie die Distanz als Anhaltspunkt für möglichen Einfluss auf Kondition bzw. Ermüdung betrachtet. Die Daten der (tatsächlichen) Distanz sowie der relativen Vmax sind in Abbildung 3 dargestellt. Zwei Tage nach den Injektionen begannen die Mäuse, latente Paresen der Hinterläufe zu entwickeln, was sich in einem Abfall der Vmax widerspiegelte. Die schon zuvor ersichtliche Reduktion der Distanz ist eher auf die Injektionsbehandlung selber zurückzuführen (vgl. Kutschenko et al. 2012). Klinisch wirkten die Tiere in der Beobachtung nicht relevant beeinträchtig.

Die ANOVA zeigt sowohl für die tatsächlichen als auch für die relativen Werte der Vmax eine signifikante Veränderung über die Zeit (vgl. Tab. 3). Eine maximale Ausprägung der Paresen mit einem Abfall der Vmax auf Tiefstwerte von 63,3\% (+/- 2,3\%) in der GastrocnemiusGruppe und 77,1\% (+/- 5,1\%) in der Tibialis-Gruppe wurde an Tag 3 bzw. Tag 4 erreicht. In 
der ANOVA zeigt sich kein signifikanter Unterschied zwischen den beiden Gruppen, jedoch ein signifikanter Interaktionseffekt zwischen dem zeitlichen Verlauf und dem Injektionsmuskel (vgl. Tab. 3). Innerhalb der folgenden zwei Wochen bildeten sich die Paresen langsam zurück und beide Gruppen erreichten in Bezug auf die Vmax wieder ein Plateau knapp zehn Prozent unter dem Ausgangslevel.
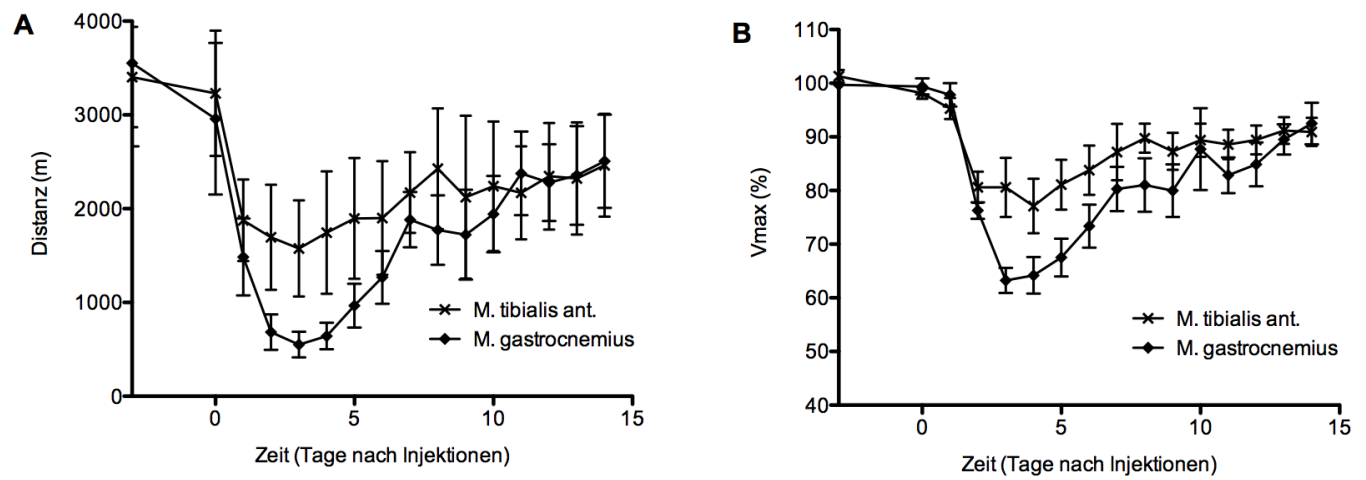

Abbildung 3: Injektion von 0,2 MU BoNT in unterschiedliche Muskeln der Hinterläufe. Darstellung der Distanz $(A)$ sowie der relativen Vmax $(B)$ nach Injektionen in den M. tibialis anterior im Vergleich zu Injektionen in den M. gastrocnemius.

Für die Distanz zeigen sich in der ANOVA ebenfalls eine signifikante Veränderung über die Zeit sowie ein Interaktionseffekt zwischen dem zeitlichen Verlauf und dem Injektionsmuskel. Wie bei der Vmax zeigt sich auch hier kein signifikanter Unterschied zwischen den beiden Gruppen (vgl. Tab. 3 und Abb. 3).

\begin{tabular}{|l|lrrr|}
\hline Parameter & Variablen & $\mathbf{d f}$ & $\mathbf{F}$ & $\mathbf{p}$ \\
\hline Vmax & Muskel & 1 & 0,534 & 0,480 \\
& zeitlicher Verlauf & 13 & 23,896 & $<0,001^{*}$ \\
& zeitlicher Verlauf x Muskel & 13 & 3,825 & $<0,001^{*}$ \\
\hline Vmax relativ & Muskel & 1 & 1,963 & 0,189 \\
& zeitlicher Verlauf & 13 & 26,601 & $<0,001^{*}$ \\
& zeitlicher Verlauf x Muskel & 13 & 3,818 & $<0,001^{*}$ \\
\hline Distanz & Muskel & 1 & 0,454 & 0,514 \\
& zeitlicher Verlauf & 13 & 13,927 & $<0,001^{*}$ \\
& zeitlicher Verlauf x Muskel & 13 & 2,934 & $0,001^{*}$ \\
\hline Distanz relativ & Muskel & 1 & 0,006 & 0,938 \\
& zeitlicher Verlauf & 13 & 13,627 & $<0,001^{*}$ \\
& zeitlicher Verlauf x Muskel & 13 & 3,610 & $<0,001^{*}$ \\
\hline
\end{tabular}

Tabelle 3: Ergebnisse der statistischen Auswertungen mittels ANOVA nach Injektion von 0,2 MU BoNT. Das Toxin war bei einer Gruppe in den M. tibialis anterior, bei der anderen in den den M. gastrocnemius injiziert worden. Sterne $\left(^{*}\right)$ kennzeichnen signifikante Ergebnisse $(p<0,05)$.

Da der größte Effekt der Injektionen auf die relative Vmax an den Tagen 3-5 nach Injektion sichtbar wurde, wurden die Laufwerte dieser drei Tage in Abbildung 4 zu einem Pool 
zusammengefasst. Dabei ergibt sich für die Tibialis-Gruppe ein Wert von 78,9 \% (+/- 3,3\%) der ursprünglichen Vmax, für die Gastrocnemius-Gruppe sind es 65,0 \% (+/- 4,9\%). Der Unterschied zwischen den beiden Gruppen ist im T-Test signifikant $\left(p<0,001^{*}\right)$. Paresen des M. gastrocnemius wirken sich somit deutlicher auf die Vmax aus als Paresen des $M$. tibialis ant., weshalb in den folgenden Versuchen der M. gastrocnemius als Injektionsmuskel gewählt wurde.

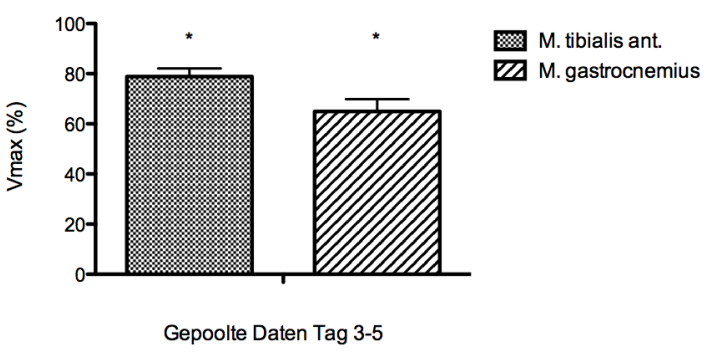

Abbildung 4: Relative Vmax nach Injektion von 0,2 MU BoNT in den M. tibialis anterior und in den M. gastrocnemius. Dargestellt sind die zusammengefassten Daten der Tage 3-5, an denen im Zeitverlauf der deutlichste Toxin-Effekt sichtbar geworden war. Sterne $\left(^{*}\right)$ kennzeichnen signifikante Unterschiede zwischen den gezeigten Gruppen $(p<0,05)$.

\subsection{BoNT-Injektionen vs. NaCl-Injektionen}

28 Mäuse im Alter von 13-14,5 Wochen und einem Gewicht von 26,4 +/- 1,3 g wurden in zwei Gruppen randomisiert. 15 Tiere bekamen $15 \mu \mathrm{NaCl}$ 0,9\% in jeden M. gastrocnemius injiziert (im Folgenden $\mathrm{NaCl}-G r u p p e), 13$ Tiere 0,1 MU BoNT in einem Volumen von ebenfalls $15 \mu$ l pro Muskel (im Folgenden BoNT-Gruppe).

Die Abbildungen 5 und 6 zeigen die Ergebnisse für sämtliche gemessene Parameter. In Tabelle 4 können die statistischen Auswertungen mittels ANOVA nachvollzogen werden. Für alle Parameter (tatsächliche und relative Werte) zeigt sich ein signifikanter Effekt über die Zeit sowie ein signifikanter Interaktionseffekt zwischen zeitlichem Verlauf und Gruppe.

Die BoNT-Gruppe entwickelte nach den Injektionen latente Paresen der Hinterläufe, die sich in einer signifikant geringeren Laufleistung im Vergleich zur $\mathrm{NaCl}-\mathrm{Gruppe}$ zeigte. Dieser Unterschied konnte für alle Parameter außer die Tmean nachgewiesen werden. Für Vmax und Vmean zeigt die BoNT-Gruppe eine geringere Laufleistung sowohl in den tatsächlichen als auch in den relativen Werten. Für Distanz, Nlauf, Tges und Distmean trifft dies nur auf die relativen Werte zu. Die reduzierte Laufleistung der BoNT-Gruppe kann dabei fast durchgehend innerhalb der ersten 12 Tage nach den Injektionen beobachtet werden. Die $\mathrm{NaCl}$-Gruppe hingegen zeigt ein stabiles Laufverhalten ohne Veränderungen, die über die durchgehend vorkommenden leichten Schwankungen hinausgehen. 

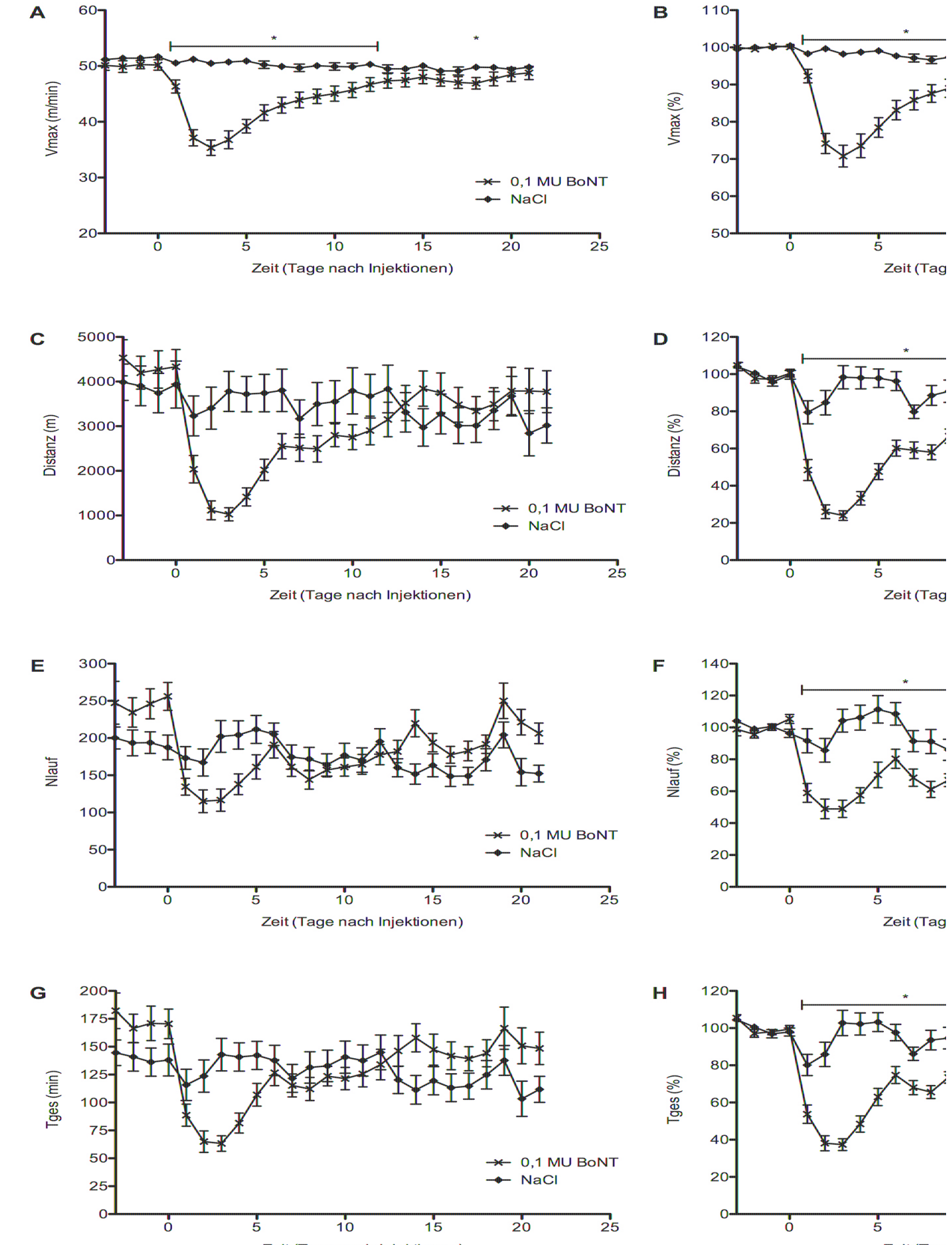

Abbildung 5: Laufparameter nach Injektion von 0,1 MU BoNT im Vergleich zu einer NaCl-Kontrollgruppe (1). Darstellung der tatsächlichen und der relativen Werte für die Parameter Vmax (A und B), Distanz (C und D), Nlauf $(E$ und $F)$ und Tges ( $G$ und $H)$. Sterne $\left(^{*}\right)$ kennzeichnen signifikante Unterschiede zwischen den beiden Gruppen $(p<0,05)$. 

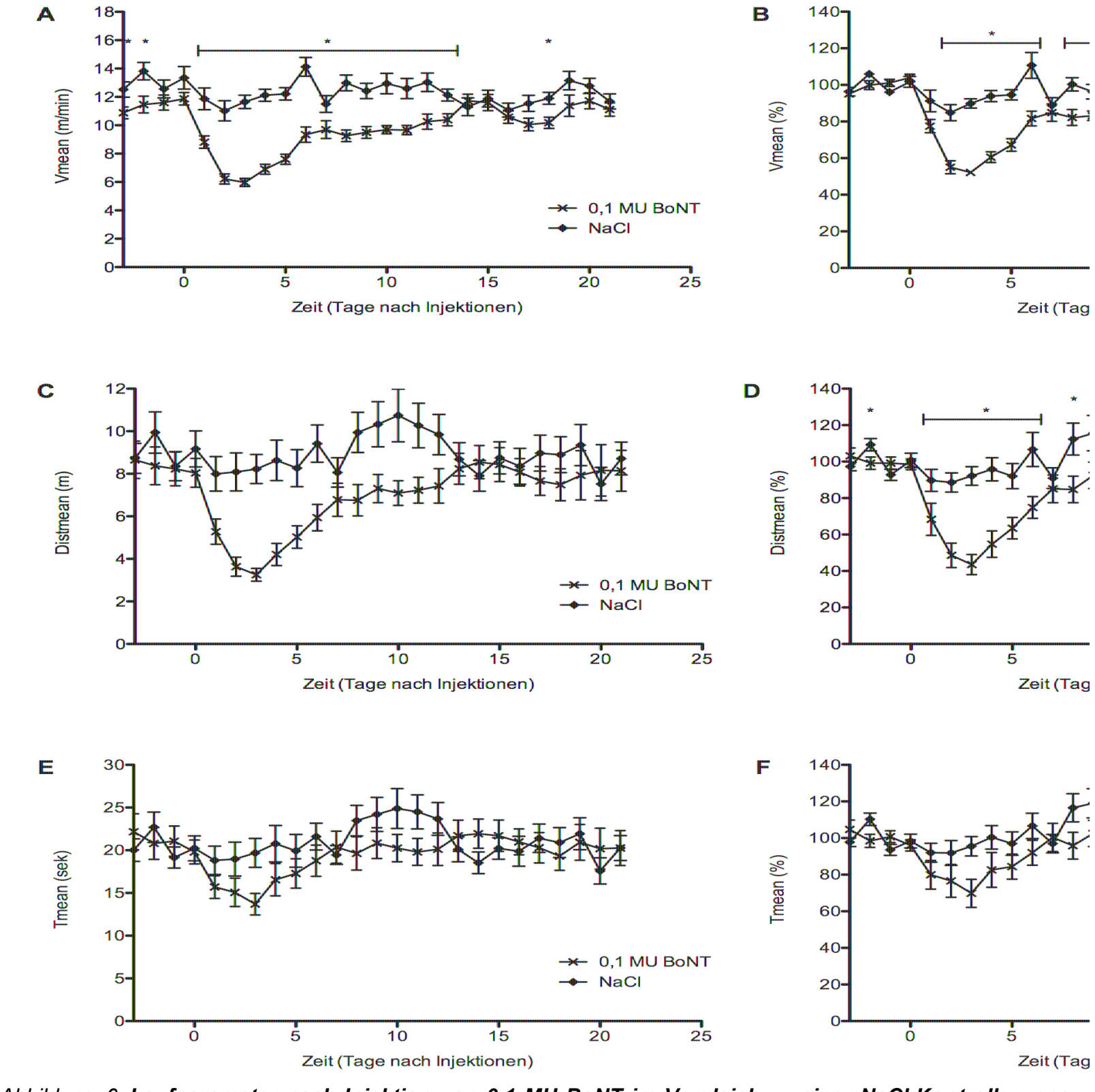

Abbildung 6: Laufparameter nach Injektion von 0,1 MU BoNT im Vergleich zu einer NaCl-Kontrollgruppe

(2). Darstellung der tatsächlichen und der relativen Werte für die Parameter Vmean ( $A$ und $B$ ), Distmean ( $C$ und $D$ ) und Tmean (E und F). Sterne (*) kennzeichnen signifikante Unterschiede zwischen den beiden Gruppen $(p<0,05)$. 


\begin{tabular}{|c|c|c|c|c|}
\hline Parameter & Variablen & df & $\mathbf{F}$ & $\mathbf{p}$ \\
\hline \multirow[t]{3}{*}{$\overline{V m a x}$} & Gruppe & 1 & 19,681 & $<0,001^{*}$ \\
\hline & zeitlicher Verlauf & 24 & 35,128 & $<0,001^{*}$ \\
\hline & zeitlicher Verlauf x Gruppe & 24 & 37,507 & $<0,001^{*}$ \\
\hline \multirow[t]{3}{*}{ Vmax relativ } & Gruppe & 1 & 22,444 & $<0,001^{*}$ \\
\hline & zeitlicher Verlauf & 24 & 37,375 & $<0,001^{*}$ \\
\hline & zeitlicher Verlauf x Gruppe & 24 & 39,835 & $<0,001^{*}$ \\
\hline \multirow[t]{3}{*}{ Distanz } & Gruppe & 1 & 0,596 & 0,447 \\
\hline & zeitlicher Verlauf & 24 & 20,527 & $<0,001^{*}$ \\
\hline & zeitlicher Verlauf x Gruppe & 24 & 21,896 & $<0,001^{*}$ \\
\hline \multirow[t]{3}{*}{ Distanz relativ } & Gruppe & 1 & 17,121 & $<0,001^{*}$ \\
\hline & zeitlicher Verlauf & 24 & 21,353 & $<0,001^{*}$ \\
\hline & zeitlicher Verlauf x Gruppe & 24 & 22,959 & $<0,001^{*}$ \\
\hline \multirow[t]{3}{*}{ Nlauf } & Gruppe & 1 & 0,172 & 0,682 \\
\hline & zeitlicher Verlauf & 24 & 12,380 & $<0,001^{*}$ \\
\hline & zeitlicher Verlauf x Gruppe & 24 & 10,831 & $<0,001^{*}$ \\
\hline \multirow[t]{3}{*}{ Nlauf relativ } & Gruppe & 1 & 10,517 & $0,003^{*}$ \\
\hline & zeitlicher Verlauf & 24 & 9,891 & $<0,001^{*}$ \\
\hline & zeitlicher Verlauf x Gruppe & 24 & 8,992 & $<0,001^{*}$ \\
\hline \multirow[t]{3}{*}{ Tges } & Gruppe & 1 & 0,026 & 0,872 \\
\hline & zeitlicher Verlauf & 24 & 18,486 & $<0,001^{*}$ \\
\hline & zeitlicher Verlauf x Gruppe & 24 & 20,278 & $<0,001^{*}$ \\
\hline \multirow[t]{3}{*}{ Tges relativ } & Gruppe & 1 & 16,169 & $<0,001^{*}$ \\
\hline & zeitlicher Verlauf & 24 & 15,772 & $<0,001^{*}$ \\
\hline & zeitlicher Verlauf x Gruppe & 24 & 17,494 & $<0,001^{*}$ \\
\hline \multirow[t]{3}{*}{ Vmean } & Gruppe & 1 & 19,165 & $<0,001^{*}$ \\
\hline & zeitlicher Verlauf & 24 & 15,527 & $<0,001^{*}$ \\
\hline & zeitlicher Verlauf x Gruppe & 24 & 9,580 & $<0,001^{*}$ \\
\hline \multirow[t]{3}{*}{ Vmean relativ } & Gruppe & 1 & 7,420 & $0,011^{*}$ \\
\hline & zeitlicher Verlauf & 24 & 16,494 & $<0,001^{*}$ \\
\hline & zeitlicher Verlauf x Gruppe & 24 & 10,808 & $<0,001^{*}$ \\
\hline \multirow[t]{3}{*}{ Distmean } & Gruppe & 1 & 3,881 & 0,060 \\
\hline & zeitlicher Verlauf & 24 & 8,900 & $<0,001^{*}$ \\
\hline & zeitlicher Verlauf x Gruppe & 24 & 6,095 & $<0,001^{*}$ \\
\hline \multirow[t]{3}{*}{ Distmean relativ } & Gruppe & 1 & 4,293 & $0,048^{*}$ \\
\hline & zeitlicher Verlauf & 24 & 9,490 & $<0,001^{*}$ \\
\hline & zeitlicher Verlauf x Gruppe & 24 & 6,300 & $<0,001^{*}$ \\
\hline \multirow[t]{3}{*}{ Tmean } & Gruppe & 1 & 0,499 & 0,486 \\
\hline & zeitlicher Verlauf & 24 & 4,538 & $<0,001^{*}$ \\
\hline & zeitlicher Verlauf x Gruppe & 24 & 2,984 & $<0,001^{*}$ \\
\hline \multirow[t]{3}{*}{ Tmean relativ } & Gruppe & 1 & 1,630 & 0,213 \\
\hline & zeitlicher Verlauf & 24 & 4,721 & $<0,001^{*}$ \\
\hline & zeitlicher Verlauf x Gruppe & 24 & 2,621 & $<0,001^{*}$ \\
\hline
\end{tabular}

Tabelle 4: Ergebnisse der statistischen Auswertungen mittels ANOVA nach Injektion von NaCl vs. 0,1 MU BoNT. Sterne $\left(^{*}\right)$ kennzeichnen signifikante Ergebnisse $(p<0,05)$. 


\subsubsection{Laufleistung nach $\mathrm{NaCl}-$ Injektionen}

Betrachtet man die Laufleistung der $\mathrm{NaCl}$-Gruppe, also der Kontrollgruppe, über die Zeit, zeigt sich innerhalb des beobachteten Zeitraums eine signifikante Reduktion sowohl der Vmax als auch der Distanz, wobei die prozentuale Reduktion der Distanz stärker ist als die der Vmax (vgl. Abb. 7 und Tab. 5). Die Abnahme der Laufleistung vollzieht sich dabei weitestgehend stetig über die Zeit hinweg, ohne dass ein massiverer Abfall der Werte unmittelbar nach den Injektionen ausgemacht werden kann. Dies ist am ehesten auf die schon in Kapitel 3.1 beschriebene altersabhängige Reduktion der Laufleistung und somit unabhängig von den Injektionen zu sehen.
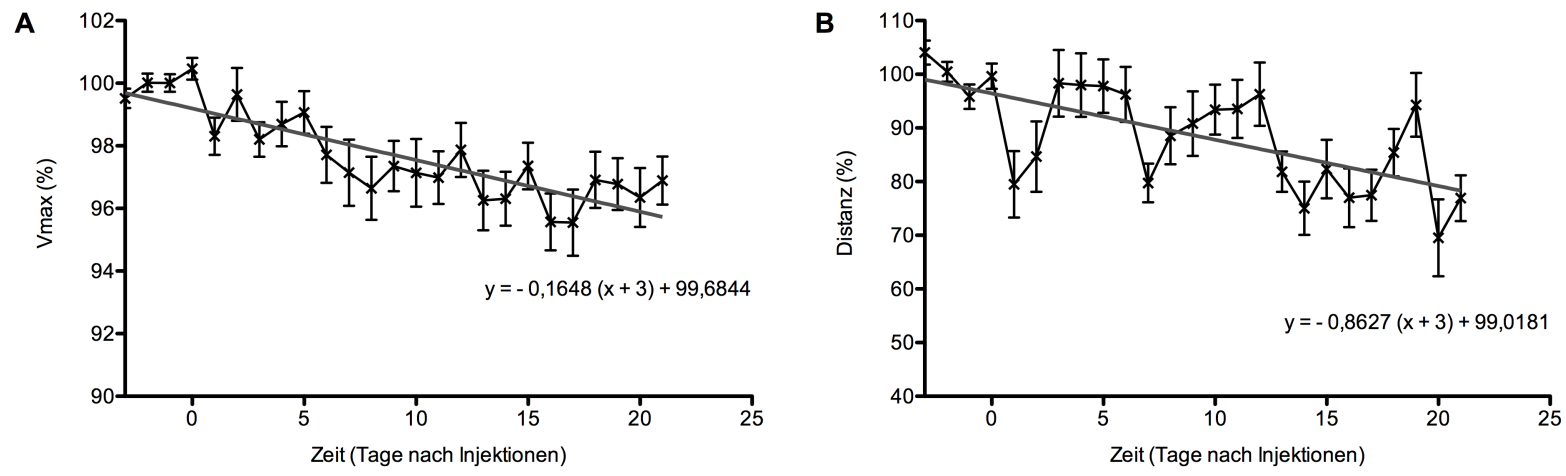

Abbildung 7: Laufleistung nach Injektion von $\mathbf{N a C l}$. Darstellung der relativen Werte der Vmax (A) sowie der Distanz (B) und der entsprechenden Regressionsgeraden unter Angabe der Geradengleichungen. Die angegebene Steigung unterscheidet sich jeweils signifikant von Null (vgl. Tab 5).

\begin{tabular}{|l|l|l|l|l|r|r|r|}
\hline \multirow{2}{*}{ Parameter } & \multicolumn{2}{|l|}{ Anpassungsgüte } & Steigung der & \multicolumn{4}{l|}{ Abweichung der Steigung von Null } \\
\cline { 6 - 9 } & $\mathbf{r}^{2}$ & Sy.x & Regressionsgeraden & F & DFn & DFd & P \\
\hline Relative Vmax & 0,7277 & 0,7579 & $-0,1648(+/-0,02102)$ & 61,47 & 1 & 23 & $<0,0001^{*}$ \\
\hline Relative Distanz & 0,4321 & 7,436 & $-0,8627(+/-0,2062)$ & 17,50 & 1 & 23 & $0,0004^{*}$ \\
\hline
\end{tabular}

Tabelle 5: Lineare Regresisonsanalysen für relative Distanz und Vmax nach NaCl-Injektion. Darstellung der Anpassungsgüte sowie der Steigung der jeweiligen Regressionsgeraden. Darüber hinaus Darstellung der Berechnungen der Wahrscheinlichkeit, dass die Steigung der Geraden von Null abweicht. Sterne (*) kennzeichnen eine signifikante Abweichung der Steigung der Regressionsgeraden von Null $(p<0,05)$. 


\subsection{Die Auswirkungen unterschiedlich hoher Toxin-Dosierungen auf die verschiedenen Laufparameter}

Um den dosisabhängigen Effekt intramuskulärer BoNT-Injektionen auf das Laufverhalten zu untersuchen, wurden 53 Mäuse im Alter von ca. 19 Wochen in zwei Gruppen randomisiert. Einer Gruppe ( $\mathrm{n}=27$, Gewicht 28,38 g +/- 0,29 g) wurde eine BoNT-Dosis von 0,1 MU in die Mm. gastrocnemii injiziert, der anderen Gruppe ( $n=26$, Gewicht 29,23 g +/- 0,38) eine Dosis von 0,2 MU. Die Abbildungen 8 und 9 stellen den Verlauf der einzelnen Parameter über die fünf Wochen nach den Injektionen grafisch dar.

Beide Behandlungsgruppen entwickelten latente Paresen der Wadenmuskulatur, welche einen dosisabhängigen Effekt auf das Laufverhalten hatten. Nach den Injektionen ließ sich für alle Parameter eine signifikante Veränderung des Laufverhaltens über die Zeit beobachten (vgl. Tab. 6). Bis auf die Tmean, die nach den Injektionen zunächst stabil blieb, war bei allen Parametern eine Veränderung im Sinne einer Reduktion der Werte bereits in der ersten Nacht nach den Injektionen erkennbar.

Die Laufdistanz sank in den ersten drei Nächten zunächst kontinuierlich weiter ab und erreichte die niedrigsten Werte für beide Gruppen an Tag 3 mit 35,9 \% (+/- 3,5\%, Gruppe 0,1 MU BoNT) bzw. 24,1 \% (+/- 3,1\%, Gruppe 0,2 MU BoNT) des Ausgangslevels, ohne dass ein signifikanter Unterschied zwischen den beiden Gruppen gezeigt werden konnte (vgl. Abb. 8 C und 8 D).

Die niedrigste Maximalgeschwindigkeit wurde von beiden Gruppen am vierten Tag nach den Injektionen erreicht. Die Vmax lag nach Injektion von 0,1 MU BoNT zu diesem Zeitpunkt bei 78,2 \% (+/- 1,6 \%, Gruppe 0,1 MU BoNT) bzw. 62,9 \% (+/- 1,8 \%, Gruppe 0,2 MU BoNT) des Ausgangslevels. Der Effekt ist dabei sowohl für die tatsächlichen als auch für die relativen Werte dosisabhängig (vgl. Tab. 6). Für die tatsächlichen Werte ergab der T-Test eine signifikant geringere Vmax in der Gruppe 0,2 MU BoNT an allen auf die Injektionen folgenden Tagen des Beobachtungszeitraums mit Ausnahme von Tag 31. Die Vmax beider Gruppen hatte sich jedoch schon vor den Injektionen signifikant voneinander unterschieden. In den relativen Werten zeigt sich eine signifikant geringere Vmax nach Injektion von 0,2 MU BoNT für die Tage 1-19 sowie für Tag 23 nach den Injektionen (vgl. Abb. 8 A und 8 B).

Neben der Vmax zeigte sich ein in den ANOVAs signifikanter dosisabhängiger Effekt auf die Nlauf (relative Werte) sowie die Vmean (tatsächliche Werte). Beide Parameter fielen nach höherer BoNT-Dosis stärker ab. Dieser Effekt konnte für einen Zeitraum von ca. 2,5 Wochen nachgewiesen werden. (Vgl. Abb. $8 \mathrm{~F}$ und $9 \mathrm{~A}$ ) 
Darüber hinaus konnte eine Interaktion der beiden Variablen „zeitlicher Verlauf“ und "Dosis“ für die Parameter Vmax, Distanz (nur relative Werte), Nlauf, Tges (nur relative Werte) und Vmean gezeigt werden (vgl. Tab. 6).

\begin{tabular}{|c|c|c|c|c|}
\hline Parameter & Variablen & df & $\mathbf{F}$ & $\mathbf{p}$ \\
\hline \multirow[t]{3}{*}{ Vmax } & Dosis & 1 & 15,883 & $<0,001^{*}$ \\
\hline & zeitlicher Verlauf & 38 & 129,766 & $<0,001^{*}$ \\
\hline & zeitlicher Verlauf $x$ Dosis & 38 & 14,664 & $<0,001^{*}$ \\
\hline \multirow[t]{3}{*}{ Vmax relativ } & Dosis & 1 & 20,096 & $<0,001^{*}$ \\
\hline & zeitlicher Verlauf & 38 & 121,892 & $<0,001^{*}$ \\
\hline & zeitlicher Verlauf x Dosis & 38 & 16,358 & $<0,001^{*}$ \\
\hline \multirow[t]{3}{*}{ Distanz } & Dosis & 1 & 1,076 & 0,304 \\
\hline & zeitlicher Verlauf & 38 & 24,602 & $<0,001^{*}$ \\
\hline & zeitlicher Verlauf x Dosis & 38 & 0,996 & 0,529 \\
\hline \multirow[t]{3}{*}{ Distanz relativ } & Dosis & 1 & 2,825 & 0,099 \\
\hline & zeitlicher Verlauf & 38 & 31,218 & $<0,001^{*}$ \\
\hline & zeitlicher Verlauf x Dosis & 38 & 1,590 & $0,013^{*}$ \\
\hline \multirow[t]{3}{*}{ Nlauf } & Dosis & 1 & 3,511 & 0,067 \\
\hline & zeitlicher Verlauf & 38 & 32,570 & $<0,001^{*}$ \\
\hline & zeitlicher Verlauf $x$ Dosis & 38 & 2,265 & $<0,001^{*}$ \\
\hline \multirow[t]{3}{*}{ Nlauf relativ } & Dosis & 1 & 8,976 & $0,004^{*}$ \\
\hline & zeitlicher Verlauf & 38 & 32,232 & $<0,001^{*}$ \\
\hline & zeitlicher Verlauf $x$ Dosis & 38 & 2,511 & $<0,001^{*}$ \\
\hline \multirow[t]{3}{*}{ Tges } & Dosis & 1 & 0,553 & 0,461 \\
\hline & zeitlicher Verlauf & 38 & 23,832 & $<0,001^{*}$ \\
\hline & zeitlicher Verlauf $x$ Dosis & 38 & 1,073 & 0,352 \\
\hline \multirow[t]{3}{*}{ Tges relativ } & Dosis & 1 & 2,088 & 0,155 \\
\hline & zeitlicher Verlauf & 38 & 24,548 & $<0,001^{*}$ \\
\hline & zeitlicher Verlauf $x$ Dosis & 38 & 1,462 & $0,035^{*}$ \\
\hline \multirow{3}{*}{ Vmean } & Dosis & 1 & 4,675 & $0,035^{\star}$ \\
\hline & zeitlicher Verlauf & 38 & 52,276 & $<0,001^{*}$ \\
\hline & zeitlicher Verlauf x Dosis & 38 & 2,216 & $<0,001^{*}$ \\
\hline \multirow[t]{3}{*}{ Vmean relativ } & Dosis & 1 & 3,279 & 0,076 \\
\hline & zeitlicher Verlauf & 38 & 53,034 & $<0,001^{*}$ \\
\hline & zeitlicher Verlauf x Dosis & 38 & 2,602 & $<0,001^{*}$ \\
\hline \multirow[t]{3}{*}{ Distmean } & Dosis & 1 & 0,063 & 0,803 \\
\hline & zeitlicher Verlauf & 38 & 13,214 & $<0,001^{*}$ \\
\hline & zeitlicher Verlauf $x$ Dosis & 38 & 0,861 & 0,711 \\
\hline \multirow[t]{3}{*}{ Distmean relativ } & Dosis & 1 & 0,207 & 0,651 \\
\hline & zeitlicher Verlauf & 38 & 12,286 & $<0,001^{*}$ \\
\hline & zeitlicher Verlauf $x$ Dosis & 38 & 0,941 & 0,574 \\
\hline \multirow[t]{3}{*}{ Tmean } & Dosis & 1 & 0,539 & 0,466 \\
\hline & zeitlicher Verlauf & 38 & 8.575 & $<0,001^{*}$ \\
\hline & zeitlicher Verlauf $x$ Dosis & 38 & 1,070 & 0,356 \\
\hline \multirow[t]{3}{*}{ Tmean relativ } & Dosis & 1 & 2,794 & 0,101 \\
\hline & zeitlicher Verlauf & 38 & 8,327 & $<0,001^{*}$ \\
\hline & zeitlicher Verlauf x Dosis & 38 & 0,888 & 0,665 \\
\hline
\end{tabular}

Tabelle 6: Ergebnisse der statistischen Auswertungen mittels ANOVA nach Injektion von 0,1 und 0,2 MU BoNT. Dargestellt sind die Ergebnisse für sämtliche untersuchte Laufparameter. Sterne (*) kennzeichnen signifikante Ergebnisse $(p<0,05)$. 

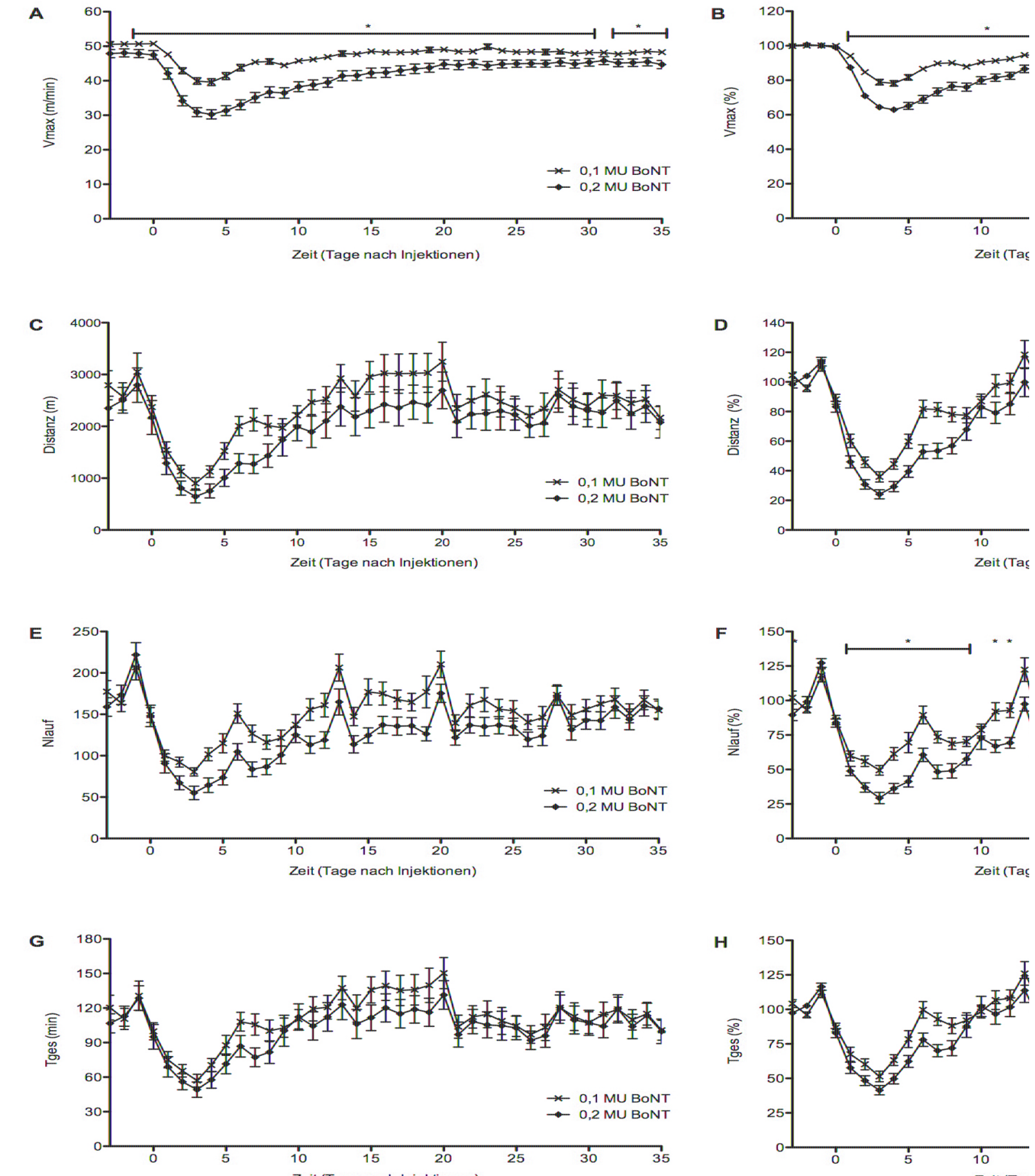

Abbildung 8: Laufparameter nach Injektion von 0,1 MU und 0,2 MU BoNT (1). Darstellung der tatsächlichen und der relativen Werte für die Parameter Vmax (A und B), Distanz (C und D), Nlauf (E und F) und Tges ( $G$ und $H)$. Sterne $\left(^{*}\right)$ kennzeichnen signifikante Unterschiede zwischen den beiden Gruppen $(p<0,05)$. 

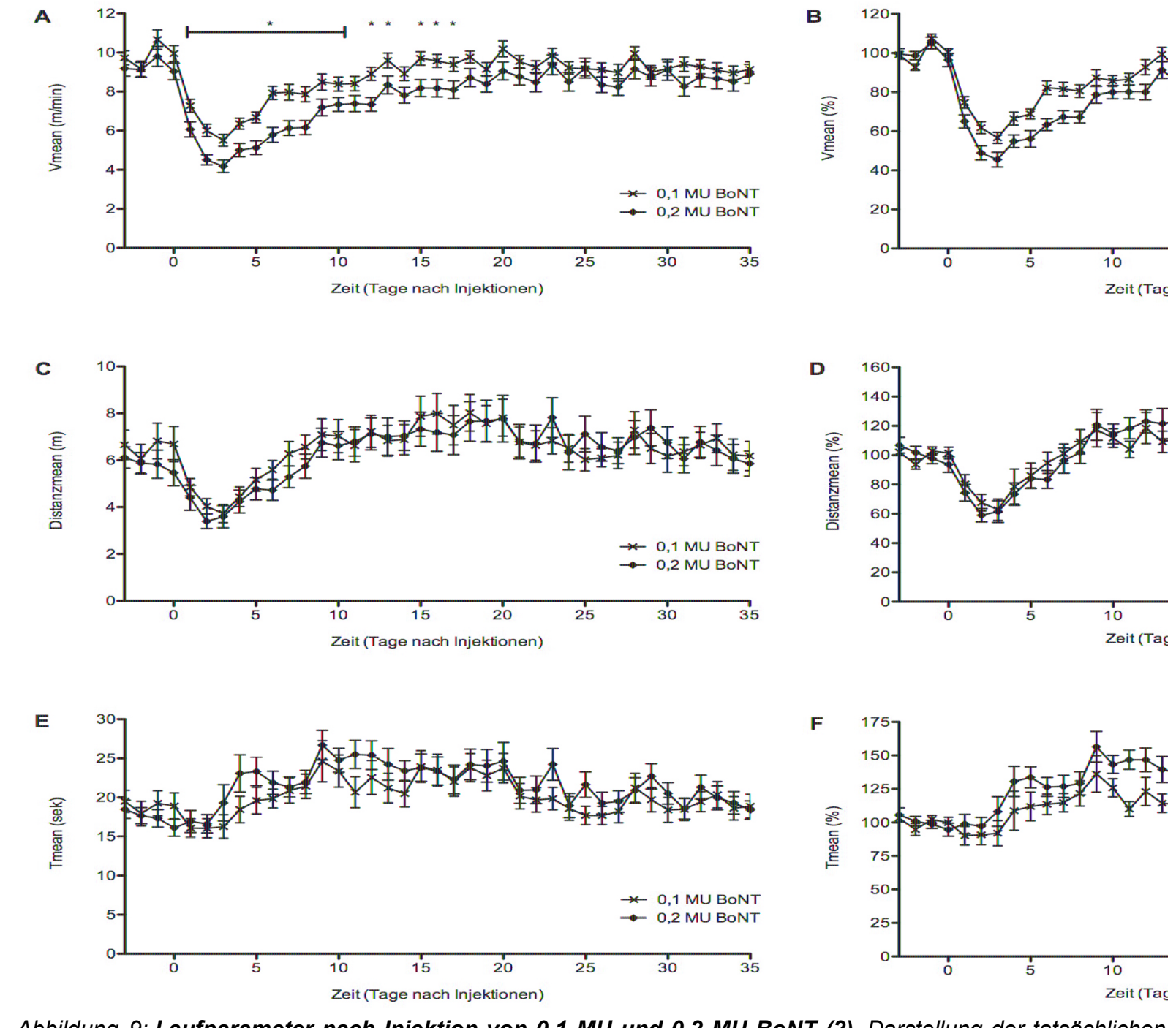
Abbildung 9: Laufparameter nach Injektion von 0,1 MU und 0,2 MU BoNT (2). Darstellung der tatsächlichen und der relativen Werte für die Parameter Vmean ( $A$ und $B)$, Distmean $(C$ und $D)$ und Tmean $(E$ und $F)$. Sterne $\left.{ }^{*}\right)$ kennzeichnen signifikante Unterschiede zwischen den beiden Gruppen $(p<0,05)$. 


\subsection{Vergleich der Toxin-Wirkung bei Mäusen unterschiedlichen Alters und Gewichts}

Mäuse dreier unterschiedlicher Altersgruppen wurden mit zwei unterschiedlichen BoNTDosierungen entsprechend Tabelle 7 injiziert. Ein höheres Alter ging dabei mit einem höheren Durchschnittsgewicht der jeweiligen Gruppe einher.

Die Injektionen einer Altersgruppe erfolgten jeweils zum selben Zeitpunkt. Die Versuche der unterschiedlichen Altersgruppen fanden nicht zeitgleich statt, wurden aus Gründen der Übersicht und zur Vergleichbarkeit jedoch in einer Grafik dargestellt.

\begin{tabular}{|c|c|c|c|c|}
\hline Gruppe & Anzahl der Tiere & Dosis & Alter & Gewicht \\
\hline 1 & 15 & $0,08 \mathrm{MU}$ & \multirow[t]{2}{*}{8 Wochen } & \multirow[t]{2}{*}{$27,07 \mathrm{~g} \mathrm{(+/-} 0,25 \mathrm{~g})$} \\
\hline 2 & 14 & $0,24 \mathrm{MU}$ & & \\
\hline 3 & 14 & $0,08 \mathrm{MU}$ & \multirow[t]{2}{*}{17 Wochen } & \multirow[t]{2}{*}{$33,64 \mathrm{~g}(+/-0,58 \mathrm{~g})$} \\
\hline 4 & 13 & $0,24 \mathrm{MU}$ & & \\
\hline 5 & 15 & $0,24 \mathrm{MU}$ & 29 Wochen & $39,11 \mathrm{~g}(+/-0,95 \mathrm{~g})$ \\
\hline
\end{tabular}

Tabelle 7: Gruppenübersicht der Mäuse unterschiedlichen Alters und Gewichts. Insgesamt wurden fünf Gruppen mit BoNT injiziert. 29 Tiere im Alter von acht Wochen sowie 27 Tiere, die bereits 17 Wochen alt und durchschnittlich etwa 6,5 g schwerer waren, wurden jeweils in zwei Dosisgruppen randomisiert. Je eine Gruppe bekam eine Dosis von 0,8 MU BoNT injiziert, die andere 0,24 MU. Die Tiere der fünften Gruppe mit einem Alter von 29 Wochen waren durchschnittliche $12 \mathrm{~g}$ schwerer als die jüngsten und 6,5 g schwerer als die 17 Wochen alten Tiere und erhielten alle die höhere BoNT-Dosis.

\subsubsection{Laufverhalten nach Injektion von 0,08 MU BoNT}

Nach Injektion von 0,08 MU BoNT (Gruppe 1 und 3) wurden die Vmax sowie die Distanz untersucht und in Abbildung 10 dargestellt. Die statistischen Ergebnisse zeigt Tabelle 8. Zunächst stellt sich in der statistischen Untersuchung mittels ANOVA für beide Parameter eine signifikante Veränderung über die Zeit dar. In der Distanz liegt darüber hinaus ein signifikanter Interaktionseffekt zwischen den Variablen „zeitlicher Verlauf“ und „Alter“ vor.

Im Vergleich der beiden unterschiedlichen Altersgruppen lassen sich mittels ANOVA in den tatsächlichen Werten der Vmax und der Distanz signifikante Unterschiede zwischen den 8 Wochen und den 17 Wochen alten Tieren zeigen. Die jüngeren Tiere zeigen zu jedem beobachteten Zeitpunkt eine höhere Vmax sowie eine größere Laufdistanz (vgl. Abb. 10 A und $10 \mathrm{C}$ ), wobei der Unterschied der Distanz an den Tagen 2, 3 und 18 nicht signifikant ist. Die relative Distanz zeigt ein ähnliches Bild (vgl. Abb. $10 \mathrm{D}$ ), während für die relative Vmax kein Unterschied zwischen den beiden Altersgruppen nachgewiesen werden kann ( $p<0,001^{*}$, vgl. Abb. 10 B). Obwohl die älteren Tiere im Rahmen des Versuchs langsamer und weniger 
gelaufen sind als die jüngeren Tiere, ist die relative Ausprägung der durch BoNT induzierten Paresen dieselbe. Dies spiegelt sich in einem identischen Verlauf der relativen Vmax wider.

\begin{tabular}{|l|lrr|r|}
\hline Parameter & Variablen & df & $\mathbf{F}$ & $\mathbf{p}$ \\
\hline Vmax & Alter & 1 & 25,823 & $<0,001^{*}$ \\
& zeitlicher Verlauf & 24 & 34,576 & $<0,001^{*}$ \\
& zeitlicher Verlauf x Alter & 24 & 0,958 & 0,522 \\
\hline Vmax relativ & Alter & 1 & 0,694 & 0,412 \\
& zeitlicher Verlauf & 24 & 34,395 & $<0,001^{*}$ \\
& zeitlicher Verlauf x Alter & 24 & 0,903 & 0,598 \\
\hline Distanz & Alter & 1 & 17,690 & $<0,001^{*}$ \\
& zeitlicher Verlauf & 24 & 13,579 & $<0,001^{*}$ \\
& zeitlicher Verlauf x Alter & 24 & 8,066 & $<0,001^{*}$ \\
\hline Distanz relativ & Alter & 1 & 23,293 & $<0,001^{*}$ \\
& zeitlicher Verlauf & 24 & 29,741 & $<0,001^{*}$ \\
& zeitlicher Verlauf x Alter & 24 & 8,566 & $<0,001^{*}$ \\
\hline
\end{tabular}

Tabelle 8: Ergebnisse der statistischen Auswertungen mittels ANOVA nach Injektion von 0,08 MU BoNT. Die beiden Gruppen entsprechen Mäusen im Alter von 8 Wochen und 17 Wochen. Sterne $\left(^{*}\right)$ kennzeichnen signifikante Ergebnisse $(p<0,05)$.
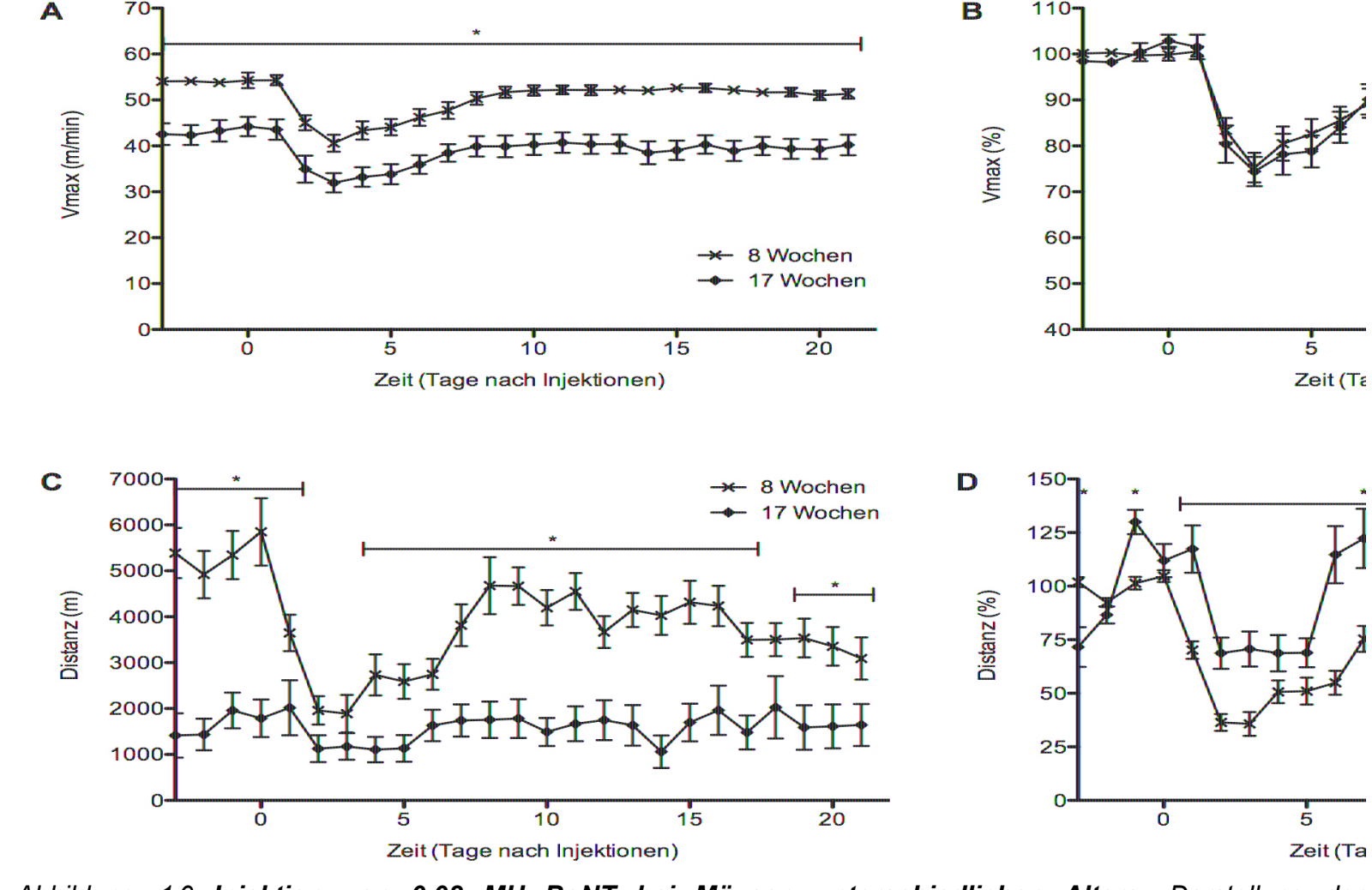
Abbildung 10: Injektion von 0,08 MU BoNT bei Mäusen unterschiedlichen Alters. Darstellung der

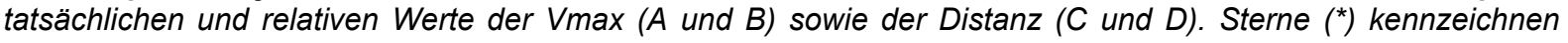
signifikante Unterschiede zwischen den Gruppen „8 Wochen“ und „17 Wochen“ ( $p<0,05)$. 


\subsubsection{Laufverhalten nach Injektion von 0,24 MU BoNT}

In Abbildung 11 ist die Vmax nach Injektion von 0,24 MU BoNT für die drei untersuchten Altersgruppen (Gruppe 2, 4 und 5) dargestellt. Sowohl für die tatsächlichen als auch für die relativen Werte zeigen sich in der ANOVA eine signifikante Veränderung über die Zeit sowie ein Interaktionseffekt zwischen dem zeitlichen Verlauf und dem Alter der Mäuse (vgl. Tab. 9). Bezüglich der Altersgruppen zeigt sich in den tatsächlichen Werten (Abb. 11 A) an allen Tagen der Plateauphase vor den Injektionen eine altersabhängige signifikante Unterscheidung der Vmax mit den höchsten Werten für die jüngsten Tiere, während die ältesten Tiere die geringste Maximalgeschwindigkeit aufwiesen. Im Gegensatz zu der Plateauphase vor den Injektionen sowie dem späteren Verlauf nach den Injektionen, ergibt der post-hoc T-Test an den Tagen der maximalen Reduktion der Vmax (Tag 3 bzw. 4) keinen signifikanten Unterschied zwischen den Gruppen (vgl. Abb. 11 A).

Die ANOVA der relativen Werte zeigt im Gegensatz dazu keinen signifikanten Unterschied zwischen den drei Altersgruppen (vgl. Tab. 9 und Abb. 11 B). Im Vergleich zu Kapitel 3.5.1 zeigt sich demnach auch bei höher dosiertem BoNT und somit stärkeren Paresegraden ein identischer Verlauf der relativen Vmax trotz unterschiedlichem Alter und Ausgangslevel der Tiere.

A

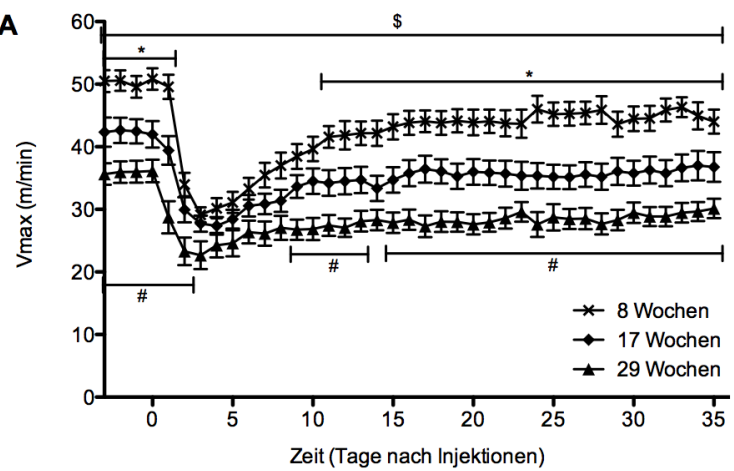

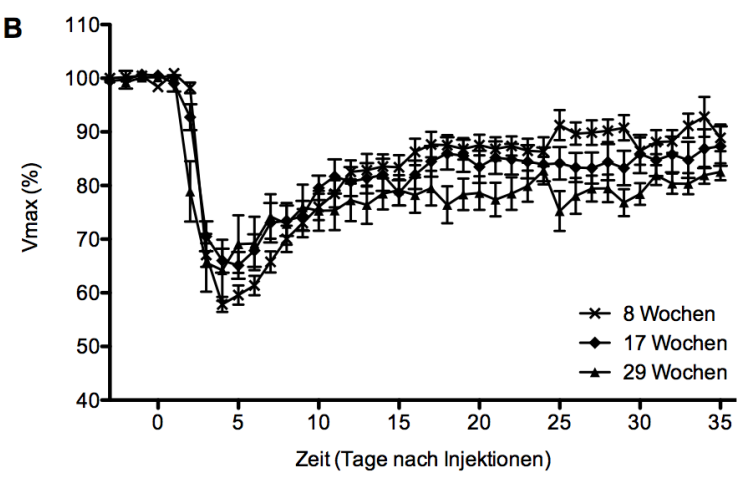

Abbildung 11: Vmax nach Injektion von 0,24 MU BoNT. Dargestellt sind die tatsächlichen Werte $(A)$ und die relativen Werte (B). Die drei Gruppen entsprechen Mäusen unterschiedlichen Alters (8, 17 und 29 Wochen). Sterne $\left({ }^{*}\right)$ kennzeichnen signifikante Unterschiede $(p<0,05)$ zwischen den Gruppen 8 Wochen und 17 Wochen, Rauten (\#) zwischen den Gruppen 8 Wochen und 29 Wochen und Dollarzeichen (\$) zwischen den Gruppen 17 Wochen und 29 Wochen. 
Ergebnisse

\begin{tabular}{|c|c|c|c|c|}
\hline Parameter & Variablen & df & $\mathbf{F}$ & p \\
\hline \multirow[t]{3}{*}{ Vmax } & Alter & 2 & 18,041 & $<0,001^{*}$ \\
\hline & zeitlicher Verlauf & 38 & 73,151 & $<0,001^{*}$ \\
\hline & zeitlicher Verlauf x Alter & 38 & 5,330 & $<0,001^{*}$ \\
\hline \multirow[t]{3}{*}{ Vmax relativ } & Alter & 2 & 1,463 & 0,244 \\
\hline & zeitlicher Verlauf & 38 & 66,582 & $<0,001^{*}$ \\
\hline & zeitlicher Verlauf x Alter & 38 & 3,459 & $<0,001^{*}$ \\
\hline
\end{tabular}

Tabelle 9: Ergebnisse der statistischen Auswertungen mittels ANOVA nach Injektion von 0,24 MU BoNT. Die drei injizierten Gruppen entsprechen Mäusen im Alter von 8 Wochen, 17 Wochen und 29 Wochen. Sterne $\left(^{*}\right)$ kennzeichnen signifikante Ergebnisse $(p<0,05)$.

\subsubsection{Korrelationsanalyse von Laufleistung und Gewicht bei Mäusen einer Altersgruppe}

Für die Gruppe der 17 Wochen alten Mäuse $(n=27)$ wurde der Korrelationskoeffizient nach Pearson für die Verhältnisse von Gewicht und Distanz sowie von Gewicht und Vmax berechnet. Grundlage bildeten die Laufdaten der Plateauphase vor den Injektionen (Tag -3 bis 0 , vgl. Abb. 10 und 11) sowie das Gewicht, welches im Rahmen der Injektionen (Tag 0) gewogen wurde. Abbildung 12 zeigt die entsprechenden Datenkorrelationen. In der Berechnung des Korrelationskoeffizienten zeigt sich eine signifikante Korrelation des Gewichts mit der Vmax $\left(p=0,0024^{*}\right)$ sowie mit der Distanz $\left(p=0,0004^{*}\right)$, wobei ein höheres Körpergewicht der Maus mit einer geringeren Laufleistung einhergeht (vgl. Tab. 10).
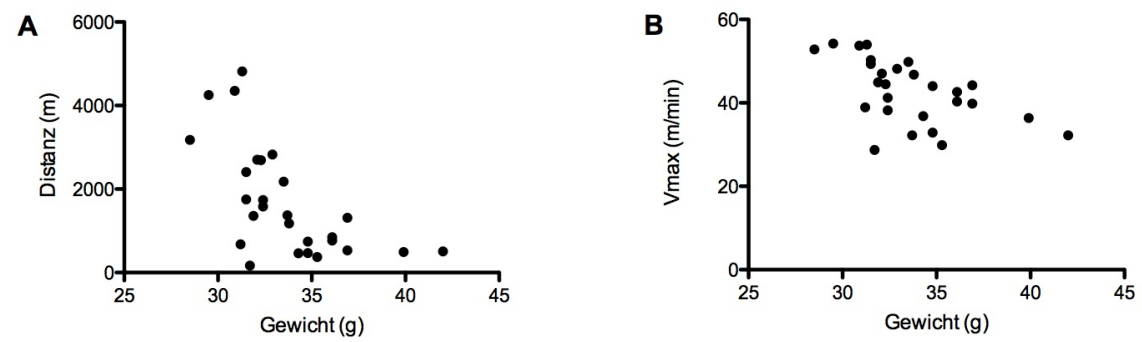

Abbildung 12: Korrelation von Gewicht und Laufleistung. Korrelation von Gewicht und Distanz (A) sowie von Gewicht und Vmax (B) einer Gruppe altersidentischer Mäuse.

\begin{tabular}{|l|c|r|r|r|r|}
\hline $\begin{array}{l}\text { Korrelations- } \\
\text { parameter }\end{array}$ & $\begin{array}{l}\text { Nummer der } \\
\text { Korrelationspaare }\end{array}$ & Pearson r & 95\%-Konfidenzintervall & $\mathbf{r}^{2}$ & $\mathbf{p}$ \\
\hline Gewicht und Distanz & 27 & $-0,6286$ & $-0,8142$ bis $-0,3265$ & 0,3951 & $0,0004^{*}$ \\
\hline Gewicht und Vmax & 27 & $-0,5598$ & $-0,7750$ bis $-0,2283$ & 0,3134 & $0,0024^{*}$ \\
\hline
\end{tabular}

Tabelle 10: Korrelation von Gewicht und Laufleistung. Ergebnisse der Berechnung des Korrelationskoeffizienten nach Pearson. Sterne $\left(^{*}\right)$ kennzeichnen signifikante Korrelationen $(p<0,05)$. 


\subsubsection{Korrelationsanalyse von Gewicht und maximalem Toxin-Effekt in einer Altersgruppe}

Für die Gruppe der 17 Wochen alten Mäuse, die im Rahmen des in Kapitel 3.5.1 beschriebenen Versuchs 0,24 MU BoNT injiziert bekommen hatten ( $n=13)$, wurde für jedes Tier der niedrigste prozentuale Wert der Vmax sowie der Distanz innerhalb der ersten Woche nach den Injektionen bestimmt. Mit Hilfe des Korrelationskoeffizienten nach Pearson wurde dann die Korrelation zwischen dem prozentualen Abfall des entsprechenden Parameters und dem Gewicht der jeweiligen Maus berechnet. Die Daten sind in Abbildung 13 grafisch dargestellt. Dabei konnte keine Korrelation zwischen dem Gewicht der Mäuse und dem prozentualen Abfall der beiden Laufparameter festgestellt werden (vgl. Tab. 11).
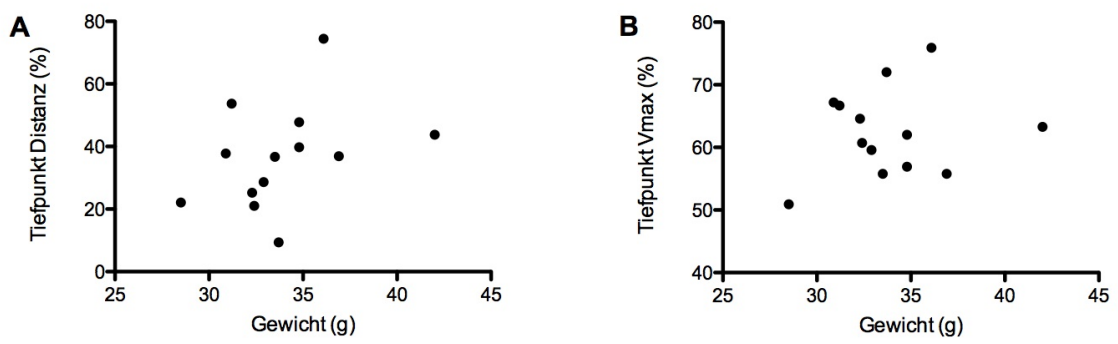

Abbildung 13: Korrelation von Gewicht und Abfall der Laufleistung nach BoNT-Injektion. Korrelation von Gewicht und prozentualem Tiefpunkt der Distanz (A) sowie von Gewicht und prozentualem Tiefpunkt der Vmax (B) einer Gruppe altersidentischer Mäuse nach Injektion von 0,24 MU BoNT.

\begin{tabular}{|l|c|r|r|r|r|}
\hline $\begin{array}{l}\text { Korrelations- } \\
\text { parameter }\end{array}$ & $\begin{array}{l}\text { Nummer der } \\
\text { Korrelationspaare }\end{array}$ & Pearson $\mathbf{r}$ & 95\%-Konfidenzintervall & $\mathbf{r}^{2}$ & $\mathbf{p}$ \\
\hline $\begin{array}{l}\text { Gewicht und } \\
\text { Tiefpunkt Distanz }\end{array}$ & 13 & 0,3616 & $-0,2367$ bis 0,7610 & 0,1307 & 0,2248 \\
\hline $\begin{array}{l}\text { Gewicht und } \\
\text { Tiefpunkt Vmax }\end{array}$ & 13 & 0,1820 & $-0,4103$ bis 0,6662 & 0,0331 & 0,5519 \\
1
\end{tabular}

Tabelle 11: Korrelation von Gewicht und Abfall der Laufleistung nach BoNT-Injektion. Ergebnisse der Berechnung des Korrelationskoeffizienten nach Pearson. Sterne $\left(^{*}\right)$ kennzeichnen signifikante Korrelationen $(p<0,05)$. 


\subsection{Die Auswirkung neuromuskulärer Aktivität auf die Wirkung der BoNT-Injektionen}

56 Mäuse mit einem Gewicht von durchschnittlich 28,8 g (+/- 0,24 g) wurden im Alter von 19 Wochen in vier Gruppen (dreimal $n=13$, einmal $n=14$ ) randomisiert. Es wurden zwei unterschiedliche Dosierungen BoNT eingesetzt (0,1 MU und 0,2 MU). Es erhielten immer zwei Gruppen dieselbe Toxin-Dosis, allerdings wurde diese jeweils einer Gruppe morgens (ca. 7:00 bis 8:00 Uhr) und einer Gruppe abends (ca. 17:30 bis 18:30 Uhr) injiziert.

Abbildung 14 zeigt eine Darstellung der Laufwerte direkt vor und nach den Injektionen im Stundenprofil am Beispiel der kumulierten Laufzeit (Tges). Dort lässt sich beobachten, dass die meiste Laufaktivität (im Sinne der im Laufrad verbrachten Zeit) jeweils direkt nach Beginn des Dunkelzyklus (18:30 Uhr) in den ersten Stunden der Nacht stattfand. In den Tagesstunden war so gut wie keine Laufaktivität nachzuweisen. Auch nach den morgendlichen Injektionen war dieses Verhalten nicht stress- oder injektionsbedingt verändert, und die Tiere zeigten in den Stunden nach den Injektionen kaum Laufaktivität. Die im Laufrad verbrachte Zeit betrug in den ersten fünf Stunden nach den morgendlichen Injektionen für die entsprechenden Tiere lediglich 4,5\% (+/- 1,4\%) der Laufzeit, die in den folgenden 24 Stunden insgesamt erreicht wurde. Durch den deutlichen Anstieg der Laufaktivität mit Beginn des Dunkelzyklus fielen nach den abendlichen Injektionen hingegen 43,2 \% (+/- 4,4 \%) der Laufzeit der folgenden 24 Stunden auf die fünf Stunden direkt nach den Injektionen. Das Laufprofil der Nacht nach den Injektionen stellt sich bei den abends injizierten Tieren im Vergleich zu vorangegangenen Nächten insgesamt leicht verändert dar. Der Zeitraum der größten Laufaktivität ist um 2 Stunden nach hinten verschoben und der Peak der stärksten Laufaktivität weniger ausgeprägt.

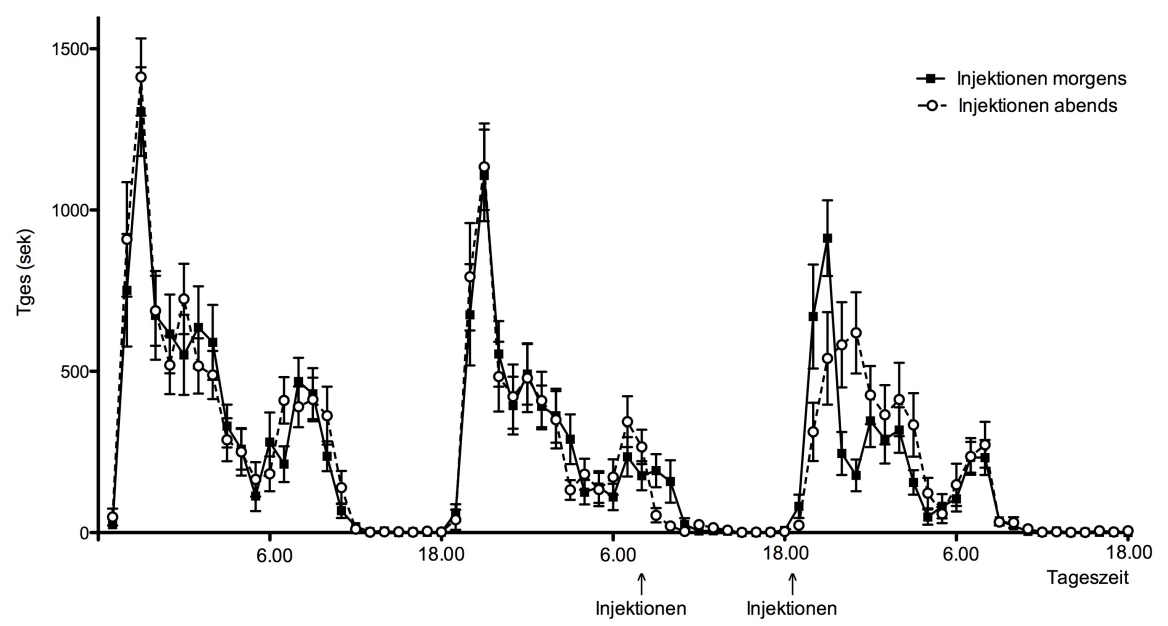

Abbildung 14: Profile der Tges für die beiden Nächte vor sowie die Nacht nach den Injektionen. Darstellung der morgens sowie der abends injizierten Tiere. Die Dosis-Gruppen (0,1 MU und 0,2 MU) des jeweiligen Injektionszeitpunktes wurden zusammengefasst. Die Injektionszeitpunkte sind mit Pfeilen markiert. 
Für die Beurteilung der Toxin-Wirkung wurden die Laufparameter als 24-Stunden-Werte betrachtet, die in Abbildung 15 dargestellt sind. Die ANOVA zeigt für die Laufparameter Distanz und Vmax - jeweils sowohl für die tatsächlichen als auch für die relativen Werte signifikante Veränderungen über die Zeit. Die Mäuse entwickelten dosisabhängige Paresen der Wadenmuskulatur, was sich in einer dosisabhängigen Veränderung der Vmax darstellt. Die beiden Gruppen, welche die geringe Dosis BoNT $(0,1 \mathrm{MU})$ erhalten hatten, zeigen im post-hoc T-Test einen signifikant geringeren Abfall der relativen Vmax an den Tagen 1 bis 19 sowie Tag 23 nach den Injektionen. In der Vmax zeigt sich außerdem ein Interaktionseffekt zwischen zeitlichem Verlauf und Dosis. In Bezug auf den Zeitpunkt der Injektionen zeigen sich sowohl für die Distanz als auch für die Vmax keine signifikanten Unterschiede zwischen den Gruppen (vgl. Tab. 12 und Abb. 15). Der BoNT-induzierte Paresegrad ist demnach unabhängig von einer gesteigerten neuromuskulären Aktivität nach den Injektionen für beide Gruppen identisch.
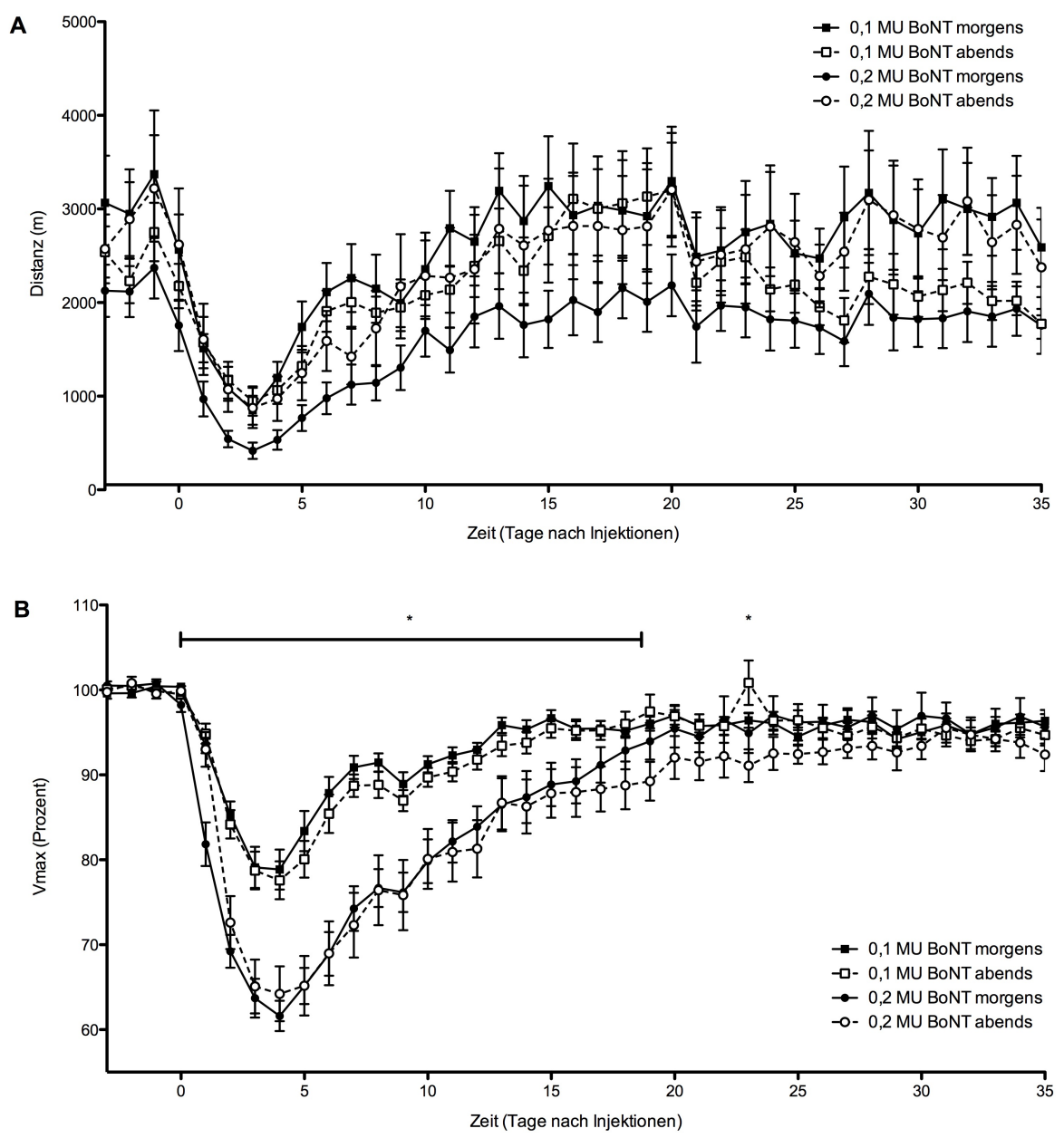

Abbildung 15: Verlauf der Distanz (A) und der relativen Vmax (B) nach morgendlichen und abendlichen Injektionen von 0,1 und 0,2 MU BoNT. Sterne $\left({ }^{*}\right)$ kennzeichnen signifikante Unterschiede zwischen den Dosisgruppen 0,1 und 0,2 $\mathrm{MU}(p<0,05)$. 
Ergebnisse

\begin{tabular}{|c|c|c|c|c|}
\hline Parameter & Variablen & df & $\mathbf{F}$ & $p$ \\
\hline \multirow[t]{7}{*}{ Vmax } & Injektionszeitpunkt & 1 & $<0,001$ & 0,986 \\
\hline & Dosis & 1 & 15,496 & $<0,001^{*}$ \\
\hline & Injektionszeitpunkt x Dosis & 1 & 0,464 & 0,499 \\
\hline & zeitlicher Verlauf & 38 & 129,790 & $<0,001^{*}$ \\
\hline & zeitlicher Verlauf $x$ Injektionszeitpunkt & 38 & 1,003 & 0,465 \\
\hline & zeitlicher Verlauf $x$ Dosis & 38 & 14,759 & $<0,001^{*}$ \\
\hline & zeitlicher Verlauf $x$ Dosis $x$ Injektionszeitpunkt & 38 & 1,142 & 0,255 \\
\hline \multirow[t]{7}{*}{ Vmax relativ } & Injektionszeitpunkt & 1 & 0,527 & 0,471 \\
\hline & Dosis & 1 & 19,603 & $<0,001^{*}$ \\
\hline & Injektionszeitpunkt x Dosis & 1 & 0,065 & 0,088 \\
\hline & zeitlicher Verlauf & 38 & 122,851 & $<0,001^{*}$ \\
\hline & zeitlicher Verlauf x Injektionszeitpunkt & 38 & 1,104 & 0,306 \\
\hline & zeitlicher Verlauf x Dosis & 38 & 16,585 & $<0,001^{*}$ \\
\hline & zeitlicher Verlauf $x$ Dosis $x$ Injektionszeitpunkt & 38 & 1,444 & $0,040^{*}$ \\
\hline \multirow[t]{7}{*}{ Distanz } & Injektionszeitpunkt & 1 & 0,275 & 0,602 \\
\hline & Dosis & 1 & 1,152 & 0,288 \\
\hline & Injektionszeitpunkt x Dosis & 1 & 3,084 & 0,085 \\
\hline & zeitlicher Verlauf & 38 & 24,594 & $<0,001^{*}$ \\
\hline & zeitlicher Verlauf x Injektionszeitpunkt & 38 & 0,585 & 0,980 \\
\hline & zeitlicher Verlauf $x$ Dosis & 38 & 0,935 & 0,584 \\
\hline & zeitlicher Verlauf $x$ Dosis $x$ Injektionszeitpunkt & 38 & 1,223 & 0,166 \\
\hline \multirow[t]{7}{*}{ Distanz relativ } & Injektionszeitpunkt & 1 & 0,092 & 0,763 \\
\hline & Dosis & 1 & 2,716 & 0,106 \\
\hline & Injektionszeitpunkt x Dosis & 1 & 0,054 & 0,817 \\
\hline & zeitlicher Verlauf & 38 & 31,337 & $<0,001^{*}$ \\
\hline & zeitlicher Verlauf $\mathrm{x}$ Injektionszeitpunkt & 38 & 0,767 & 0,847 \\
\hline & zeitlicher Verlauf $x$ Dosis & 38 & 1,554 & $0,017^{*}$ \\
\hline & zeitlicher Verlauf $x$ Dosis $x$ Injektionszeitpunkt & 38 & 1,458 & $0,036^{*}$ \\
\hline
\end{tabular}

Tabelle 12: Ergebnisse der statistischen Auswertungen mittels ANOVA nach morgendlichen und abendlichen Injektionen von 0,1 und 0,2 MU BoNT. Sterne $\left(^{*}\right)$ kennzeichnen signifikante Ergebnisse $(p<0,05)$. Abbildung 15 zeigt die zugehörigen Ergebnisse. Die Daten der Vmax (tatsächliche Werte) sowie der relativen Distanz wurden nicht grafisch dargestellt. 


\section{$4 \quad$ Diskussion}

\subsection{Im Laufradmodell können durch niedrig dosierte BoNT-Injektionen in die $\mathrm{Mm}$. gastrocnemii induzierte latente Paresen unter Verwendung komplexer Laufräder sicher detektiert werden}

Im Sinne ethischer, finanzieller und logistischer Aspekte ist in Tierversuchen generell stets eine möglichst geringe Gruppengröße anzustreben. Mit Versuchsgruppen von 13-15 Tieren konnten in dieser Arbeit aussagekräftige Ergebnisse erzielt werden. Damit liegt die benötigte Tierzahl im Vergleich mit anderen In-vivo-Methoden in einem ähnlichen Bereich (DAS-Assay 10 Tiere, Aoki 2001; Zehenspreiz-Reflex 15 Tiere, Wilder-Kofie et al. 2011; mouse abdominal ptosis Assay 16 Tiere, Sesardic et al. 1996). In Kapitel 3.4 war die Gruppengröße mit $n=26$ und $n=27$ Tieren ausnahmsweise und bewusst sehr groß gewählt, um zunächst sicherzu-gehen, dass eine fehlende Dosisabhängigkeit eines Parameters nicht auf eine zu klein gewählte Gruppengröße zurückzuführen ist. Die aussichtsreichsten Parameter wurden später auf ihre Anwendbarkeit bei kleineren Gruppen überprüft (vgl. Kapitel 3.5 und 3.6), und auch für den Vergleich der Toxin-Wirkung mit einer Kontrollgruppe lag die Gruppengröße lediglich bei 13-15 Tieren (vgl. Kapitel 3.3).

Nachdem in Kapitel 3.3 gezeigt werden konnte, dass die Injektion von $\mathrm{NaCl}$ 0,9 \% keinen Effekt auf das Laufverhalten hat, wurde in allen weiteren Versuchen aus ethischen Gründen auf Kontrollgruppen verzichtet.

\subsubsection{Der M. gastrocnemius ist ein geeigneter Injektionsmuskel}

Um mit einer möglichst geringen Toxin-Dosis einen größtmöglichen Effekt auf das Laufverhalten zu erzielen, müssen die Injektionen in für das Laufen im Laufrad stark relevante Muskeln erfolgen. Es wurde im Rahmen dieser Arbeit davon ausgegangen, dass die Hinterläufe aufgrund der ausgeprägteren Muskulatur am meisten zur Kraftentwicklung und Laufleistung beitragen. Durch Allen et al. 2001 konnte außerdem gezeigt werden, dass es durch freiwilliges Laufradtraining zu trainingsbedingten Veränderungen der Muskelfasern im Sinne eines veränderten Expressionsmusters der unterschiedlichen schweren Ketten des Myosins sowohl im M. tibialis anterior als auch im M. gastrocnemius kommt. Das spricht für die Relevanz beider Muskeln für das Laufen im Laufrad. Darüber hinaus sind Injektionen in beide Muskeln aufgrund ihrer Größe und Lokalisation technisch gut möglich. Auch wurden in bekannten Laufrad-basierten Modellen zur Untersuchung von Clostridium-Neurotoxinen ebenfalls sowohl der M. gastrocnemius (BoNT, Keller 2006 und Auguet et al. 2011) als auch der M. tibialis anterior (TeNT, Kutschenko et al. 2012) für Injektionen genutzt. 
Die Ergebnisse in Kapitel 3.2 zeigen, dass beide Muskeln prinzipiell geeignet scheinen, da nach Injektion einer identischen Toxin-Dosis von 0,2 MU BoNT jeweils ein Effekt sowohl auf die Vmax als auch auf die Distanz gezeigt werden konnte (vgl. Abb. 3). Eine latentes motorisches Defizit des M. gastrocnemius hat eine stärkere Beeinträchtigung der Lauffähigkeit im Laufrad (gemessen durch die Vmax) zur Folge als eines des M. tibialis anterior. Das in Abbildung 4 angewendete Verfahren, die Daten von drei Beobachtungstagen zu einem Pool zusammenzufassen, muss jedoch kritisch betrachtet werden, da es eine künstliche Vergrößerung der Stichprobe darstellt. Da sich ohne diesen Schritt kein Unterschied zwischen den beiden Injektionsmuskeln zeigte, kann jedoch in jedem Fall davon ausgegangen werden, dass beide Muskeln mindestens ebenbürtig sind. Aufgrund der technisch einfacheren Injektion und damit einer besseren Reproduzierbarkeit wäre auch dann der M. gastrocnemius der Muskel der Wahl.

\subsubsection{Die Nutzung eines einheitlichen Injektionsvolumens von $10 \mu \mathrm{l}$ pro Muskel eignet sich gut für Dosierungen, die eine subtotale Paralyse induzieren}

In der klinischen Anwendung wird davon ausgegangen, dass die Verdünnung des Toxins in einem größeren Injektionsvolumen zu einer verstärkten Diffusion und somit zu einer besseren Verteilung in insbesondere großen Muskeln führt, wodurch mehr motorische Endplatten erreicht werden können, jedoch auch eine Diffusion in umliegendes Gewebe resultieren kann (Lim und Seet 2008). Da die therapeutischen Dosierungen unter anderem auch abhängig von der Muskelgröße sind, wird damit einhergehend im klinischen Alltag mittlerweile meist eine konstante Toxin-Konzentration mit entsprechend dosisabhängigem Volumen verwendet, während früher konstante Volumina unterschiedlicher Konzentration verwendet wurden (Kinnett 2004).

Die Frage, inwieweit Injektionsvolumen und Toxin-Effekt miteinander korrelieren, konnte in der Vergangenheit nicht eindeutig beantwortet werden. Die widersprüchlichen Ergebnisse tierexperimenteller Arbeiten (Hulst et al. 2014, Kim HS et al. 2003, Kutschenko et al. 2016, Shaari und Sanders 1993), könnten zum einen durch die unterschiedlichen Methoden zur Quantifizierung des Toxin-Effekts begründet sein, zum anderen könnten die unterschiedlichen Dosierungen im Vergleich zur Muskelgröße eine Rolle spielen (Kim HS et al. 2003). Bei Injektion von 0,2 MU in den M. tibialis ant. der Ratte sowie bei einer Injektion von 0,1 MU in den M. gastrocnemius der Maus wurde ein Effekt des Volumens nachgewiesen (Kutschenko et al. 2016, Shaari und Sanders 1993), bei Injektionen von 1 MU, 3 MU und $6 \mathrm{MU}$ in den M. tibialis ant. der Ratte hingegen nicht (Hulst et al. 2014). Das legt nahe, dass dann, wenn die Toxin-Dosis ohnehin eine komplette Lähmung des Muskels verursacht, 
höhere Volumina keinen Einfluss mehr haben, während bei einer subtotalen Paralyse das Injektionsvolumen eine Rolle spielt (Kim HS et al. 2003). Da in der vorliegenden Arbeit subtotale Lähmungen induziert wurden, ist somit von einem Einfluss des Injektionsvolumens auszugehen. Diese These unterstützend konnte in eigenen Versuchen nach Injektion von 0,1 MU BoNT in den M. gastrocnemius der Maus ein signifikant stärkerer Effekt bei einem Injektionsvolumen von $15 \mu \mathrm{l}$ im Vergleich zu einem Injektionsvolumen von $2 \mu \mathrm{l}$ festgestellt werden (Kutschenko et al. 2016).

Stone et al. 2011 sahen nach BoNT-Injektion, die ebenso wie in der vorliegenden Arbeit in den M. gastrocnemius der Maus erfolgten, mittels neurophysiologischer Methoden (Messung des Summenaktionspotenzials und der Muskelkrafterzeugung) eine Beeinflussung des Toxin-Effekts durch das Injektionsvolumen. Dieser Einfluss stellte jedoch keine einfache Korrelation dar, sondern die größte neuromuskuläre Blockade zeigte sich bei einem Volumen von $10 \mu \mathrm{l}$, während sowohl höhere als auch niedrigere Volumina geringere Effekte bewirkten (ebd.). Daher erscheint die Nutzung eines Volumens von $10 \mu \mathrm{l}$ pro Muskel am sinnvollsten und wurde, mit Ausnahme von Kapitel 3.3, für alle im Rahmen dieser Arbeit durchgeführten Versuche einheitlich verwendet. Dadurch wurden mögliche Auswirkungen unterschiedlicher Volumina sowie damit einhergehende unterschiedlich ausgeprägte (Mikro-)Traumen vermieden und lediglich der Effekt unterschiedlicher Toxin-Konzentrationen untersucht.

\subsubsection{Niedrigdosierte BoNT-Injektionen haben einen massiven Einfluss auf das Laufverhalten im Laufrad}

Kapitel 3.3 zeigt für alle Parameter nach Injektion von 0,1 MU BoNT vs. $\mathrm{NaCl}$ 0,9\% eine signifikante Veränderung des Laufverhaltens über die Zeit. Dies kann, neben dem Toxin-Effekt, teilweise auch auf eine generelle Instabilität der einzelnen Parameter zurückzuführen sein, die in Abbildung 5 und 6 deutlich wird. Die unterschiedlich starken Schwankungen scheinen unter anderem auch durch eine unterschiedlich ausgeprägte Beeinflussbarkeit der Parameter durch äußere Faktoren bedingt zu sein. So zeigt die Nlauf in Abbildung $5 \mathrm{E}$ und $5 \mathrm{~F}$ Peaks, die mit dem wöchentlichen Umsetzen der Mäuse in neue Boxen zusammenfallen. Selbiges zeigt sich auch bei einigen anderen Parametern (Distanz, Vmean, Tges), allerdings deutlich dezenter (vgl. Abb. 5 und 6). Insgesamt scheint die Vmax die größte intraindividuelle Stabilität vorzuweisen (vgl. Abb. 5 A und 5 B). Stärkere Schwankungen der Distanz im Vergleich zur Vmax zeigt auch die Arbeit von Allen et al. 2001.

Es zeigt sich jedoch auch, dass die Injektion von 0,1 MU BoNT im Vergleich zur Injektion von $\mathrm{NaCl}$ zu einer signifikanten Reduktion aller gemessenen Parameter mit Ausnahme der Tmean führt. Die Injektion von 0,1 MU BoNT, verteilt auf beide Mm. gastrocnemii, führt also 
zu einem eindeutigen Effekt auf das Laufverhalten im Laufrad. Zudem besteht ein globale Auswirkung der Toxin-Wirkung auf fast alle gemessenen Laufparameter. Somit scheint ein Laufradmodell generell eine sinnvolle Methode für die Arbeit mit BoNT.

\subsubsection{Durch das Laufradmodell können Toxin-Effekte qualitativ untersucht werden, die in einem Niedrigdosisbereich vergleichbar mit therapeutischen Dosierungen liegen}

Für qualitative Fragestellungen sollte, insbesondere wenn es um Fragen in Bezug auf die klinische Anwendung geht, ein Dosisbereich erfasst werden, der dem therapeutischen Bereich ähnlich ist. Ziel sollte also sein, Dosierungen im deutlich subletalen Bereich zu erfassen. Ziel des hier entwickelten Modells ist nicht die Detektion kleinster Toxin-Mengen, beispielsweise in Lebensmitteln, sondern es soll einen klinisch gewollter Effekt imitiert werden. Es wurde daher nicht versucht, die Sensitivität bis in einen Minimaldosisbereich hinein zu steigern, wie es durch einige neue In-vitro-Methoden aktuell berechtigterweise für andere Fragestellungen geschieht (u.a. Koh et al. 2015).

Die BoNT-Dosierungen lassen sich nicht direkt aus der klinischen Anwendung in ein TierModell übertragen, da sich auch im klinischen Kontext die Dosierungen, je nach zu behandelndem Krankheitsbild und der entsprechenden Ausprägung, Muskelgröße, Körpergewicht und ggf. bestehenden Erfahrungswerten früherer Injektionen, unterscheiden. Dosierungen, die zu einem messbaren Effekt führen, jedoch keine komplette Lähmung des Muskels oder sogar Distanzeffekte verursachen, scheinen jedoch als Äquivalente zu therapeutischen Dosierungen nutzbar. Bei Überschreiten einer „kritischen Dosierung“ kann durch höhere Dosierungen keine Steigerung der neuromuskulären Blockade mehr erreicht werden (Brillante et al. 2002). Genutzte Toxin-Mengen sollten also unterhalb dieses Bereichs liegen, da ansonsten eher die Ausbreitung des Toxins über den Injektionsmuskel hinweg oder systemische Effekte die Ergebnisse beeinflussen.

Durch das BoNT-Laufradmodell konnten in dieser Arbeit die verwendeten Dosierungen, die zwischen 0,08 MU und 0,24 MU lagen, nicht nur detektiert sondern auch mit aussagekräftigen Ergebnissen untersucht werden. Da diese Dosierungen keine direkt sichtbaren klinischen Beeinträchtigungen der Tiere verursachten und erst recht keine systemischen Effekte beobachtet werden konnten, kann davon ausgegangen werden, dass mit Dosierungen dieser Größenordnung einer therapeutischen oder sogar subtherapeutischen Dosis entsprochen wird. Eine Untersuchung noch niedriger Dosierungen wurde daher als nicht sinnvoll erachtet. Die verwendeten Dosierungen liegen in einem Bereich, der in der Vergangenheit mit vergleichbaren Methoden (z.B. mouse abdominal ptosis Assay, DAS-Assay) genutzt wurde (Aoki 2001, Sesardic et al. 1996). Andere Methoden mussten höhere Dosierungen 
verwenden, um Effekte eindeutig darstellen zu können. So führt in der Analyse mittels Zehenspreiz-Reflex zwar $1 \mathrm{MU}$ BoNT zu einem signifikanter Effekt, Dosierungen unter $1 \mathrm{MU}$ sind jedoch nicht oder nur inkonsistent nachweisbar (Wilder-Kofie et al. 2011). Da die MPU qua definitionem zumindest in einem Teil der Tiere zu einer kompletten Lähmung des entsprechenden Muskels führen muss, liegen auch hier die Dosierungen in einem höheren Bereich von 0,24-0,74 MU (Pearce et al. 1995a).

\subsection{Die relative Maximalgeschwindigkeit ist der Laufparameter, der sich am besten zur Analyse der BoNT-Wirkung eignet}

Für die Parameter Distanz, Nlauf und Tges zeigt sich eine signifikante Reduktion der Laufleistung nach BoNT-Injektionen im Vergleich zu einer $\mathrm{NaCl-Kontrollgruppe} \mathrm{nur} \mathrm{für} \mathrm{die} \mathrm{rela-}$ tiven Werte (vgl. Abb. 5 C-H). Das kann als ein erster Hinweis darauf gewertet werden, dass durch die Berechnung relativer Werte eine höhere Sensitivität der Methode und damit eine größere Aussagekraft erreicht werden kann. Ursache sind unterschiedliche Ausgangswerte der Tiere. Besonders deutlich wird diese Rolle unterschiedlicher Ausgangslevels bei Tieren unterschiedlichen Alters (vgl. Kapitel 3.5, insbesondere Abb. 10 und 11). Wenn sich schon vor der Injektion signifikante Unterschiede zwischen zwei Gruppen zeigen, lassen sich nach den Injektionen keine Rückschlüsse darauf ziehen, welcher Effekt tatsächlich gruppenabhängig und welcher durch die unterschiedlichen Ausgangslevels bedingt ist. Es erscheint daher sinnvoll, generell die prozentualen Werte als entscheidenden Parameter zu betrachten. Die zusätzliche Auswertung tatsächlicher Daten ist, insbesondere zur Beurteilung der generellen Laufleistung eines Tieres oder einer Gruppe, trotzdem sinnvoll, um Tiere, die eine unzureichende Laufaktivität für eine sinnvolle Datenanalyse zeigen, frühzeitig identifizieren zu können (vgl. Kapitel 2.2).

Auch wenn die Injektion von 0,1 MU BoNT einen Effekt auf fast alle gemessenen Laufparameter hat, zeigen die Abbildungen 5 und 6, dass sich die prozentuale Reduktion der einzelnen Parameter zum Zeitpunkt des maximalen Toxin-Effekts teilweise deutlich unterscheidet. Die Vmax ist dabei der Wert, der prozentual am wenigsten abfällt, während sich die Distanz am deutlichsten reduziert. Nichtsdestoweniger vermag die Vmax die Effekte von Injektionen von 0,1 und 0,2 MU BoNT zu differenzieren, nicht jedoch die Distanz (vgl. Abb. 8 A-D). Eine Unterscheidung des Effekts von 0,1 vs. 0,2 MU BoNT gelingt neben der Vmax nur mit Hilfe der Parameter Nlauf (relative Werte) und Vmean (tatsächliche Werte), kein anderer Parameter kann die Effekte eine Verdoppelung der Toxin-Dosis in einem an sich gut detektierbaren Bereich nachweisen (vgl. Abb. 8 und 9). 
Es wird vermutet, dass die Vmax am besten die (maximal aufbringbare) Muskelkraft widerspiegelt. Die Muskelkraft kann als das wichtigste Kriterium angesehen werden, um die Wirksamkeit von BoNT, eine Muskelschwäche zu induzieren, zu bewerten (Ma et al. 2004). Das bestärkt die Ergebnisse, in denen sich die (relative) Vmax als der Parameter herauskristallisiert, der sich am besten eignet, um eine BoNT-induzierte Muskelschwäche zu messen. Sowohl 0,1 MU im Vergleich zu NaCl als auch der Unterscheid zwischen 0,1 und 0,2 MU können sicher nachgewiesen werden. Hinzu kommt die große intraindividuelle Stabilität der Vmax und ihre vergleichsweise geringe Beeinflussung durch äußere Faktoren.

In bisherigen Arbeiten, die auf einem Laufradmodell basieren, wurde die Distanz als Laufparameter genutzt (Keller 2006 und Auguet et al. 2011). Diese fällt nach BoNT-Injektionen zwar prozentual am deutlichsten ab, was zunächst auf eine hohe Sensitivität schließen lässt, es kommt jedoch auch rasch zum Erreichen eines Bodeneffekts bei höheren Toxin-Dosierungen (Keller 2006). Auch konnte in einem Ratten-Modell bereits gezeigt werden, dass sich dort die Maximalgeschwindigkeit bereits bei einer BoNT-Dosis signifikant verringert hat, die noch keinen Effekt auf die Laufdistanz zeigte (Legerlotz et al. 2009), was ebenfalls für eine größere Sensitivität der Vmax spricht.

Ein Bodeneffekt der Distanz zeigt sich in dieser Arbeit in der fehlenden Dosisabhängigkeit des Laufverhaltens nach Injektion von 0,1 und 0,2 MU BoNT (vgl. Abb. 8). So wird eine Differenzierung zwischen unterschiedlichen Dosierungen anhand der Distanz schon im Niedrigdosisbereich schnell unmöglich. Keller 2006 bezieht sich entsprechend teilweise auf die Dauer der kompletten Paralyse, die ebenfalls eine Dosisabhängigkeit zeigt (Keller 2006). Solch ein Wert als Analyseinstrument bringt jedoch mit sich, dass Dosierungen nur dann gut miteinander verglichen werden können, wenn sie zu einer (nahezu) kompletten Aufgabe der Laufaktivität für einen bestimmten Zeitraum führen, was erst bei Dosierungen ab ca. 0,5 MU BoNT/A der Fall ist (Keller 2006). Bei höheren Dosierungen ist auch bei der Vmax mit einem Bodeneffekt zu rechnen. Dies lässt Abbildung $11 \mathrm{~A}$ vermuten, in der sich die Vmax der verschiedenen (Alters-)Gruppen nach Injektion von 0,24 MU BoNT, trotz stark unterschiedlicher Ausgangslevels, zum Zeitpunkt der stärksten Toxin-Wirkung nicht signifikant unterscheidet.

Ein Bodeneffekt bei höheren Toxin-Dosierungen zeigt sich auch in anderen Methoden, beispielsweise bei der Muskelkrafterzeugung durch elektrische Stimulation nach BoNTInjektionen. Zwar können im Maus-Modell vergleichbare prozentuale Abfälle der Muskelkraft bei der selben Toxin-Dosis beobachtet werden, jedoch tritt bereits bei einer Dosis von 3 MU/kg (ca. 0,07 MU/Maus) ein Bodeneffekt auf, so dass bei höheren Dosierungen keine weitere Differenzierung mehr möglich ist (Stone et al. 2011). Solch ein methodenabhängiger Bodeneffekt muss unterschieden werden von der so genannten „kritischen Dosis“ im Sinne 
der Toxin-Dosis, ab der eine Erhöhung der Dosis zu keiner physiologischen Verstärkung der Blockade der neuromuskulären Übertragung mehr führt, da nahezu alle Nervenendigungen blockiert werden (Brillante et al. 2002).

Der Toxin-Effekt und seine Messbarkeit im BoNT-Laufradmodell weisen eine hohe Stabilität auf. Unabhängig von Alter, Gewicht oder Tageszeit der Injektionen kommt es bei einer identischen Dosis BoNT zu einem reproduzierbaren identischen Effekt auf die relative Vmax (vgl. Abb. $5 \mathrm{~B}, 8 \mathrm{~B}, 10 \mathrm{~B}, 11 \mathrm{~B}, 13$ und $15 \mathrm{~B})$.

Es wird an dieser Stelle postuliert, dass die objektive Messung der Daten dazu entscheidend beiträgt und dies einen Vorteil gegenüber einigen anderen In-vivo-Modellen darstellt. In Falle des mouse abdominal ptosis Assays und des DAS-Assays muss aufgrund einer hohen Subjektivität der Beurteilung der Toxin-Wirkung die Reproduzierbarkeit der Ergebnisse zumindest kritisch betrachtet werden. Im mouse abdominal ptosis Assay kann zwar insgesamt eine gute Übereinstimmung mit $L_{50}$-Test-Ergebnissen gezeigt werden, jedoch stimmen die beiden verblindeten Beobachter nur in 57-62 \% der Fälle in ihrer Beurteilung überein (Sesardic et al. 1996). Das lässt auf eine nicht unwesentliche Beeinflussung des Ergebnisses durch die Subjektivität der Beurteilung und somit auf eine UntersucherAbhängigkeit schließen. Beim DAS-Assay besteht aufgrund der Beurteilung durch Beobachter ein ähnlicher Grad an Subjektivität wie beim mouse abdominal ptosis Assay, jedoch beschreibt Aoki 2001 eine deutlich höhere Interrater-Reliabilität mit 83 \% identischen Scores. Das lässt darauf schließen, dass der DAS-Assay verlässlichere Ergebnisse liefert und die Einteilung des Grads der Paralyse eindeutiger zu erkennen ist, als beim mouse abdominal ptosis Assay. $17 \%$ der Bewertungen stimmen jedoch auch beim DAS-Assay nicht überein.

Neben der Objektivität ist ein weiterer möglicher Grund für die gute Reproduzierbarkeit der Ergebnisse im Laufradmodell die Tatsache, dass die Messung der Laufleistung auf einer Verhältnisskala erfolgt. Somit wird das höchste statistische Skalenniveau verwendet, welches zusätzlich eine deutlich feinere Unterscheidung aufgrund der großen Anzahl an Intervallen liefert. Selbiges Skalenniveau mit seinen Vorteilen findet sich auch bei neurophysiologischen Methoden wie dem EMG und Messungen der Muskelkraft, aber auch bei der Messung der dorsiflexion torque (Brillante et al. 2002, Minamoto et al. 2007, Pickett et al. 2008). Dem gegenüber stehen andere Methoden wie der DAS-Assay oder der mouse abdominal ptosis Assay, die mit einer Ordinalskala arbeiten (Aoki 1999, Sesardic et al. 1996). Statistisch liegt das Problem der Ordinalskalen zum einen in der begrenzten Anzahl der Stufen (fünf Stufen beim DAS-Assay, vier Stufen beim mouse abdominal ptosis Assay), 
die automatisch eine begrenzte Unterscheidbarkeit sehr ähnlicher Dosierungen mit sich bringt. Zum anderen kommt es zu Problemen, wenn Ordinalskalen statistisch wie eine Intervallskala behandelt werden, obwohl zwischen den festgelegten Stufen keine messbaren identischen Abstände bestehen. So dürfte bei einer Ordinalskala lediglich der Median, nicht jedoch der Mittelwert bestimmt werden (Jann 2005), was jedoch sowohl bei Nutzung des DAS-Assays als auch beim mouse abdominal ptosis Assay häufig nicht beachtet wird (Aoki 1999, Aoki 2001, Aoki 2002, Sesardic et al. 1996, Wang et al. 2011).

\subsubsection{Das Laufradmodell ermöglicht Aussagen zur Wirkstärke des Toxins}

Die maximale Reduktion der Laufleistung kann als Äquivalent für die Potenz des Toxins angesehen werden, da sie dem größten Toxin-Effekt auf das Laufverhalten und somit dem maximalen induzierten Paresegrad entspricht. Es konnte in dieser Arbeit gezeigt werden, dass dieselbe Toxin-Dosis zu einer vergleichbaren prozentualen Reduktionen der Vmax führt (vgl. Abb. 5 B, 8 B, 10 B, 11 B, 13 und 15 B). Von den relativen Tiefstwerten lässt sich also aufgrund einer guten Reproduzierbarkeit der Ergebnisse auf die tatsächliche Potenz schließen. Die Aussagefähigkeit bezüglich der Wirkstärke zeigt sich auch in der Fähigkeit, Dosisunterschiede von 0,1 MU sicher nachzuweisen, wie es mit Hilfe der Parameter Vmax, Vmean und Nlauf möglich ist (vgl. Kapitel 3.4).

Mit Hilfe des Zeitpunktes der Tiefstwerte können darüber hinaus Aussagen zum Wirkungsverlauf im Sinne des Zeitpunktes eines maximalen Effektes gemacht werden. Der Zeitpunkt des Tiefstwertes der Vmax lag bei den genutzten Dosierungen $(0,8$ bis $0,24 \mathrm{MU})$ stets an Tag 3 oder 4 nach den Injektionen (vgl. Abb. 3 B, 5 B, 8 B, 10 B, 11 B und 15 B). Im DASAssay werden nach Injektionen subletaler Dosierungen von BoNT Höchstwerte an den Tagen 2 und 3 beschrieben (Aoki 1999, Aoki 2001, Aoki 2002). Als Ursache für diesen Unterschied kommen zum einen die teilweise deutlich höheren Dosierungen in Frage. Darüber hinaus werden Laufraddaten kontinuierlich ausgewertet, während durch den DASAssay eine punktuelle Messung stattfindet, was zu Ungenauigkeiten bzgl. des Zeitpunktes führen kann. Außerdem entsprechen maximale Effekte auf einen Test nicht zwangsläufig der maximalen Wirkung des Toxins, sondern lediglich dem maximalen Effekt, der auch durch sekundäre Toxin-Folgen (bspw. Muskelatrophie) beeinflusst sein kann. Ein Zusammenhang zwischen Injektionsdosis und dem Zeitpunkt des maximalen Toxin-Effekts auf das Laufverhalten lässt sich im Rahmen dieser Arbeit nicht erkennen. Dies deckt sich mit den Ergebnissen von Aoki 1999 und Pearce et al. 1995a. 


\subsubsection{Das Laufradmodell ermöglicht Aussagen zur Wirkdauer des Toxins}

Viele BoNT-Untersuchungsmethoden lassen keine Aussagen zur Effektdauer zu. Dies gilt insbesondere für alle In-vitro- und Ex-vivo-Methoden sowie für In-vivo-Methoden, die auf letalen Endpunkten basieren, wie der LD $_{50}$-Test. Bei allen anderen In-vivo-Methoden ist zunächst prinzipiell von einer generellen Aussagefähigkeit zur Wirkdauer auszugehen. Wie gut dies dann tatsächlich in der Praxis möglich ist, unterscheidet sich jedoch deutlich.

Im Laufradmodell erfolgt eine kontinuierliche Datenaufzeichnung. Damit ist eine sehr exakte Langzeitbeobachtung möglich, die sich deutlich von Methoden unterscheidet, die nur eine punktuelle Beurteilung des Toxin-Effekts vornehmen. Dies ist bei der Mehrheit der in der Literatur beschriebenen Methoden der Fall (DAS-Assay bei Aoki 1999, dorsiflexion torque bei Minamoto et al. 2007, RMF-Assay bei Pickett et al. 2008, mouse abdomninal ptosis Assay bei Sesardic et al. 1996, Zehenspreiz-Reflex bei Wilder-Kofie et al. 2011). Als besonders gravierend kann der Effekt punktueller Messungen dann vermutet werden, wenn aufgrund aufwändiger Messungen Daten nur in sehr großen Abständen erhoben werden, wie bei der Nutzung einiger neurophysiologischer Methoden mit teilweise nur wöchentlichen Messungen (Ma et al. 2004, Stone et al. 2011). So können nur grobe Aussagen über den Wirkungs-verlauf getroffen werden und es besteht die Gefahr, den Zeitpunkt des maximalen Toxin-Effekts oder das Ende des Toxin-Effekts gar nicht zu erfassen. Der RMF-Assay zeigt trotz zunächst 48-stündlicher und später wöchentlicher Messungen aussagekräftige Ergebnisse, vergleicht jedoch auch nur identische sowie stark unterschiedliche BoNTDosierungen (0,1 vs. 1,0 MU) miteinander. Für einige Methoden (mouse abdominal ptosis Assay, Zehenspreiz-Reflex) sind bisher noch keine Daten zu entsprechenden LangzeitBeobachtungen veröffentlicht worden, die eine Beurteilung der Anwendbarkeit, insbesondere bezüglich der punktuell erfolgenden Datenerhebung, ermöglichen könnten.

Neben der Kontinuität trägt auch die Objektivität der Datenerfassung im Laufrad und damit die Untersucher-Unabhängigkeit zur Qualität der Methode bezüglich der Wirkdauer-Analyse bei (vgl. Kapitel 4.2).

Im Laufradmodell kann der Effekt der Injektion von 0,1 MU BoNT für insgesamt 12 Tage nachgewiesen werden (vgl. Abb. 5 und 6). Bei Keller 2006 zeigte sich im Gegensatz dazu nach Injektion von 0,14 MU bereits nach 7 Tagen keinen Effekt mehr auf die Distanz. Eine Dosis von 0,2 MU BoNT hat für insgesamt 19 Tage einen signifikanten Effekt auf die Vmax (vgl. Abb. 8 B). Der DAS-Assay zeigt bei einer vergleichbaren Dosis (10 MU/kg, entspricht ca. 0,2 MU/Maus, jedoch im Gegensatz zu dieser Arbeit nicht verteilt auf beide Beine sondern vollständig in einen M. gastrocenmius injiziert) lediglich über einen Zeitraum von 15 
Tagen einen Punktwert > 0 (Aoki 1999). Neben einigen weiteren Methoden lassen also sowohl der DAS-Assay als auch das Distanz- sowie das Vmax-basierte Laufradmodell Rückschlüsse auf die Dauer des Toxin-Effekts zu. Die verschiedenen Modelle unterscheiden sich jedoch darin, wie lange sie bei identischer Dosis einen Toxin-Effekt zeigen.

Das in dieser Arbeit entwickelte Vmax-basierte Laufradmodell zeigt vergleichsweise lange eine Beeinflussung durch das Toxin. Die Unterschiede zwischen den Ergebnissen dieser Arbeit und denen von Keller könnten u.a. auf Unterschiede in der Versuchsdurchführung zurückzuführen sein. So verwendete Keller Laufräder, die jeweils von zwei Tieren genutzt wurden (Keller 2006). Darüber hinaus nutzte Keller normale Laufräder, deren Streben in regelmäßigen, identischen Abständen angeordnet sind. In dieser Arbeit wurden ausschließlich komplexe Laufräder genutzt, deren Streben in unterschiedlichen, unregelmäßigen Abständen angeordnet sind (vgl. Abb. 1). Durch die notwendige Anpassung der Schrittlänge ist das Laufen in einem komplexen Laufrad deutlich anspruchsvoller, und die vorliegenden Ergebnisse bestätigen die Hypothese, dass ein latentes motorisches Defizit mit Hilfe komplexer Laufräder deutlich sensitiver detektiert werden kann.

Es konnte in der Vergangenheit gezeigt werden, dass es dosisabhängige Unterschiede in der zeitlichen Dauer der BoNT-Effekte gibt, jedoch nicht bei allen BoNT-Serotypen. So konnten Houser et al. 1998 und Brillante et al. 2002 für BoNT/F eine Dosisabhängigkeit der Effektdauer zeigen. Nach BoNT/A-Injektionen zeigten EMG-basierte Untersuchungen keine dosisabhängige Wirkdauer, jedoch einen Zusammenhang zwischen der Dosis und dem Beginn der Erholungsphase (Brillante et al. 2002). In dieser Arbeit zeigt sich im Gegensatz dazu, wie auch im DAS-Assay (Aoki 1999) oder im RMF-Assay (Pickett et al. 2008), eine dosisabhängige Wirkdauer von BoNT/A. Im Vergleich von 0,1 MU zu 0,2 MU BoNT zeigten sich in der relativen Vmax signifikant niedrigere Werte nach Injektion der höheren Dosis für insgesamt 19 Tage, während 0,1 MU lediglich 12 Tage einen signifikanten Effekt auf das Laufverhalten hatte (vgl. Abb. 5 B und 8 B). Ein längerer Effekt bei höherer Dosis kann demnach eindeutig gezeigt werden. Der Unterschied zu den EMG-basierten Ergebnissen ist am ehesten in den unterschiedlichen Messmethoden zu suchen, wobei den Ergebnissen von DAS-Assay und Laufradmodell die größere Relevanz für die Klinik zugesprochen werden sollte, da der Effekt auf die natürliche Muskelaktivität entscheidend ist, nicht die Beeinflussung neurophysiologischer Parameter. 


\subsubsection{Die Regeneration zeigt einen mehrphasigen Verlauf mit inkompletter Erholung}

In der gesamten Arbeit lässt sich beobachten, dass - nach einem mit der Injektion von BoNT einhergehenden Abfall der Laufleistung auf einen Tiefstwert - nach ca. 3-4 Tagen eine Erholungsphase einsetzt. Es fällt jedoch auf, dass nicht immer für alle Parameter das Ausgangslevel der Laufleistung innerhalb des Beobachtungszeitraums wieder erreicht wird. Das betrifft vor allem die Vmax, in Einzelfällen auch die Distanz und die Nlauf.

Die Erholungsphase nach BoNT-induzierter Parese lässt sich auf molekularer Ebene in verschiedene Phasen einteilen. Zunächst kommt es in einer ersten Rehabilitationsphase zum Aussprossen zusätzlicher präsynaptischer Endigungen, die die neuromuskuläre Übertragung übernehmen, während die ursprünglichen motorischen Endplatten durch das Toxin noch nicht wieder funktionsfähig sind (Angaut-Petit et al. 1990, de Paiva et al. 1999, Duchen und Strich 1968). So kann eine komplette Regeneration der motorischen Fähigkeiten beobachtet werden, während auf histologischer und molekularer Ebene die Kompensations- und Regenerationsmechanismen noch lange nicht abgeschlossen sind (de Paiva et al. 1999, Juzans et al. 1996). Auf zellulärer Ebene kommt es nach einer ersten, nicht-neuronalen Phase mit Hochregulation von Insulin-like growth factor 1 (IGF-1) und nikotinergen Acetylcholinrezeptoren zu einer neuronalen Regenerationsphase mit Re-Innervation und Myogenese, die im Rattenmodell erst nach 4-6 Wochen einsetzt, wenn der eigentliche Toxin-Effekt bereits nachlässt (Shen et al. 2006). Erst in dieser zweiten Phase kommt es nach und nach zu einer Reaktivierung der eigentlichen motorischen Endplatten und damit einhergehend zu einem Rückgang der Aktivität der neu gewachsenen Nervenendigungen (de Paiva et al. 1999). So ist beispielsweise im Bereich des $M$. sternomastoideus der Maus erst ca. 3 Monate nach BoNT-Injektion das ursprüngliche neuronale Aktivitätsmuster wieder hergestellt (de Paiva et al. 1999). Je nach Toxin-Dosis schließt sich an dieser Stelle eine dritte Phase an, in der es zu keiner weiteren funktionellen bzw. klinischen Regeneration mehr kommt, ohne dass jedoch im EMG ein Ausgangslevel wieder erreicht wird (Brillante et al. 2002).

Die beobachtete unzureichende Erholung der Laufleistung könnte dieser dritten Phase bzw. diesem Stadium der Regeneration entsprechen. Nach Injektionen im Niedrigdosisbereich (ca. 0,02-0,14 MU/Maus) konnten auch Stone et al. 2011 sowohl im Summenaktionspotential als auch mittels Messung der Muskelkraft nach vier Wochen, und damit nach einem Zeitraum, der vergleichbar mit der Beobachtungsphase im Rahmen dieser Arbeit ist, noch keine komplette Erholung feststellen.

Darüber hinaus kommt es nach BoNT-Injektionen im Bereich der betroffenen Muskeln zu vielfältigen strukturellen Veränderungen (Chen CM et al. 2002, Dodd et al. 2005, Duchen 1971, Hassan et al 1995, Thacker et al. 2012, Thesleff et al. 1990). Diese können länger 
nachgewiesen werden als die klinische Parese (Hassan et al 1995). Neben Veränderungen auf molekularer Ebene kommt es durch die BoNT-induzierte funktionelle Denervierung zu einer Muskelatrophie (Caron et al. 2014, Dodd et al. 2005, Ma et al. 2004, Morbiato et al. 2007, Thesleff et al. 1990), deren Ausprägung eine Dosisabhängigkeit zeigt (Frick et al. 2007). Dabei fällt auf, dass die Atrophie sich noch progredient verstärkt, während sich andere Parameter, wie die Muskelspannung, bereits wieder erholen (Adler M et al. 2001, Ma et al. 2004, Stone et al. 2011). Morbiato et al. 2007 zeigten im Maus-Modell nach Injektionen von 0,5 MU BoNT, dass noch 25 Tage nach der vollständigen klinischen Erholung (gemessen mit Hilfe des DAS-Assays) das Muskelgewicht unter $70 \%$ des Ausgangslevels lag. Diese Daten legen die Vermutung nahe, dass auch eine Persistenz der Muskelatrophie zu einer persistierenden Reduktion der Laufleistung und insbesondere der Vmax nach den Injektionen beitragen könnte. Im Gegensatz dazu vermag beispielsweise der DAS-Assay diesen Effekt nicht darzustellen (Morbiato et al. 2007).

Neben den möglichen Toxin-bedingten Ursachen einer inkompletten Erholung der Laufleistung konnte in dieser Arbeit auch eine altersabhängige Abnahme der Laufleistung beobachtet werden (vgl. Kapitel 3.1, 3.3.1 und 3.5). Darüber hinaus geht ein höheres Gewicht (und dieses wird mit steigendem Alter erreicht, vgl. Tab. 7) mit einer geringeren Laufleistung einher (vgl. Kapitel 3.5.3, insbesondere Abb. 12). Ob dabei alleine das Alter (und/oder das Gewicht) der Mäuse entscheidend ist oder aber die kumulative Laufleistung mit möglichen Folgen, wie beispielsweise Abnutzungserscheinungen im Bereich der Gelenke, ebenfalls eine Rolle spielt, lässt sich im Rahmen dieser Arbeit nicht abschließend beurteilen. Kapitel 3.1 zeigt jedoch, dass die Reduktion der Vmax erst in einem Alter von ca. 4 Monaten einsetzt und der Parameter davor weitestgehend stabil zu sein scheint. Ein fehlendes Wiedererreichen des Ausgangslevels der Vmax nach BoNT-Injektionen konnte jedoch auch bei deutlich jüngeren Tieren (Alter bei Injektion 8 Wochen) festgestellt werden (vgl. Abb. $10 \mathrm{~B}$ und $11 \mathrm{~B})$. Somit kann dem Alter bzgl. der inkompletten Erholung lediglich ein additiver Effekt zugesprochen werden.

Der mögliche Einfluss kardiorespiratorischer Aspekte auf die (inkomplette) Erholung ist durch die erhobenen Daten nur eingeschränkt beurteilbar. Durch das regelmäßige Laufen im Laufrad kommt es zu einem Trainingseffekt, der sich in strukturellen Veränderungen der Skelettmuskulatur sowie einer vergrößerten Herzmuskelmasse zeigt (Allen et al. 2000). Es wäre denkbar, dass eine reduzierte Fitness durch die initiale Phase der Toxin-Wirkung, die mit einer verringerter Laufaktivität einhergeht, einen längerfristigen Effekt auf das Laufverhalten hat. 


\subsection{Der BoNT-Effekt auf das Laufverhalten ist unabhängig von Gewicht und Alter der Mäuse}

Wie in Kapitel 3.5.3 gezeigt werden konnte, besteht eine Korrelation des Gewichts einer Maus mit ihrer Laufleistung im Laufrad. Darüber hinaus wurde in dieser Arbeit, wie bereits im vorangegangenen Kapitel diskutiert, eine altersabhängige Abnahme der Laufleistung festgestellt. Da das steigende Alter der Mäuse in dieser Arbeit jedoch auch mit einem steigenden Gewicht einhergeht, lässt sich auf Basis der bisherigen Ergebnisse keine Aussage darüber treffen, welchen Einfluss das Alter alleine, unabhängig vom Gewicht, auf die Laufleistung hat. Ebenfalls nicht differenziert werden kann auf Basis der vorliegenden Ergebnisse ein möglicher Einfluss der kumulierten Laufzeit.

Der prozentuale Abfall der Vmax nach BoNT-Injektionen korreliert jedoch nicht mit dem Gewicht und/oder dem Alter der Tiere (vgl. Kapitel 3.5.4, insbesondere Abb. 13). Dies lässt sich durch den Wirkmechanismus des Toxins erklären. BoNT wirkt ausschließlich an den motorischen Endplatten. Daher scheint naheliegend, dass deren Anzahl entscheidend für die Toxin-Wirkung ist. So wird vermutet, dass die Dichte der motorischen Endplatte bei Kindern größer ist als bei Erwachsenen und diese daher mehr Toxin pro Kilogramm Körpergewicht vertragen (Kinnett 2004). Zwar spielt für die Toxin-Dosierung bei Kindern neben Muskelgröße und Lokalisation sowie dem Grad der Spastik auch das Körpergewicht eine Rolle (Kinnett 2004), Dosisempfehlungen für therapeutische BoNT-Injektionen bei Erwachsenen beziehen sich jedoch in der Regel auf den zu injizierenden Muskel, nicht auf das Körpergewicht (Berlit 2009, Ochs 2004). Auch eine Vergrößerung des zu injizierenden Muskels dürfte primär für die Frage einer ausreichenden Verteilung im Muskel und damit des Injektionsvolumens eine Rolle spielen (vgl. Kapitel 4.1.2), nicht jedoch für die Toxin-Dosis. Die Ergebnisse dieser Arbeit bestätigen, dass die Zahl der motorischen Endplatten, nicht jedoch das Körpergewicht oder auch eine trainingsbedingte Muskelhypertrophie für die Toxin-Wirkung entscheidend sind und daher im Maus-Modell eine Körpergewichts-adaptierte Anpassung der Toxin-Dosis nicht notwendig ist bzw. sogar Ergebnisse verfälschen könnte.

Auf Basis dieser Ergebnisse ist generell die Nutzung älterer Tiere und damit - nach vollständiger Erholung von den Injektionen - auch die mehrfache Nutzung derselben Tiere für die Methode möglich. Dies führt zu einer Reduktion der insgesamt benötigten Tiere. Darüber hinaus sind auch Daten von Tieren unterschiedlichen Alters und Gewicht bzw. unterschiedlicher Ausgangslevels direkt vergleichbar, wenn prozentuale Werte verwendet werden. 


\subsection{Motorische Aktivität nach den Injektionen zeigt keine Auswirkungen auf die durch BoNT-Injektionen induzierten Paresen}

Die vielfältigen Studien, die auf einen positiven Effekt von neuromuskulärer Aktivität auf die BoNT-Wirkung schließen lassen (vgl. Kapitel 1.4.2), können durch die Ergebnisse dieser Arbeit (bereits publiziert, vgl. Kutschenko et al. 2011) nicht bestätigt werden. Abbildung 14 zeigt, dass nach den abendlichen Injektionen eine deutlich stärkere motorische Aktivität, also eine vermehrte neuromuskuläre Aktivierung, stattfand als nach den morgendlichen Injektionen. Trotzdem konnte kein signifikanter Unterschied im Effekt des Toxins auf die Distanz und die Vmax festgestellt werden.

Für die Diskrepanz zu anderen Studien kommen unterschiedliche Erklärungen in Frage. Zunächst wurden in dieser Arbeit gesunde Mäuse verwendet. Ein Vergleich mit dem Einsatz von BoNT-Injektionen mit anschließender neuromuskulärer Aktivierung bei Menschen, die an einer spastischen Parese leiden, ist nur eingeschränkt möglich - unter anderem, weil spastische oder dystone Muskeln schon per se eine vermehrte Aktivierung zeigen.

Im Rahmen dieser Arbeit sowie der in Kapitel 1.4.2 beschriebenen tierexperimentellen Untersuchungen wurden außerdem unterschiedliche Methoden zur Validierung der Toxin-Wirkung eingesetzt. Es könnte sein, dass das im Rahmen dieser Arbeit entwickelte Laufradmodell einen Unterschied durch bessere Effektivität des Toxins nicht detektiert, den andere Methoden erkennen. Ebenso ist es möglich, dass Methoden wie die EMG (Kim et al. 2003), die dorsiflexion torque oder histologische Untersuchungen (Minamoto et al. 2007) Unterschiede auf muskulärer Ebene erkennen, die auf alltägliche motorische Abläufe keinen Einfluss haben und somit im Laufrad nicht erfasst werden. Darüber hinaus wurden mit Maus, Ratte und Kaninchen verschiedene Tiermodelle genutzt, und auch die Toxin-Dosis pro Muskel variierte (1,75 bzw. 3,5 MU/kg im Rahmen dieser Arbeit, 3,33-4 MU/kg bei Kim HS et al. 2003, $6 \mathrm{MU} / \mathrm{kg}$ bei Minamoto et al. 2007).

Unterschiede lassen sich auch in Umfang und Zeitpunkt der (neuro-)muskulären Aktivität nach den BoNT-Injektionen feststellen. Bereits durch 20 Minuten isometrische Kontraktionen oder passive Bewegung nach den Injektionen konnten Minamoto et al. 2007 einen signifikant besseren Toxin-Effekt erzielen. Daher könnte es sein, dass die Mäuse im Rahmen dieser Arbeit nach den morgendlichen Injektionen durch das Herumlaufen im Käfig und/oder durch minimale Laufradaktivität, die kurz nach den Injektionen noch vorhanden war, ausreichende Aktivität zeigten, um auch in dieser Gruppe die Effektivität des Toxins zu erhöhen. Da durch das Laufradmodell eine Erfassung zusätzlicher Laufaktivität im Käfig nicht erfolgt, sind diesbezügliche Aussagen nur eingeschränkt möglich. Auch muss beachtet werden, dass auch die morgens injizierten Tiere ca. 10-11 Stunden nach den Injektionen durch das Einsetzen 
des Dunkelzyklus eine gewohnt hohe Laufaktivität zeigten. Dies könnte trotz der längeren Latenzphase nach den Injektionen bereits einen Effekt haben, da auch andere Studien die Aktivierung der motorischen Endplatte durch elektrische Stimulation über einen Zeitraum von 24 Stunden bis zu mehreren Tagen nach den Injektionen durchführten und zu besseren Ergebnissen kamen als die Kontrollgruppen ohne neuromuskuläre Aktivierung (Bayram et al. 2006, Eleopra et al.1997, Frasson et al. 2005, Hesse et al. 1995).

Die These, dass die morgens injizierten Mäuse - entweder direkt nach den Injektionen oder in der folgenden Nacht - so viel Aktivität zeigten, dass diese bereits zu einer verbesserten BoNT-Wirkung führte und deshalb kein Unterschied zu den abends injizierten Tieren erkennbar war, könnte in einer weiteren Studie überprüft werden. Möglich wäre, eine Gruppe für 24 Stunden nach den Injektionen ohne Laufräder zu lassen. Eine längere Zeit ohne Laufräder wäre vermutlich nicht möglich, da es ansonsten durch eine zu lange Lauf-Pause auch Auswirkungen auf das darauf folgende Laufverhalten geben und somit zu einer Verfälschung der Daten kommen könnte.

\subsection{Schlussfolgerung und Ausblick}

In der vorliegenden Arbeit konnte ein Laufradmodell zur Analyse der Effekte niedrig-dosierter intramuskulärer BoNT-Injektionen entwickelt werden. Durch den Einsatz komplexer Laufräder sowie die Nutzung der relativen Vmax als wichtigsten Laufparameter kann eine hohe Sensitivität, Stabilität und Reproduzierbarkeit der Ergebnisse erreicht werden. Insbesondere letztere wird unter anderem durch eine objektive Messmethode ohne UntersucherAbhängigkeit gewährleistet. Da Toxin-Dosierungen verwendet werden, die mit therapeutischen Dosierungen vergleichbar sind, und auch das Injektionsverfahren der klinischen Anwendung sehr nahe kommt, ist ein praxisorientierter Einsatz und die Nutzung für klinisch relevante Fragestellungen möglich. Dabei ermöglicht die Methode neben einer Analyse der Toxin-Potenz auch Erkenntnisse zur Wirkungsdauer sowie zum Wirkungsverlauf.

Viele Vergleiche mit anderen Methoden und Vorteile des in dieser Arbeit entwickelten Laufradmodells wurden in den vorangegangenen Kapiteln bereits beschrieben. Tabelle 13 fasst die wichtigsten Aspekte der vergleichbaren In-vivo-Modelle noch einmal zusammen. Es wird deutlich, dass die Vorteile des Laufradmodells vor allem in der objektiven Messmethode, der Verhältnisskala und der Anwendung im Niedrigdosisbereich liegen. Durch die Messung des Einflusses des Toxins auf eine Alltagsaktivität, das Laufen, besteht durch die große Nähe zur klinischen Anwendung ein Vorteil gegenüber neurophysiologischen Messmethoden wie dem 
RMF-Assay, dem DAS-Assay, der dorsiflexion torque und dem Zehenspreiz-Reflex, die den Toxin-Effekt durch eine künstlich erzeugte Aktivität messen.

Die Grenzen der hier diskutierten Ergebnisse bzgl. der Vergleichbarkeit mit der klinischen Anwendung liegen vor allem in der Tatsache, dass bisher ausschließlich gesunde Mäuse verwendet wurden. Das trifft jedoch auch für die anderen dargestellten Methoden zu, die in den vergangenen Jahren entwickelt wurden.

Ein besonderer Fokus soll aufgrund der großen Ähnlichkeit der Methoden an dieser Stelle noch einmal zusammenfassend auf den Vergleich mit der Arbeit von Keller 2006 gelegt werden, wobei die einzelnen Aspekte teilweise bereits in den vorangegangenen Kapiteln erwähnt wurden. Zunächst muss festgestellt werden, dass aus der Veröffentlichung von Keller nicht hervor geht, ob Toxin in den M. gastrocnemius eines oder beider Beine injiziert wurde. Ebenso ist die Anzahl der Tiere der einzelnen Gruppen nicht klar ersichtlich. Darüber hinaus muss kritisch betrachtet werden, dass in der Arbeit von Keller immer zwei Mäuse in einem Käfig mit einem Laufrad untergebracht waren (Keller 2006). Dieses Vorgehen bedeutet, dass die Laufdaten immer bereits einen Mittelwert von zwei Tieren darstellen, was eine künstliche Reduktion der Varianz darstellt. Hinzu kommt die Nutzung unterschiedlicher Laufräder. Während Keller lediglich normale Laufräder mit regelmäßig angeordneten Streben verwendete, führt die Nutzung komplexer Laufräder im vorliegenden Modell zu einer höheren Sensitivität. So können niedrige Dosierungen zuverlässig analysiert worden. Es wird außerdem davon ausgegangen, dass dadurch insgesamt auch die Nutzung geringerer Tierzahlen möglich ist. Im Rahmen dieser Arbeit konnte darüber hinaus eindeutig gezeigt werden, dass die Vmax der von Keller genutzten Distanz als Analyseparameter deutlich überlegen ist und dass die Verwendung relativer, also prozentualer Daten, die Anwendbarkeit noch deutlich verbessert.

Neben dem Aspekt umfassenderer Analysemöglichkeiten der BoNT-Wirkung waren auch ethische Aspekte stets Teil der Debatte um die Entwicklung neuer Methoden zur Untersuchung von BoNT-Effekten (Adler S et al. 2010, Bitz 2010, Liebsch et al. 2011, Sesardic und Gaines Das 2008). Diese sollten nicht nur dann eine Rolle spielen, wenn es um Alternativen zum $\mathrm{LD}_{50}$-Tests geht. Die ethischen Ansprüche, die an Alternativmethoden zum $\mathrm{LD}_{50^{-}}$ Test gestellt werden, sollten auch bei Methoden zur BoNT-Analyse, die einen anderen funktionellen Anspruch haben, Beachtung finden.

Die in dieser Arbeit entwickelte Methode basiert auf Tierversuchen, was insbesondere für klinische Fragestellungen bisher in vielen Fällen nicht anders möglich ist (vgl. Kapitel 1.5.4). Auch wenn immer mehr In-vitro- (und auch Ex-vivo-) Methoden entwickelt werden (vgl. 
Kapitel 1.5.2 und 1.5.3), kommen diese durch die fehlende Beurteilbarkeit von Wirkungen im gesamten Organismus insbesondere bei Anwendungs- und pharmakokinetischen Fragestellungen an ihre Grenzen. Ein ethischer Vorteil des Laufradmodells im Vergleich zu anderen tierexperimentellen Methoden ist jedoch, dass durch die geringen Toxin-Mengen die Versuchstiere kaum beeinträchtigt werden. Bis auf die Injektionen, die in Narkose durchgeführt werden, ist kein „Handling“ der Tiere nötig, wie etwa bei all den Methoden, bei denen eine Manipulation am Tier Voraussetzung für eine Bewertung der Toxin-Wirkung ist (z.B. DAS-Assay, Zehenspreiz-Reflex, neurophysiologische Messungen wie bspw. der RMFAssay, dorsiflexion torque). Erst recht sind, abgesehen von der Injektion, die für alle Methoden notwendig ist, keinerlei invasive Maßnahmen notwendig. Durch die Möglichkeit der wiederholten Verwendung identischer Tiere können außerdem Tierzahlen gesenkt werden. Somit bietet das Laufradmodell auch aus ethischer Sicht viele Vorteile.

Aus den Ergebnissen dieser Arbeit ergeben sich vielfältige Einsatzmöglichkeiten für das Vmax-basierte BoNT-Laufradmodell. So lassen sich neue BoNT-Konstrukte sowohl auf ihre Potenz als auch auf ihre Wirkdauer sowie den Wirkungs- und Erholungsverlauf hin untersuchen. Auch Optimierungen des Injektionsverfahrens lassen sich aufgrund der großen Nähe des Modells zu klinischen Anwendungs- und Einsatzgebieten analysieren. Darüber hinaus ist der Einsatz für Krankheitsmodelle denkbar. Dieser Einsatzbereich wurde im Rahmen dieser Arbeit nicht untersucht und sollte Gegenstand künftiger Forschungsarbeiten sein. Die Grenze der Methode liegt hier allerdings in der Notwendigkeit einer ausreichenden Laufaktivität. Die Methode kann nur für Maus-Modelle von zu untersuchenden Krankheitsbildern angewandt werden, die über entsprechende motorische Fähigkeiten verfügen. Ob auch dann die relative Vmax den am besten geeigneten Parameter darstellt, wird sich in entsprechenden Untersuchungen zeigen müssen. Aber auch diesbezüglich bietet das Laufradmodell den Vorteil, dass durch die umfassende Laufanalyse die Eignung der einzelnen Laufparameter ohne zusätzlichen Aufwand für jedes Krankheitsmodell neu untersucht werden kann. 


\begin{tabular}{|c|c|c|c|c|c|c|c|c|}
\hline 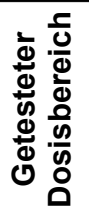 & 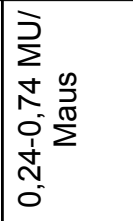 & 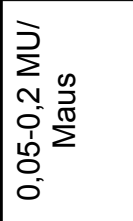 & 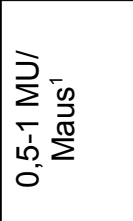 & 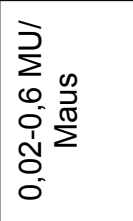 & 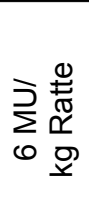 & 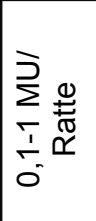 & 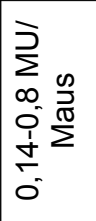 & 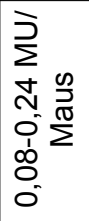 \\
\hline 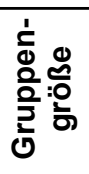 & $\stackrel{0}{\circ}$ & $\ddot{0}$ & 10 & $\stackrel{0}{\circ}$ & $\frac{0}{\frac{1}{b}}$ & $\begin{array}{l}0 \\
1 \\
\infty\end{array}$ & $m$ & $\frac{10}{\stackrel{1}{\prime}}$ \\
\hline$\stackrel{\grave{\Xi}}{=}$ & \begin{tabular}{|l}
$\frac{0}{\pi}$ \\
$\frac{\pi}{2}$
\end{tabular} & \begin{tabular}{|l}
0 \\
$\frac{0}{10}$ \\
$\frac{\pi}{2}$
\end{tabular} & \begin{tabular}{|l}
$\frac{0}{2}$ \\
$\frac{10}{20}$
\end{tabular} & 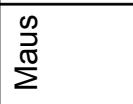 & 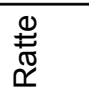 & 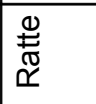 & \begin{tabular}{|l}
$\frac{0}{2}$ \\
$\frac{\pi}{20}$
\end{tabular} & \begin{tabular}{|l}
$\frac{0}{2}$ \\
$\frac{\pi}{10}$
\end{tabular} \\
\hline 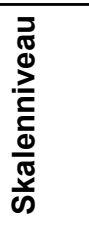 & 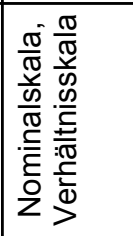 & 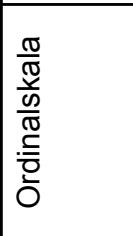 & 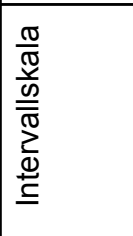 & 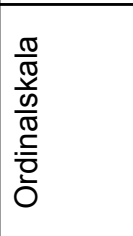 & 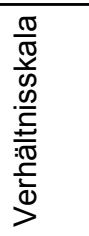 & 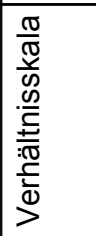 & 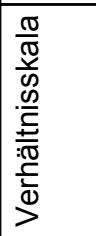 & 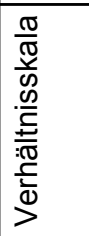 \\
\hline 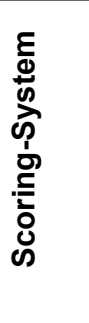 & 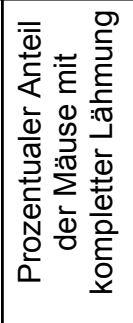 & 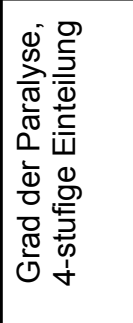 & 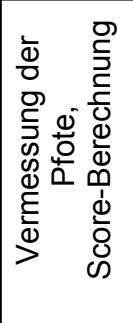 & 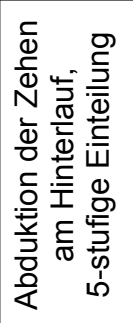 & 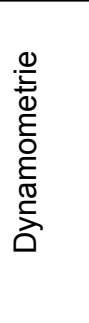 & 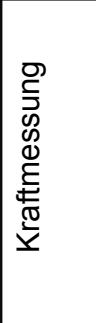 & 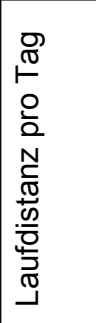 & 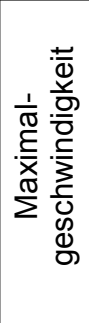 \\
\hline 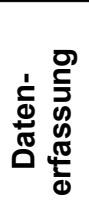 & 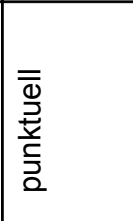 & 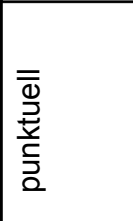 & 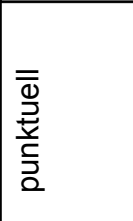 & 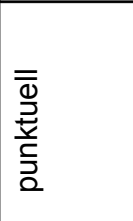 & 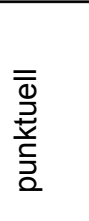 & 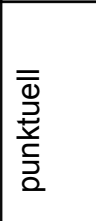 & 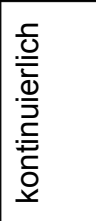 & 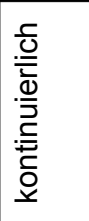 \\
\hline 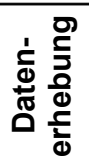 & \begin{tabular}{|l}
$\frac{2}{2}$ \\
$\frac{0}{0}$ \\
$\frac{0}{3}$ \\
$\omega$ \\
$\omega$
\end{tabular} & 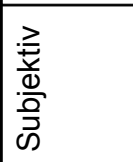 & $\frac{\frac{2}{\bar{v}}}{\frac{0}{0}}$ & 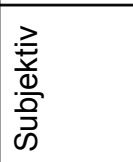 & $\frac{\frac{2}{\mathrm{v}}}{\frac{0}{0}}$ & $\frac{\frac{3}{\bar{v}}}{\frac{0}{\frac{0}{2}}}$ & 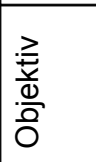 & 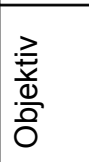 \\
\hline 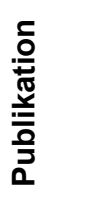 & 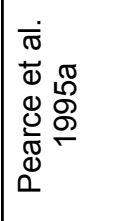 & 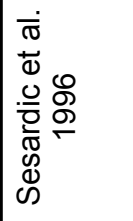 & 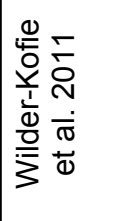 & 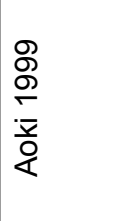 & 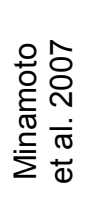 & 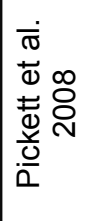 & 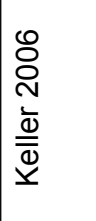 & \\
\hline 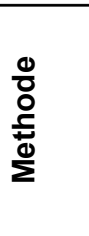 & $\frac{2}{2}$ & 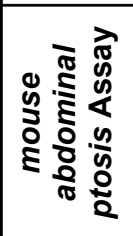 & 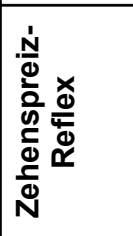 & 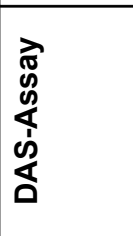 & 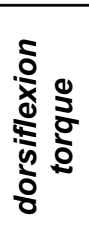 & 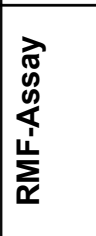 & 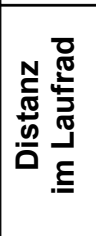 & 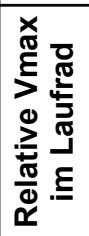 \\
\hline
\end{tabular}

Tabelle 13: In-vivo-Modelle zur Untersuchung der BoNT-Wirkung im Überblick. Darstellung der in dieser Arbeit entwickelten Methode im Vergleich mit vergleichbaren Modellen anhand relevanter Kriterien.

1 In diesem Bereich allerdings inkonsistente Ergebnisse.

2 Diese Zahl ist aufgrund der ausschließlichen Verwendung zur Potenzmessung unbekannter Toxinpräparate mit den anderen nur bedingt vergleichbar.

3 Geht aus Publikation nicht eindeutig hervor. 


\section{$5 \quad$ Zusammenfassung}

Botulinum-Neurotoxine werden zunehmend häufiger therapeutisch eingesetzt und für immer mehr Indikationen in der Therapie zugelassen. Entsprechend groß ist auch das Forschungsinteresse in diesem Bereich. Zur Wirksamkeitsoptimierung und Weiterentwicklung der pharmakologischen Präparate sind Untersuchungen mit engem Bezug zur klinischen Anwendung notwendig. Dieser Anspruch steht in einem ethischen Spannungsfeld zu dem Ansatz, Anzahl und Leiden von Versuchstieren zu reduzieren. Die Entwicklung neuer Methoden zur BoNT-Untersuchung und insbesondere die Abkehr vom $L_{50}$-Test sind daher ein wichtiger Baustein der aktuellen BoNT-Forschung.

In dieser Arbeit wurde ein Laufrad-basiertes Maus-Modell entwickelt, welches in der Lage ist, nach intramuskulärer Injektion von niedrig dosiertem BoNT die Wirkstärke und die Dauer des Toxin-Effekts sowie den Wirkungsverlauf zu beurteilen. Genutzt wird dabei die Veränderung der Maximalgeschwindigkeit in Bezug auf ein zuvor durch Training erreichtes Ausgangslevel. Hierfür wird freiwilliges Laufen in komplexen Laufrädern mit irregulär angeordneten Streben analysiert.

Mit der Methode werden alle Schritte der BoNT-Wirkung erfasst. Darüber hinaus besteht bezüglich der Dosierung und der Injektionslokalisation sowie dadurch, dass die gemessene motorische Aktivität einen physiologischen Bewegungsablauf des Tieres darstellt, eine große Nähe zu klinischen Fragestellungen. Auch der Effekt von BoNT bei Krankheitsmodellen könnte auf diese Art und Weise untersucht werden, solange den Tieren das Laufen im Laufrad möglich ist.

Die in dieser Arbeit gezeigte Reproduzierbarkeit und Stabilität der Methode bieten unter anderem den Vorteil, dass Versuchstiere mehrfach verwendet werden können und keine Abweichung durch Alters- oder Gewichtsunterschiede erwartet werden müssen. Die Einsetzbarkeit der Methode konnte am Beispiel einer klinisch relevanten Fragestellung demonstriert werden. So zeigte sich in dieser Arbeit im Gegensatz zu einigen anderen Studien kein Einfluss erhöhter neuromuskulärer Aktivität nach den Injektionen auf den Toxin-Effekt.

Trotz vielfältiger potentieller Einsatzmöglichkeiten stößt auch die in dieser Arbeit entwickelte Methode an Grenzen. Der Einsatz im Krankheitsmodell ist bisher nicht erprobt. Künftige Versuche müssen zeigen, unter welchen Bedingungen die Methode bei welchen Krankheitsmodellen sinnvoll einsetzbar ist. Für Fragestellungen ohne klinischen Bezug ist unter ethischen Gesichtspunkten außerdem die Weiterentwicklung von Ex-vivo-Modellen unabdingbar. Hinsichtlich klinischer Fragestellungen stellt das Laufradmodell aus ethischer Sicht im Vergleich zu anderen Verfahren jedoch eine deutliche Weiterentwicklung dar. 


\section{$6 \quad$ Literaturverzeichnis}

Adler M, MacDonald DA, Sellin LC, Parker GW (1996): Effect of 3, 4-diaminopyridine on rat extensor digitorum longus muscle paralyzed by local injection of botulinum neurotoxin. Toxicon $\underline{34}, 237-249$

Adler M, Keller JE, Sheridan RE, Deshpande SS (2001): Persistence of botulinum neurotoxin $A$ demonstrated by sequential administration of serotypes $A$ and $E$ in rat EDL muscle. Toxicon $\underline{39}$, 233-243

Adler S, Bicker G, Bigalke H, Bishop C, Blümel J, Dressler D, Fitzgerald J, Gessler F, Heuschen H, Kegel B (2010): The current scientific and legal status of alternative methods to the LD50 test for botulinum neurotoxin potency testing. The report and recommendations of a ZEBET Expert Meeting. Altern Lab Anim 38, 315-330

Allen DL, Harrison BC, Maass A, Bell ML, Byrnes WC, Leinwand LA (1985): Cardiac and skeletal muscle adap tations to voluntary wheel running in the mouse. J Appl Physiol $\underline{90}$, 1900-1908

Angaut-Petit D, Molgo J, Connold AL, Faille L (1987): The levator auris longus muscle of the mouse: a convenient preparation for studies of short- and long-term presynaptic effects of drugs or toxins. Neurosci Lett $\underline{82}, 83-88$

Angaut-Petit D, Molgó J, Comella JX, Faille L, Tabti N (1990): Terminal sprouting in mouse neuromuscular junctions poisoned with botulinum type A toxin: morphological and electrophysiological features. Neuroscience $\underline{37}, 799-808$

Aoki KR (1999): Preclinical update on BOTOX® (botulinum toxin type A)-purified neurotoxin complex relative to other botulinum neurotoxin preparations. Eur J Neurol $\underline{6}$ (suppl 4), 3-10

Aoki KR (2001): A comparison of the safety margins of botulinum neurotoxin serotypes $A, B$ and $\mathrm{F}$ in mice. Toxicon $\underline{39}$, 1815-1820

Aoki KR (2002): Botulinum neurotoxin serotypes A und B preparations have different safety margins in preclinical models of muscle weakening efficacy and systemic safety. Toxicon $\underline{40}$, 923-928

Atassi MZ (2004): Basic immunological aspects of botulinum toxin therapy. Mov Disord 19 (suppl 8), 68-84

Auguet M, Favre-Guilmard C, Cornet S, Carre D, Rocher MN, Pignol B, Pham B, Chabrier PE (2011): Effects of Botulinum toxin type A on Digit Abduction Score and running wheel assays and assessment of diffusion using calcium-activated potassium channel expression. Poster presented at Toxins 2011, $7^{\text {th }}$ International Conference on Basic and Therapeutic Aspects of Botulinum and Tetanus Toxins, 02.-05.10.2011, Santa Fe, New Mexico, USA

Aurora SK, Dodick DW, Turkel CC, DeGryse RE, Silberstein SD, Lipton RB, Diener HC, Brin MF; PREEMPT 1 Chronic Migraine Study Group (2010): OnabotulinumtoxinA for treatment of chronic migraine: results from the double-blind, randomized, placebo-controlled phase of the PREEMPT 1 trial. Cephalalgia 30, 793-803

Bagramyan K, Kaplan BE, Cheng LW, Strotmeier J, Rummel A, Kalkum M (2013): Substrates and controls for the quantitative detection of active botulinum neurotoxin in protease-containing samples. Anal Chem $\underline{85}, 5569-5576$ 
Bajjalieh SM, Scheller RH (1995): The biochemistry of neurotransmitter secretion. J Biol Chem 270, 1971-1974

Balls M, Straughan DW (1996): The three Rs of Russell \& Burch and the testing of biological products. Dev Biol Stand $\underline{86}, 11-18$

Bayram S, Sivrioglu K, Karli N, Ozcan O (2006): Low-dose botulinum toxin with short-term electrical stimulation in poststroke spastic drop foot: a preliminary study. Am J Phys Med Rehabil $\underline{85}, 75-81$

Benecke R (2012): Clinical relevance of botulinum toxin immunogenicity. BioDrugs $\underline{26}$, e1-e9

Bennett MK, Calakos N, Kreiner T, Scheller RH (1992): Synaptic vesicle membrane proteins interact to form a multimeric complex. J Cell Biol $\underline{116}, 761-775$

Berlit P: Memorix Neurologie. 5. Auflage; Georg Thieme Verlag KG, Stuttgart 2009

Bijvoet AG, Van Hirtum H, Vermey M, Van Leenen D, Van Der Ploeg AT, Mooi WJ, Reuser AJ (1999): Pathological features of glycogen storage disease type II highlighted in the knockout mouse model. J Pathol 189 , 416-424

Bitz S (2010): The botulinum neurotoxin LD50 test - problems and solutions. ALTEX 27, 114116

Bjornson K, Hays R, Graubert C, Price R, Won F, McLaughlin JF, Cohen M (2007): Botulinum toxin for spasticity in children with cerebral palsy: a comprehensive evaluation. Pediatrics 120, 49-58

Black JD, Dolly JO (1986): Interaction of 125I-labeled botulinum neurotoxins with nerve terminals. II. Autoradiographic evidence for its uptake into motor nerves by acceptor-mediated endocytosis. J Cell Biol 103, 535-544

Blasi J, Chapman ER, Link E, Binz T, Yamasaki S, De Camilli P, Südhof TC, Niemann H, Jahn R (1993): Botulinum neurotoxin A selectively cleaves the synaptic protein SNAP-25. Nature $\underline{365}, 160-163$

Blaustein RO, Germann WJ, Finkelstein A, DasGupta BR (1987): The N-terminal half of the heavy chain of botulinum type A neurotoxin forms channels in planar phospholipid bilayers. FEBS Lett 226, 115-120

Billante CR, Zealear DL, Billante M, Reyes JH, Sant'Anna G, Rodriguez R, Stone RE Jr (2002): Comparison of neuromuscular blockade and recovery with botulinum toxins $A$ and $F$. Muscle Nerve 26, 395-403

Bjornson K, Hays R, Graubert C, Price R, Won F, McLaughlin JF, Cohen M (2007): Botulinum toxin for spasticity in children with cerebral palsy: a comprehensive evaluation. Pediatrics $\underline{120}$, 49-58

Brin MF, Lew MF, Adler CH, Comella CL, Factor SA, Jankovic J, O'Brien C, Murray JJ, Wallace JD, Willmer-Hulme A (1999): Safety and efficacy of NeuroBloc (botulinum toxin type B) in type A-resistant cervical dystonia. Neurology $\underline{53}, 1431-1438$

Brin MF, Comella CL, Jankovic J, Lai F, Naumann M; CD-017 BoNTA Study Group (2008): Long-term treatment with botulinum toxin type $A$ in cervical dystonia has low immunogenicity by mouse protection assay. Mov Disord 23, 1353-1360 
Broide RS, Rubino J, Nicholson GS, Ardila MC, Brown MS, Aoki KR, Francis J (2013): The rat Digit Abduction Score (DAS) assay: a physiological model for assessing botulinum neurotoxin-induced skeletal muscle paralysis. Toxicon $\underline{71}, 18-24$

Bronfenbrenner JJ, Weiss H (1924): The effect of anesthesia and of sedatives on the serum therapy of experimental botulism. J Exp Med $\underline{39}, 517-532$

Bushara KO, Park DM, Jones JC, Schutta HS (1996): Botulinum toxin--a possible new treatment for axillary hyperhidrosis. Clin Exp Dermatol 21, 276-178

Cameron MH, Bethoux F, Davis N, Frederick M (2014): Botulinum toxin for symptomatic therapy in multiple sclerosis. Curr Neurol Neurosci Rep 14, 463

Caron G, Rouzi T, Grelot L, Magalon G, Marqueste T, Decherchi P (2014): Mechano- and metabosensitive alterations after injection of botulinum toxin into gastrocnemius muscle. $\mathrm{J}$

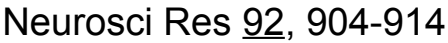

Chen CM, Stott NS, Smith HK (2002): Effects of botulinum toxin A injection and exercise on the growth of juvenile rat gastrocnemius muscle. J Appl Physiol $\underline{93}, 1437-1447$

Chen R, Karp BI, Goldstein SR, Bara-Jimenez W, Yaseen Z, Hallett M (1999): Effect of muscle activity immediately after botulinum toxin injection for writer's cramp. Mov Disord 14 , 307-312

Chen S (2012): Clinical uses of botulinum neurotoxins: current indications, limitations and future developments. Toxins (Basel) 4, 913-939

Cichon JV Jr, McCaffrey TV, Litchy WJ, Knops JL (1995): The effect of botulinum toxin type A injection on compound muscle action potential in an in vivo rat model. Laryngoscope $\underline{105}$, 144-148

Clark AW, Bandyopadhyay S, DasGupta BR (1987): The plantar nerves-lumbrical muscles: a useful nerve-muscle preparation for assaying the effects of botulinum neurotoxin. $J$ Neurosci Methods $\underline{19}$, 285-295

Council of Europe, European Pharmacopoeia Commission: European Pharmacopoeia. 8. Auflage; Council of Europe, Strasbourg 2014

Cull-Candy SG, Lundh H, Thesleff S (1976): Effects of botulinum toxin on neuromuscular transmission in the rat. J Physiol 260, 177-203

de Paiva A, Ashton AC, Foran P, Schiavo G, Montecucco C, Dolly JO (1993): Botulinum A like type $B$ and tetanus toxins fulfils criteria for being a zinc-dependent protease. $J$ Neurochem $\underline{61}, 2338-2341$

de Paiva A, Meunier FA, Molgó J, Aoki KR, Dolly JO (1999): Functional repair of motor endplates after botulinum neurotoxin type A poisoning: biphasic switch of synaptic activity between nerve sprouts and their parent terminals. Proc Natl Acad Sci U S A 96, 3200-3205

Diener HC, Dodick DW, Aurora SK, Turkel CC, DeGryse RE, Lipton RB, Silberstein SD, Brin MF; PREEMPT 2 Chronic Migraine Study Group (2010): OnabotulinumtoxinA for treatment of chronic migraine: results from the double-blind, randomized, placebo-controlled phase of the PREEMPT 2 trial. Cephalalgia 30, 804-814

Dodd SL, Selsby J, Payne A, Judge A, Dott C (2005): Botulinum neurotoxin type A causes shifts in myosin heavy chain composition in muscle. Toxicon $\underline{46}, 196-203$ 
Doellgast GJ, Triscott MX, Beard GA, Bottoms JD, Cheng T, Roh BH, Roman MG, Hall PA, Brown JE (1993): Sensitive enzyme-linked immunosorbent assay for detection of Clostridium botulinum neurotoxins $A, B$, and $E$ using signal amplification via enzyme-linked coagulation assay. J Clin Microbiol 31, 2402-2409

Dolly JO, Black J, Williams RS, Melling J (1984): Acceptors for botulinum neurotoxin reside on motor nerve terminals and mediate its internalization. Nature $\underline{307}, 457-460$

Dong M, Yeh F, Tepp WH, Dean C, Johnson EA, Janz R, Chapman ER (2006): SV2 is the protein receptor for botulinum neurotoxin A. Science $\underline{312}, 592-596$

Dong M, Liu H, Tepp WH, Johnson EA, Janz R, Chapman ER (2008): Glycosylated SV2A and SV2B mediate the entry of botulinum neurotoxin E into neurons. Mol Biol Cell 19, 52265237

Donovan JJ, Middlebrook JL (1986): Ion-conducting channels produced by botulinum toxin in planar lipid membranes. Biochemistry $\underline{25}, 2872-2876$

Dover N, Barash JR, Hill KK, Xie G, Arnon SS (2014): Molecular characterization of a novel botulinum neurotoxin type H gene. J Infect Dis $\underline{209}$, 192-202

Dowling P, Klinker F, Stadelmann C, Hasan K, Paulus W, Liebetanz D (2011): Dopamine D3 receptor specifically modulates motor and sensory symptoms in iron-deficient mice. J Neurosci $31,70-77$

Dressler D (2002): Clinical features of antibody-induced complete secondary failure of botulinum toxin therapy. Eur Neurol $\underline{48}, 26-29$

Dressler D (2004): Clinical presentation and management of antibody-induced failure of botulinum toxin therapy. Mov Disord 19 (suppl 8), S92-S100

Dressler D (2012): Five-year experience with incobotulinumtoxinA (Xeomin(®) ): the first botulinum toxin drug free of complexing proteins. Eur J Neurol 19, 385-389

Dressler D, Benecke R (2004): Autonomic side effects of botulinum toxin type B therapy. Adv Neurol $\underline{94}, 315-320$

Dressler D, Hallett M (2006): Immunological aspects of Botox, Dysport and Myobloc/NeuroBloc. Eur J Neurol 13 Suppl 1, 11-5

Dressler D, Bigalke H, Benecke R (2003): Botulinum toxin type B in antibody-induced botulinum toxin type A therapy failure. J Neurol 250, 967-969. Corrected and republished in J Neurol 250, 1263-1265

Duchen LW (1971): Changes in the electron microscopic structure of slow and fast skeletal muscle fibres of the mouse after the local injection of botulinum toxin. J Neurol Sci 14, 61-74

Duchen LW, Strich SJ (1968): The effects of botulinum toxin on the pattern of innervation of skeletal muscle in the mouse. Q J Exp Physiol Cogn Med Sci $\underline{53}$, 84-89

Dunning FM, Ruge DR, Piazza TM, Stanker LH, Zeytin FN, Tucker WC (2012): Detection of botulinum neurotoxin serotype $A, B$, and $F$ proteolytic activity in complex matrices with picomolar to femtomolar sensitivity. Appl Environ Microbiol 78, 7687-7697

Ekong TA, Feavers IM, Sesardic D (1997): Recombinant SNAP-25 is an effective substrate for Clostridium botulinum type A toxin endopeptidase activity in vitro. Microbiology 143, 33373347 
Eleopra R, Tugnoli V, de Grandis D (1997): The variability in the clinical effect induced by botulinum toxin type A: the role of muscle activity in humans. Mov Disord 12, 89-94

Eleopra R, Tugnoli V, Rossetto O, De Grandis D, Montecucco C (1998): Different time courses of recovery after poisoning with botulinum neurotoxin serotypes $A$ and $E$ in humans. Neurosci Lett 256, 135-138

Elwischger K, Kasprian G, Weber M, Meyerspeer M, Linder C, Auff E, Prayer D, Sycha T, Kranz G (2014): Intramuscular distribution of botulinum toxin--visualized by MRI. J Neurol Sci $\underline{344}, 76-79$

Fernández-Salas E, Ho H, Garay P, Steward LE, Aoki KR (2004): Is the light chain subcellular localization an important factor in botulinum toxin duration of action? Mov Disord 19 (suppl 8), S23-S34

Fernández-Salas E, Wang J, Molina Y, Nelson JB, Jacky BP, Aoki KR (2014): Botulinum neurotoxin serotype A specific cell-based potency assay to replace the mouse bioassay. PLoS One $\underline{7}$, e49516

Foran PG, Mohammed N, Lisk GO, Nagwaney S, Lawrence GW, Johnson E, Smith L, Aoki KR, Dolly JO (2003): Evaluation of the therapeutic usefulness of botulinum neurotoxin $B, C 1$, $\mathrm{E}$, and $\mathrm{F}$ compared with the long lasting type A. Basis for distinct durations of inhibition of exocytosis in central neurons. J Biol Chem $\underline{278}, 1363-1371$

Frasson E, Priori A, Ruzzante B, Didonè G, Bertolasi L (2005): Nerve stimulation boosts botulinum toxin action in spasticity. Mov Disord 20, 624-629

Frevert J (2015): Pharmaceutical, biological, and clinical properties of botulinum neurotoxin type A products. Drugs R D $\underline{15}, 1-9$

Frick CG, Richtsfeld M, Sahani ND, Kaneki M, Blobner M, Martyn JA (2007): Long-term effects of botulinum toxin on neuromuscular function. Anesthesiology 106, 1139-1146

Frueh BR, Felt DP, Wojno TH, Musch DC (1984): Treatment of blepharospasm with botulinum toxin. A preliminary report. Arch Ophthalmol $\underline{102}, 1464-1468$

Fu Z, Chen C, Barbieri JT, Kim JJ, Baldwin MR (2009): Glycosylated SV2 and gangliosides as dual receptors for botulinum neurotoxin serotype F. Biochemistry $\underline{48}, 5631-5641$

Galloux M, Vitrac H, Montagner C, Raffestin S, Popoff MR, Chenal A, Forge V, Gillet D (2008): Membrane Interaction of botulinum neurotoxin A translocation (T) domain. The belt region is a regulatory loop for membrane interaction. J Biol Chem $\underline{283}, 27668-27676$

Giess R, Naumann M, Werner E, Riemann R, Beck M, Puls I, Reiners C, Toyka KV (2000): Injections of botulinum toxin $A$ into the salivary glands improve sialorrhoea in amyotrophic lateral sclerosis. J Neurol Neurosurg Psychiatry $\underline{69}, 121-123$

Gill DM (1982): Bacterial toxins: a table of lethal amounts. Microbiol Rev $\underline{46}, 86-94$

Giovannelli M, Borriello G, Castri P, Prosperini L, Pozzilli C (2007): Early physiotherapy after injection of botulinum toxin increases the beneficial effects on spasticity in patients with multiple sclerosis. Clin Rehabil 21, 331-337

Glocker FX, Guschlbauer B, Lücking CH, Deuschl G (1995): Effects of local injections of botulinum toxin on electrophysiological parameters in patients with hemifacial spasm: role of synaptic activity and size of motor units. Neurosci Lett 187, 161-164 
Göschel H, Wohlfarth K, Frevert J, Dengler R, Bigalke H (1997): Botulinum A toxin therapy: neutralizing and nonneutralizing antibodies--therapeutic consequences. Exp Neurol 147, 96102

Greene P, Fahn S, Diamond B (1994): Development of resistance to botulinum toxin type A in patients with torticollis. Mov Disord $\underline{9}, 213-217$

Gregory RW, Werner WE, Ruegg C (2014): A quantitative bifunctional in vitro potency assay for botulinum neurotoxin serotype A. J Pharmacol Toxicol Methods $\underline{69}$, 103-107

Guo J, Pan X, Zhao Y, Chen S (2013): Engineering Clostridia Neurotoxins with elevated catalytic activity. Toxicon $\underline{74}, 158-166$

Hallis B, James BA, Shone CC (1996): Development of novel assays for botulinum type A and B neurotoxins based on their endopeptidase activities. J Clin Microbiol 34, 1934-1938

Hara H, Nolan PM, Scott MO, Bucan M, Wakayama Y, Fischbeck KH (2002): Running endurance abnormality in mdx mice. Muscle Nerve 25, 207-211

Hassan SM, Jennekens FG, Veldman H (1995): Botulinum toxin-induced myopathy in the rat. Brain 118, 533-545

Hefter H, Spiess C, Rosenthal D (2014): Very early reduction in efficacy of botulinum toxin therapy for cervical dystonia in patients with subsequent secondary treatment failure: a retrospective analysis. J Neural Transm 121, 513-519

Herrmann J, Geth K, Mall V, Bigalke H, Schulte Mönting J, Linder M, Kirschner J, Berweck S, Korinthenberg R, Heinen F, Fietzek UM (2004): Clinical impact of antibody formation to botulinum toxin A in children. Ann Neurol $\underline{55}, 732-735$

Hesse S, Jahnke MT, Luecke D, Mauritz KH (1995): Short-term electrical stimulation enhances the effectiveness of Botulinum toxin in the treatment of lower limb spasticity in hemiparetic patients. Neurosci Lett 201, 37-40

Hesse S, Reiter F, Konrad M, Jahnke MT (1998): Botulinum toxin type A and short-term electrical stimulation in the treatment of upper limb flexor spasticity after stroke: a randomized, double-blind, placebo-controlled trial. Clin Rehabil 12, 381-388

Hickey MA, Gallant K, Gross GG, Levine MS, Chesselet MF (2005): Early behavioral deficits in R6/2 mice suitable for use in preclinical drug testing. Neurobiol Dis $\underline{20}, 1-11$

Hoch DH, Romero-Mira M, Ehrlich BE, Finkelstein A, DasGupta BR, Simpson LL (1985): Channels formed by botulinum, tetanus, and diphtheria toxins in planar lipid bilayers: relevance to translocation of proteins across membranes. Proc Natl Acad Sci U S A $\underline{82}$, 1692-1696

Houser MK, Sheean GL, Lees AJ (1998): Further studies using higher doses of botulinum toxin type $F$ for torticollis resistant to botulinum toxin type A. J Neurol Neurosurg Psychiatry $\underline{64}, 577-580$

Huber A, France RM, Riccalton-Banks L, McLaren J, Cox H, Quirk RA, Shakesheff KM, Thompson D, Panjwani N, Shipley S (2008): The Intercostal NMJ Assay: a new alternative to the conventional LD50 assay for the determination of the therapeutic potency of botulinum toxin preparations. Altern Lab Anim $\underline{36}, 141-152$ 
Hughes R, Whaler BD (1962): Influence of nerve-ending activity and of drugs on the rate of paralysis of rat diaphragm preparations by $\mathrm{Cl}$. botulinum type A toxin. J Physiol $\underline{160}, 221-$ 233

Hulst JB, Minamoto VB, Lim MB, Bremner SN, Ward SR, Lieber RL (2014): Systematic test of neurotoxin dose and volume on muscle function in a rat model. Muscle Nerve $\underline{49}, 709-715$

Jankovic J, Orman J (1987): Botulinum A toxin for cranial-cervical dystonia: a double-blind, placebo-controlled study. Neurology $\underline{37}, 616-623$

Jankovic J, Schwartz K (1995): Response and immunoresistance to botulinum toxin injections. Neurology $\underline{45}, 1743-1746$

Jann B: Einführung in die Statistik (Hand- Und Lehrbücher Der Sozialwissenschaften). 2. Auflage; Oldenbourg Wissenschaftsverlag, München 2005

Jenzer G, Mumenthaler M, Ludin HP, Robert F (1975): Autonomic dysfunction in botulism B: a clinical report. Neurology $\underline{25}, 150-153$

Juzans P, Comella JX, Molgo J, Faille L, Angaut-Petit D (1996): Nerve terminal sprouting in botulinum type-A treated mouse levator auris longus muscle. Neuromuscul Disord $\underline{6}, 177-$ 185

Kaji R, Osako Y, Suyama K, Maeda T, Uechi Y, Iwasaki M; GSK1358820 Spasticity Study Group (2010): Botulinum toxin type A in post-stroke lower limb spasticity: a multicenter, double-blind, placebo-controlled trial. J Neurol 257, 1330-1337

Karalewitz AP, Fu Z, Baldwin MR, Kim JJ, Barbieri JT (2012): Botulinum neurotoxin serotype $\mathrm{C}$ associates with dual ganglioside receptors to facilitate cell entry. J Biol Chem 287, 4080640816

Keller JE (2006): Recovery from Botulinum Neurotoxin Poisoning in vivo. Neuroscience 139, 629-637

Keller JE, Neale EA, Oyler G, Adler M (1999): Persistence of botulinum neurotoxin action in cultured spinal cord cells. FEBS Lett $\underline{456}, 137-142$

Kessler KR, Skutta M, Benecke R (1999): Long-term treatment of cervical dystonia with botulinum toxin A: efficacy, safety, and antibody frequency. German Dystonia Study Group. J Neurol $\underline{246}, 265-274$

Kinnett D (2004): Botulinum toxin A injections in children: technique and dosing issues. Am J Phys Med Rehabil 83, S59-S64

Kim HS, Hwang JH, Jeong ST, Lee YT, Lee PK, Suh YL, Shim JS (2003): Effect of muscle activity and botulinum toxin dilution volume on muscle paralysis. Dev Med Child Neurol $\underline{45}$, 200-206

Kim SH, Kim SB, Yang GH, Rhee CH (2012): Mouse compound muscle action potential assay: an alternative method to conduct the LD50 botulinum toxin type A potency test. Toxicon $\underline{60}, 341-347$

Kitahara Y, Maki T, Torii K (1997): Development of degenerative muscle weakness by chronic administration of beta, beta'-iminodipropionitrile in the drinking water to rats: a model for motorneuropathy. Physiol Behav $\underline{62}, 443-451$ 
Klinker F, Hasan K, Paulus W, Nitsche MA, Liebetanz D (2013): Pharmacological blockade and genetic absence of the dopamine D2 receptor specifically modulate voluntary locomotor activity in mice. Behav Brain Res 242, 117-124

Koh C, Schaff UY, Piccini ME, Stanker LH, Cheng LW, Ravichandran E, Singh BR, Sommer GJ, Singh AK (2015): Centrifugal Microfluidic Platform for Ultra-sensitive Detection of Botulinum Toxin. Anal Chem 87, 922-928

Koman LA, Mooney JF 3rd, Smith B, Goodman A, Mulvaney T (1993): Management of cerebral palsy with botulinum-A toxin: preliminary investigation. J Pediatr Orthop $\underline{13}, 489-495$

Koriazova LK, Montal M (2003): Translocation of botulinum neurotoxin light chain protease through the heavy chain channel. Nat Struct Biol 10, 13-18

Kroken AR, Karalewitz AP, Fu Z, Baldwin MR, Kim JJ, Barbieri JT (2011): Unique ganglioside binding by botulinum neurotoxins $C$ and D-SA. FEBS J $\underline{278}$, 4486-4496

Kukreja R, Chang TW, Cai S, Lindo P, Riding S, Zhou Y, Ravichandran E, Singh BR (2009): Immunological characterization of the subunits of type A botulinum neurotoxin and different components of its associated proteins. Toxicon $\underline{53}, 616-624$

Kutschenko A, Reinert MC, Klinker F, Paulus W, Hesse S, Liebetanz D (2011): Botulinum toxin-induced focal paresis in mice is unaffected by muscle activity. Muscle Nerve $44,930-$ 936

Kutschenko A, Reinert MC, Klinker F, Paulus W, Hesse S, Liebetanz D (2012): Accurate quantification of tetanus neurotoxin-induced focal spasticity in mice using complex running wheels. J Neurosci Methods 205, 45-48

Kutschenko A, Manig A, Reinert MC, Mönnich A, Liebetanz D (2016): In-vivo comparison of the neurotoxic potencies of incobotulinumtoxinA, onabotulinumtoxinA, and abobotulinumtoxinA. Neuroscience Lett $\underline{627}, 216-221$

Lange O, Bigalke H, Dengler R, Wegner F, deGroot M, Wohlfarth K (2009): Neutralizing antibodies and secondary therapy failure after treatment with botulinum toxin type A: much ado about nothing? Clin Neuropharmacol $\underline{32}$, 213-218

Lawrence G, Wang J, Chion CK, Aoki KR, Dolly JO (2007): Two protein trafficking processes at motor nerve endings unveiled by botulinum neurotoxin E. J Pharmacol Exp Ther $\underline{320}, 410-$ 418

Legerlotz K, Matthews KG, McMahon CD, Smith HK (2009): Botulinum toxin-induced paralysis leads to slower myosin heavy chain isoform composition and reduced titin content in juvenile rat gastrocnemius muscle. Muscle Nerve 39, 472-479

Lévêque C, Ferracci G, Maulet Y, Grand-Masson C, Blanchard MP, Seagar M, El Far O (2013): A substrate sensor chip to assay the enzymatic activity of Botulinum neurotoxin $A$. Biosens Bioelectron 49, 276-281

Lew MF, Adornato BT, Duane DD, Dykstra DD, Factor SA, Massey JM, Brin MF, Jankovic J, Rodnitzky RL, Singer C (1997): Botulinum toxin type B: a double-blind, placebo-controlled, safety and efficacy study in cervical dystonia. Neurology $\underline{49}, 701-707$

Liebetanz D, Merkler D (2006): Effects of commissural de- and remyelination on motor skill behaviour in the cuprizone mouse model of multiple sclerosis. Exp Neurol 202, 217-224 
Liebetanz D, Hagemann K, von Lewinski F, Kahler E, Paulus W (2004): Extensive exercise is not harmful in amyotrophic lateral sclerosis. Eur J Neurosci $\underline{20}, 3115-3120$

Liebetanz D, Baier PC, Paulus W, Meuer K, Bähr M, Weishaupt JH (2007): A highly sensitive automated complex running wheel test to detect latent motor deficits in the mouse MPTP model of Parkinson's disease. Exp Neurol 205, 207-213

Liebetanz D, Gerber J, Schiffner C, Schütze S, Klinker F, Jarry H, Nau R, Tauber SC (2012): Pre-infection physical exercise decreases mortality and stimulates neurogenesis in bacterial meningitis. J Neuroinflammation $\underline{9}, 168$

Liebsch M, Grune B, Seiler A, Butzke D, Oelgeschläger M, Pirow R, Adler S, Riebeling C, Luch A (2011): Alternatives to animal testing: current status and future perspectives. Arch Toxicol $\underline{85}, 841-858$

Lim EC, Seet RC (2008): Botulinum toxin: description of injection techniques and examination of controversies surrounding toxin diffusion. Acta Neurol Scand 117, 73-84

Liu YY, Rigsby P, Sesardic D, Marks JD, Jones RG (2012): A functional dual-coated (FDC) microtiter plate method to replace the botulinum toxin LD50 test. Anal Biochem $\underline{425}, 28-35$

Lukban MB, Rosales RL, Dressler D (2009): Effectiveness of botulinum toxin A for upper and lower limb spasticity in children with cerebral palsy: a summary of evidence. J Neural Transm 116, 319-331

Ma J, Elsaidi GA, Smith TL, Walker FO, Tan KH, Martin E, Koman LA, Smith BP (2004): Time course of recovery of juvenile skeletal muscle after botulinum toxin $A$ injection: an animal model study. Am J Phys Med Rehabil $\underline{83}$, 774-780

Masuyer G, Chaddock JA, Foster KA, Acharya KR (2014): Engineered botulinum neurotoxins as new therapeutics. Annu Rev Pharmacol Toxicol $\underline{54}$, 27-51

Midura TF (1996): Update: infant botulism. Clin Microbiol Rev $\underline{9}, 119-125$

Miles AA (1951): Biological standards and the measurement of therapeutic activity. Br Med Bull $\underline{7}, 283-291$

Minamoto VB, Hulst JB, Lim M, Peace WJ, Bremner SN, Ward SR, Lieber RL (2007): Increased efficacy and decreased systemic-effects of botulinum toxin $A$ injection after active or passive muscle manipulation. Dev Med Child Neurol 49, 907-914

Mohammadi B, Buhr N, Bigalke H, Krampfl K, Dengler R, Kollewe K (2009): A long-term follow-up of botulinum toxin A in cervical dystonia. Neurol Res $\underline{31}, 463-466$

Montal M (2009): Translocation of botulinum neurotoxin light chain protease by the heavy chain protein-conducting channel. Toxicon $\underline{54}, 565-569$

Montecucco C (1986): How do tetanus and botulinum toxins bind to neuronal membranes? Trends Biochem Sci 11, 314-317

Morbiato L, Carli L, Johnson EA, Montecucco C, Molgó J, Rossetto O (2007): Neuromuscular paralysis and recovery in mice injected with botulinum neurotoxins $A$ and $\mathrm{C}$. Eur $\mathrm{J}$ Neurosci $\underline{25}, 2697-2704$

Müller K, Mix E, Adib Saberi F, Dressler D, Benecke R (2009): Prevalence of neutralising antibodies in patients treated with botulinum toxin type A for spasticity. J Neural Transm $\underline{116}$, $579-585$ 
Muraro L, Tosatto S, Motterlini L, Rossetto O, Montecucco C (2009): The N-terminal half of the receptor domain of botulinum neurotoxin $A$ binds to microdomains of the plasma membrane. Biochem Biophys Res Commun 380, 76-80

Naumann M, Carruthers A, Carruthers J, Aurora SK, Zafonte R, Abu-Shakra S, Boodhoo T, Miller-Messana MA, Demos G, James L (2010): Meta-analysis of neutralizing antibody conversion with onabotulinumtoxinA (BOTOX®) across multiple indications. Mov Disord $\underline{25}$, 2211-2218

Nishiki T, Kamata Y, Nemoto Y, Omori A, Ito T, Takahashi M, Kozaki S (1994): Identification of protein receptor for Clostridium botulinum type B neurotoxin in rat brain synaptosomes. $\mathrm{J}$ Biol Chem 269, 10498-10503

Notermans S, Dufrenne J, Kozaki S (1979): Enzyme-linked immunosorbent assay for detection of Clostridium botulinum type E toxin. Appl Environ Microbiol 37, 1173-1175

Ochs G: Die Behandlung der schweren Spastizität: Baclofen intrathecal - Botulinumtoxin Leitfaden für die praktische Anwendung. 2. Auflage; Georg Thieme Verlag, Stuttgart 2004

Ouimet T, Duquesnoy S, Poras H, Fournié-Zaluski MC, Roques BP (2013): Comparison of fluorigenic peptide substrates PL50, SNAPTide, and BoTest A/E for BoNT/A detection and quantification: exosite binding confers high-assay sensitivity. J Biomol Screen 18, 726-735

Pal PK, Calne DB, Calne S, Tsui JK (2000): Botulinum toxin A as treatment for drooling saliva in PD. Neurology $\underline{54}, 244-247$

Pearce LB, Borodic GE, Johnson EA, First ER, MacCallum R (1995a): The median paralysis unit: a more pharmacologically relevant unit of biologic activity for botulinum toxin. Toxicon $\underline{33}, 217-227$

Pearce LB, First ER, Borodic GE (1995b): Botulinum toxin: death versus localized denervation. J R Soc Med $\underline{88}$, 239-240

Pellett S (2013): Progress in cell based assays for botulinum neurotoxin detection. Curr Top Microbiol Immunol $\underline{364}$, 257-285

Pellett S, Tepp WH, Toth SI, Johnson EA (2010): Comparison of the primary rat spinal cord cell (RSC) assay and the mouse bioassay for botulinum neurotoxin type A potency determination. J Pharmacol Toxicol Methods $\underline{61}, 304-310$

Pellett S, Du ZW, Pier CL, Tepp WH, Zhang SC, Johnson EA (2011): Sensitive and quantitative detection of botulinum neurotoxin in neurons derived from mouse embryonic stem cells. Biochem Biophys Res Commun 404, 388-392

Peng L, Tepp WH, Johnson EA, Dong M (2011): Botulinum neurotoxin D uses synaptic vesicle protein SV2 and gangliosides as receptors. PLoS Pathog 7, e1002008

Peng L, Berntsson RP, Tepp WH, Pitkin RM, Johnson EA, Stenmark P, Dong M (2012): Botulinum neurotoxin D-C uses synaptotagmin I and II as receptors, and human synaptotagmin II is not an effective receptor for type B, D-C and G toxins. J Cell Sci $\underline{125}$, 3233-3242

Peters D, Barash IA, Burdi M, Yuan PS, Mathew L, Fridén J, Lieber RL (2003): Asynchronous functional, cellular and transcriptional changes after a bout of eccentric exercise in the rat. J Physiol $\underline{553}$, 947-957 
Pickett A, O'Keeffe R, Judge A, Dodd S (2008): The in vivo rat muscle force model is a reliable and clinically relevant test of consistency among botulinum toxin preparations. Toxicon $\underline{52}$, 455-464

Porte M, Chaléat-Valayer E, Patte K, D'Anjou MC, Boulay C, Laffont I (2014): Relevance of intraglandular injections of Botulinum toxin for the treatment of sialorrhea in children with cerebral palsy: A review. Eur J Paediatr Neurol 18, 649-657

Ramakrishnan NA, Drescher MJ, Drescher DG (2012): The SNARE complex in neuronal and sensory cells. Mol Cell Neurosci $\underline{50}, 58-69$

Reitz A, Stöhrer M, Kramer G, Del Popolo G, Chartier-Kastler E, Pannek J, Burgdörfer H, Göcking K, Madersbacher H, Schumacher S (2004): European experience of 200 cases treated with botulinum-A toxin injections into the detrusor muscle for urinary incontinence due to neurogenic detrusor overactivity. Eur Urol $\underline{45}, 510-515$

Rossetto O, Pirazzini M, Montecucco C (2014): Botulinum neurotoxins: genetic, structural and mechanistic insights.. Nat Rev Microbiol 12, 535-49

Ruge DR, Dunning FM, Piazza TM, Molles BE, Adler M, Zeytin FN, Tucker WC (2011): Detection of six serotypes of botulinum neurotoxin using fluorogenic reporters. Analytical Biochemistry 411, 200-209

Rummel A (2006): Botulinum Neurotoxin: Determination of Potency Using a Mouse Ex Vivo Test. Vortrag auf dem ICCVAM-NICEATM/ECVAM Scientific Workshop on Alternative Methods to Refine, Reduce or Replace the Mouse LD $_{50}$ Assay for Botulinum Toxin Testing. Silver Spring, Maryland, USA. Online im Internet:

http://ntp.niehs.nih.gov/iccvam/docs/biologics-docs/bontwkshprept.pdf (17.07.2015)

Rummel A (2013): Double receptor anchorage of botulinum neurotoxins accounts for their exquisite neurospecificity. Curr Top Microbiol Immunol $\underline{364}$, 61-90

Rummel A, Eichner T, Weil T, Karnath T, Gutcaits A, Mahrhold S, Sandhoff K, Proia RL, Acharya KR, Bigalke H (2007): Identification of the protein receptor binding site of botulinum neurotoxins B and $G$ proves the double-receptor concept. Proc Natl Acad Sci U S A 104 , 359-364

Rummel A, Mahrhold S, Bigalke H, Binz T (2011): Exchange of the $H(C C)$ domain mediating double receptor recognition improves the pharmacodynamic properties of botulinum neurotoxin. FEBS J 278, 4506-4515

Russell W, Burch R: The Principles of Humane Experimental Technique. Methuen, London 1959

Savino PJ, Sergott RC, Bosley TM, Schatz NJ (1985): Hemifacial spasm treated with botulinum A toxin injection. Arch Ophthalmol 103, 1305-1306

Schantz EJ, Kautter DA (1978): Microbiological methods. Standardized assay for Clostridium botulinum neurotoxins. J Assoc Off Anal Chem 61, 96-99

Schantz EJ, Johnson EA (1990): Dose standardisation of botulinum toxin. Lancet $\underline{335}, 421$

Schiavo G, Benfenati F, Poulain B, Rossetto O, Polverino de Laureto P, DasGupta BR, Montecucco C (1992): Tetanus and botulinum-B neurotoxins block neurotransmitter release by proteolytic cleavage of synaptobrevin. Nature $\underline{359}, 832-835$ 
Schiavo G, Shone CC, Rossetto O, Alexander FC, Montecucco C (1993a): Botulinum neurotoxin serotype $F$ is a zinc endopeptidase specific for VAMP/synaptobrevin. J Biol Chem $\underline{268}$, 11516-11519

Schiavo G, Rossetto O, Catsicas S, Polverino de Laureto P, DasGupta BR, Benfenati F, Montecucco C (1993b): Identification of the nerve terminal targets of botulinum neurotoxin serotypes A, D, and E. J Biol Chem 268, 23784-23787

Schiavo G, Shone CC, Bennett MK, Scheller RH, Montecucco C (1995): Botulinum neurotoxin type $\mathrm{C}$ cleaves a single Lys-Ala bond within the carboxyl-terminal region of syntaxins. $\mathrm{J}$ Biol Chem 270, 10566-10570

Schmitz T, Endesfelder S, Reinert MC, Klinker F, Müller S, Bührer C, Liebetanz D (2012): Adolescent hyperactivity and impaired coordination after neonatal hyperoxia. Exp Neurol 235, 374-379

Schnider P, Binder M, Auff E, Kittler H, Berger T, Wolff K (1997): Double-blind trial of botulinum $A$ toxin for the treatment of focal hyperhidrosis of the palms. Br J Dermatol $\underline{136}, 548-552$

Schulte-Baukloh H, Bigalke H, Miller K, Heine G, Pape D, Lehmann J, Knispel HH (2008): Botulinum neurotoxin type $\mathrm{A}$ in urology: antibodies as a cause of therapy failure. Int $\mathrm{J}$ Urol $15,407-415$

Schulte-Baukloh H, Herholz J, Bigalke H, Miller K, Knispel HH (2011): Results of a BoNT/A antibody study in children and adolescents after onabotulinumtoxin A (Botox®) detrusor injection. Urol Int 87, 434-438

Scott AB (1980): Botulinum toxin injection into extraocular muscles as an alternative to strabismus surgery. J Pediatr Ophthalmol Strabismus 17, 21-25

Scott AB, Rosenbaum A, Collins CC (1973): Pharmacologic weakening of extraocular muscles. Invest Ophthalmol 12, 924-927

Sesardic D (2006a): Endopeptidase Assays for Botulinum Toxins. Vortrag auf dem ICCVAMNICEATM/ECVAM Scientific Workshop on Alternative Methods to Refine, Reduce or Replace the Mouse $L_{50}$ Assay for Botulinum Toxin Testing. Silver Spring, Maryland, USA. Online im Internet: http://ntp.niehs.nih.gov/iccvam/docs/biologics-docs/bontwkshprept.pdf (17.07.2015)

Sesardic D (2006b): Mouse Abdominal Ptosis Assay or Flaccid Paralysis: Non-lethal Mouse Model for Botulinum Toxin Potency Testing. Vortrag auf dem ICCVAM-NICEATM/ECVAM Scientific Workshop on Alternative Methods to Refine, Reduce or Replace the Mouse LD $_{50}$ Assay for Botulinum Toxin Testing. Silver Spring, Maryland, USA. Online im Internet: http://ntp.niehs.nih.gov/iccvam/docs/biologics-docs/bontwkshprept.pdf (17.07.2015)

Sesardic D, Gaines Das R (2008): Alternatives to the LD50 assay for botulinum toxin potency testing strategies and progress towards refinement, reduction and replacement. Special Issue $14,581-585$

Sesardic D, McLellan K, Ekong TA, Gaines Das R (1996): Refinement and validation of an alternative bioassay for potency testing of therapeutic botulinum type $A$ toxin. Pharmacol Toxicol $\underline{78}, 283-288$

Shaari CM, Sanders I (1993): Quantifying how location and dose of botulinum toxin injections affect muscle paralysis. Muscle Nerve $\underline{16}, 964-969$ 
Shaw L, Rodgers H, Price C, van Wijck F, Shackley P, Steen N, Barnes M, Ford G, Graham L; BoTULS investigators (2010): BoTULS: a multicentre randomised controlled trial to evaluate the clinical effectiveness and cost-effectiveness of treating upper limb spasticity due to stroke with botulinum toxin type A. Health Technol Assess 14, 1-113

Shen J, Ma J, Lee C, Smith BP, Smith TL, Tan KH, Koman LA (2006): How muscles recover from paresis and atrophy after intramuscular injection of botulinum toxin $A$ : Study in juvenile rats. J Orthop Res 24, 1128-1135

Shone C, Wilton-Smith P, Appleton N, Hambleton P, Modi N, Gatley S, Melling J (1985): Monoclonal antibody-based immunoassay for type A Clostridium botulinum toxin is comparable to the mouse bioassay. Appl Environ Microbiol $\underline{50}, 63-67$

Simpson LL (1980): Kinetic studies on the interaction between botulinum toxin type A and the cholinergic neuromuscular junction. J Pharmacol Exp Ther. 212, 16-21

Simpson LL, Rapport MM (1971): The binding of botulinum toxin to membrane lipids: sphingolipids, steroids and fatty acids. J Neurochem $\underline{18}, 1751-1759$

Simpson LL, Dasgupta BR (1983): Botulinum neurotoxin type E: studies on mechanism of action and on structure-activity relationships. J Pharmacol Exp Ther 224, 135-140

Singh BR, Lopes T, Silvia MA (1996): Immunochemical characterization of type A botulinum neurotoxin in its purified and complexed forms. Toxicon $\underline{34}, 267-275$

Smith CP, Boone TB, de Groat WC, Chancellor MB, Somogyi GT (2003): Effect of stimulation intensity and botulinum toxin isoform on rat bladder strip contractions. Brain Res Bull $\underline{61}, 165-171$

Snow BJ, Tsui JK, Bhatt MH, Varelas M, Hashimoto SA, Calne DB (1990): Treatment of spasticity with botulinum toxin: a double-blind study. Ann Neurol $\underline{28}, 512-515$

Sobel J (2005): Botulism. Clin Infect Dis $\underline{41}, 1167-1173$

Stone AV, Ma J, Whitlock PW, Koman LA, Smith TL, Smith BP, Callahan MF (2007): Effects of Botox and Neuronox on muscle force generation in mice. J Orthop Res $\underline{25}, 1658-1664$

Stone AV, Ma J, Callahan MF, Smith BP, Garrett JP, Smith TL, Koman LA (2011): Dose- and volume dependent-response to intramuscular injection of botu-linum neurotoxin-A optimizes muscle force decrement in mice. J Orthop Res $\underline{29}$, 1764-1770

Sugiyama H (1980): Clostridium botulinum neurotoxin. Microbiol Rev $\underline{44}$, 419-448

Sugiyama H, Brenner SL, Dasgupta BR (1975): Detection of Clostridium botulinum toxin by local paralysis elicited with intramuscular challenge. Appl Microbiol 30, 420-423

Takahashi M, Kameyama S, Sakaguchi G (1990): Assay in mice for low levels of Clostridium botulinum toxin. Int J Food Microbiol 11, 271-277

Thacker BE, Tomiya A, Hulst JB, Suzuki KP, Bremner SN, Gastwirt RF, Greaser ML, Lieber RL, Ward SR (2012): Passive mechanical properties and related proteins change with botulinum neurotoxin A injection of normal skeletal muscle. J Orthop Res $\underline{30}$, 497-502

Thesleff S, Molgó J, Tågerud S (1990): Trophic interrelations at the neuromuscular junction as revealed by the use of botulinal neurotoxins. J Physiol (Paris) $\underline{84}, 167-173$ 
Truong D, Brodsky M, Lew M, Brashear A, Jankovic J, Molho E, Orlova O, Timerbaeva S; Global Dysport Cervical Dystonia Study Group (2010): Long-term efficacy and safety of botulinum toxin type A (Dysport) in cervical dystonia. Parkinsonism Relat Disord 16, 316-323

Tsai YC, Maditz R, Kuo CL, Fishman PS, Shoemaker CB, Oyler GA, Weissman AM (2010): Targeting botulinum neurotoxin persistence by the ubiquitin-proteasome system. Proc Natl Acad Sci U S A 107, 16554-16559

Tsui JK, Eisen A, Stoessl AJ, Calne S, Calne DB (1986): Double-blind study of botulinum toxin in spasmodic torticollis. Lancet $\underline{2}, 245-247$

Tsui JK, Bhatt M, Calne S, Calne DB (1993): Botulinum toxin in the treatment of writer's cramp: a double-blind study. Neurology $\underline{43}, 183-185$

Turton K, Chaddock JA, Acharya KR (2002): Botulinum and tetanus neurotoxins: structure, function and therapeutic utility. Trends Biochem Sci $\underline{27}, 552-558$

van Uhm JI, Beckers GM, van der Laarse WJ, Meuleman EJ, Geldof AA, Nieuwenhuijzen JA (2014): Development of an in vitro model to measure bioactivity of botulinum neurotoxin $A$ in rat bladder muscle strips. BMC Urol $\underline{14}, 37$

van der Walt A, Sung S, Spelman T, Marriott M, Kolbe S, Mitchell P, Evans A, Butzkueven H (2012): A double-blind, randomized, controlled study of botulinum toxin type A in MS-related tremor. Neurology $\underline{79}$, 92-99

Wang J, Zurawski TH, Meng J, Lawrence G, Olango WM, Finn DP, Wheeler L, Dolly JO (2011): A dileucine in the protease of botulinum toxin $A$ underlies its long-lived neuroparalysis: transfer of longevity to a novel potential therapeutic. J Biol Chem 286, 63756385

Wang J, Zurawski TH, Bodeker MO, Meng J, Boddul S, Aoki KR, Dolly JO (2012): Longeracting and highly potent chimaeric inhibitors of excessive exocytosis created with domains from botulinum neurotoxin A and B. Biochem J $444,59-67$

Watts C, Nye C, Whurr R (2006): Botulinum toxin for treating spasmodic dysphonia (laryngeal dystonia): a systematic Cochrane review. Clin Rehabil 20, 112-122

Weller C, Zschüntzsch J, Makosch G, Metselaar JM, Klinker F, Klinge L, Liebetanz D, Schmidt J (2012): Motor performance of young dystrophic mdx mice treated with longcirculating prednisolone liposomes. J Neurosci Res $\underline{90}$, 1067-1077

Whitemarsh RC, Tepp WH, Johnson EA, Pellett S (2014): Persistence of botulinum neurotoxin a subtypes $1-5$ in primary rat spinal cord cells. PLoS One $\underline{9}$, e90252

Wictome M, Newton K, Jameson K, Hallis B, Dunnigan P, Mackay E, Clarke S, Taylor R, Gaze J, Foster K (1999): Development of an in vitro bioassay for Clostridium botulinum type $B$ neurotoxin in foods that is more sensitive than the mouse bioassay. Appl Environ Microbiol $\underline{65}, 3787-3792$

Wilder-Kofie TD, Lúquez C, Adler M, Dykes JK, Coleman JD, Maslanka SE (2011): An Alternative In Vivo Method to Refine the Mouse Bioassay for Botulinum Toxin Detection. Comp Med 61, 235-342

Williamson LC, Halpern JL, Montecucco C, Brown JE, Neale EA (1996): Clostridial neurotoxins and substrate proteolysis in intact neurons: botulinum neurotoxin $\mathrm{C}$ acts on synaptosomal-associated protein of $25 \mathrm{kDa}$. J Biol Chem 271, 7694-7699 
Wohlfarth K, Göschel H, Frevert J, Dengler R, Bigalke H (1997): Botulinum A toxins: units versus units. Naunyn Schmiedebergs Arch Pharmacol $\underline{355}$, 335-340

Yamasaki S, Binz T, Hayashi T, Szabo E, Yamasaki N, Eklund M, Jahn R, Niemann H (1994): Botulinum neurotoxin type $G$ proteolyses the Ala81-Ala82 bond of rat synaptobrevin 2. Biochem Biophys Res Commun 200, 829-835

Zhao X, Aronowski J, Liu SJ, Schallert T, Zhang J, Strong R, Ou ZS, Nguyen T, Grotta JC. (2005): Wheel-running modestly promotes functional recovery after a unilateral cortical lesion in rats. Behav Neurol $\underline{16}, 41-49$ 


\section{Danksagung:}

Ganz besonders danke ich Prof. Dr. David Liebetanz für die sehr gute Betreuung dieser Arbeit, das Beantworten vieler Fragen und das in mich gesetzte Vertrauen in sämtlichen wissenschaftlichen Projekten, in denen ich mitarbeiten durfte. Ein ebenso großer Dank gilt Dr. Anna Kutschenko für die gute und konstruktive Zusammenarbeit, die langen Stunden im Labor und die Anregungen bei der Verschriftlichung dieser Arbeit.

Ich danke Dr. Andreas Rummel für die fruchtbare Kooperation, die mir die Erhebung weiterer wichtiger Daten ermöglicht hat. Ich danke außerdem Dr. Florian Klinker für die Hilfe bei allen technischen Fragen und Problemen.

Ich danke der Studienstiftung des Deutschen Volkes für die Förderung während meines Studiums und während der Promotionszeit sowie der Universitätsmedizin Göttingen, die mich im Rahmen des Jacob-Henle-Programms gefördert und mir damit ein weiteres Semester für die wissenschaftliche Arbeit ermöglicht hat. 